\title{
Procedure to Measure Indoor Lighting Energy Performance
}

Technical Report NREL/TP-550-38602

October 2005

M. Deru, N. Blair, and P. Torcellini

\section{Form}

Pack

http://www.nrel.gov/docs/fy06osti/38602 fmpak.doc

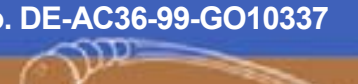




\section{Procedure to Measure Indoor Lighting Energy Performance}

M. Deru, N. Blair, and P. Torcellini

Prepared under Task No(s). BEC3.3003
Technical Report NREL/TP-550-38602

October 2005

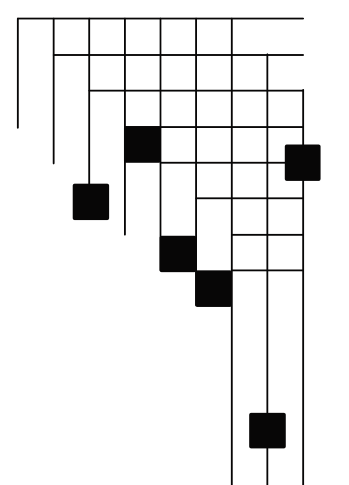




\section{NOTICE}

This report was prepared as an account of work sponsored by an agency of the United States government. Neither the United States government nor any agency thereof, nor any of their employees, makes any warranty, express or implied, or assumes any legal liability or responsibility for the accuracy, completeness, or usefulness of any information, apparatus, product, or process disclosed, or represents that its use would not infringe privately owned rights. Reference herein to any specific commercial product, process, or service by trade name, trademark, manufacturer, or otherwise does not necessarily constitute or imply its endorsement, recommendation, or favoring by the United States government or any agency thereof. The views and opinions of authors expressed herein do not necessarily state or reflect those of the United States government or any agency thereof.

Available electronically at http://www.osti.gov/bridge

Available for a processing fee to U.S. Department of Energy and its contractors, in paper, from:

U.S. Department of Energy

Office of Scientific and Technical Information

P.O. Box 62

Oak Ridge, TN 37831-0062

phone: 865.576 .8401

fax: 865.576 .5728

email: mailto:reports@adonis.osti.gov

Available for sale to the public, in paper, from:

U.S. Department of Commerce

National Technical Information Service

5285 Port Royal Road

Springfield, VA 22161

phone: 800.553.6847

fax: 703.605.6900

email: orders@ntis.fedworld.gov

online ordering: http://www.ntis.gov/ordering.htm

Printed on paper containing at least $50 \%$ wastepaper, including $20 \%$ postconsumer waste 


\section{DISCLAIMER AGREEMENT \\ (“Agreement")}

This document includes definitions, calculations and measurements of building energy use for use in energy performance analyses and is provided by the National Renewable Energy Laboratory ("NREL"), which is operated by the Midwest Research Institute ("MRI") for the U.S. Department of Energy ("DOE"). Access to and use of the information contained in this document shall impose the following obligations on the user, as set forth in this Agreement. The user is granted the right, without any fee or cost, to use, copy, modify, alter, enhance and distribute the information in this document for any purpose whatsoever, except commercial sales or other commercial purposes, provided that this entire notice appears in all copies of this document. Further, the user agrees to credit DOE/NREL/MRI in any publication that results from or includes any of the information contained in this document. The names DOE/NREL/MRI, however, may not be used in any advertising or publicity to endorse or promote any product or commercial entity unless prior specific written permission is obtained from the DOE/NREL/MRI. The user also understands that DOE/NREL/MRI is not obligated to provide the user with any support or assistance of any kind whatsoever with regard to the use of the information contained in this document or to provide the user with any updates, revisions or new versions of the information contained in this document.

YOU, THE USER, AGREE TO INDEMNIFY DOE/NREL/MRI, AND ITS SUBSIDIARIES, AFFILIATES, OFFICERS, AGENTS, AND EMPLOYEES AND HOLD THEM HARMLESS AGAINST ANY CLAIM OR DEMAND, INCLUDING REASONABLE ATTORNEYS' FEES, RELATED TO YOUR USE OF THE INFORMATION CONTAINED IN THIS DOCUMENT. THIS DOCUMENT, AND THE INFORMATION CONTAINED THEREIN ARE PROVIDED BY DOE/NREL/MRI "AS IS" AND ANY EXPRESS OR IMPLIED WARRANTIES, INCLUDING BUT NOT LIMITED TO, THE IMPLIED WARRANTIES OF MERCHANTABILITY AND FITNESS FOR A PARTICULAR PURPOSE ARE DISCLAIMED. IN NO EVENT SHALL DOE/NREL/MRI BE LIABLE FOR ANY SPECIAL, INDIRECT OR CONSEQUENTIAL DAMAGES OR ANY DAMAGES WHATSOEVER, INCLUDING BUT NOT LIMITED TO CLAIMS ASSOCIATED WITH AN ACTION IN CONTRACT, NEGLIGENCE OR OTHER TORTIOUS CLAIM THAT ARISES OUT OF OR IN CONNECTION WITH THE ACCESS, USE OR PERFORMANCE OF ANY OF THE INFORMATION CONTAINED IN THIS DOCUMENT. 


\section{Acknowledgements}

The authors want to thank the following individuals for reviewing this document. David Hansen, Drury Crawley, John Ryan (DOE), Shanti Pless, Dennis Barley (NREL), Brian Liebel (AfterImage + Space), and Ed Hancock (Mountain Energy Partnership). 


\section{Table of Contents}

QUICK REFERENCE GUIDE ................................................................................................ IV

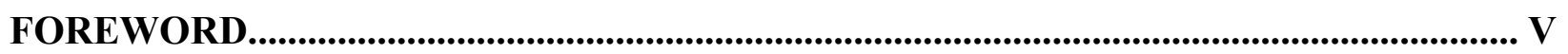

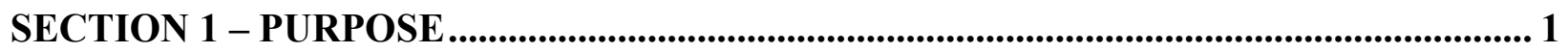

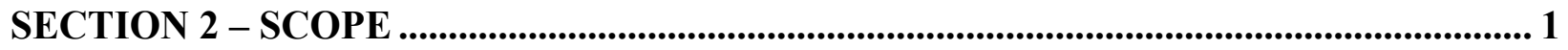

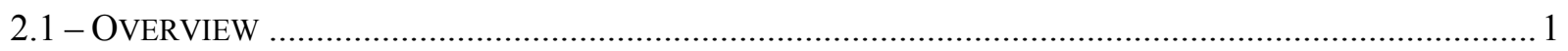

2.2 - WHAT THIS PROCEDURE DOES ...................................................................................... 1

2.3 - What ThIS PRocedure DoES Not Do .................................................................................. 1

SECTION 3 - DEFINITIONS, ABBREVIATIONS, AND ACRONYMS .............................. 2

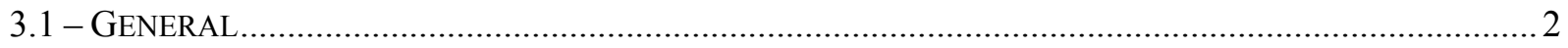

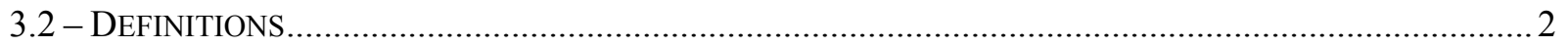

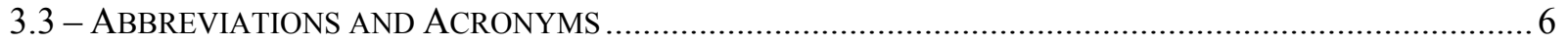

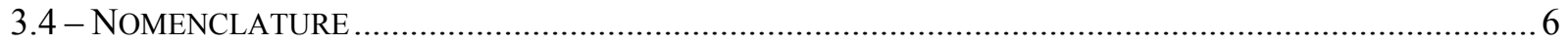

SECTION 4 - PERFORMANCE METRICS DETERMINED IN THIS PROCEDURE ..... 6

SECTION 5 - REQUIRED ADDITIONAL REFERENCES ………......................................... 12

SECTION 6 - DESCRIPTION OF PROCEDURE ............................................................... 12

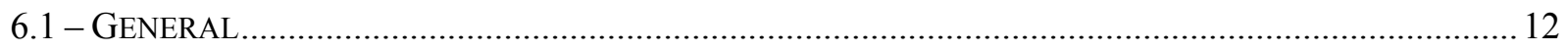

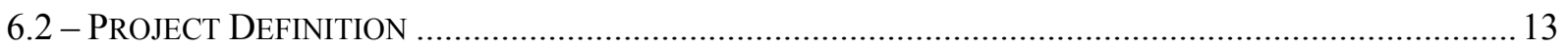

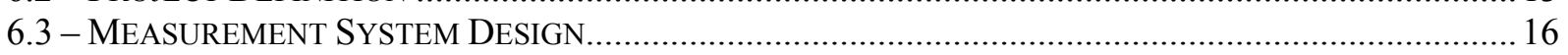

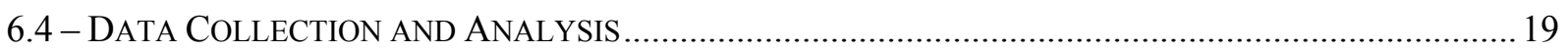

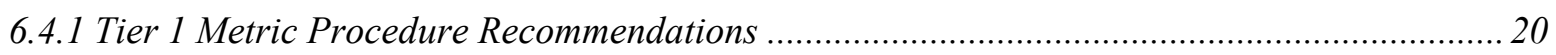

6.4.2 Tier 2 Metric Procedure Recommendations .................................................................... 20

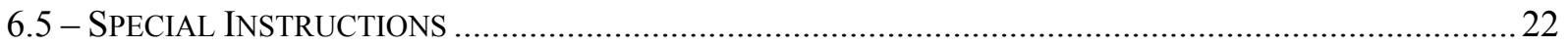

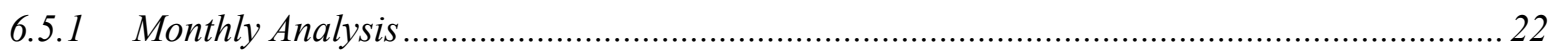

6.5.2 Special Instructions for Plug-in Lighting Energy Use …………………………………..... 23

6.5.3 Special Instructions for Average Daily Lighting Load Profile …………………………......2. 23

6.5.4 Discussion of the Use of Energy Simulations.................................................................... 24

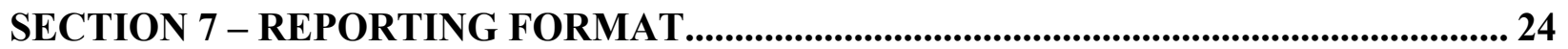

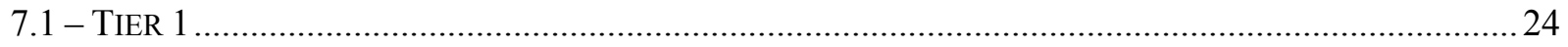

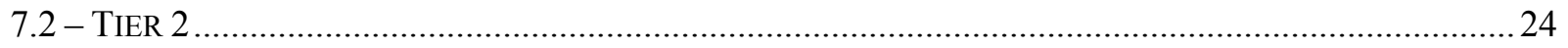

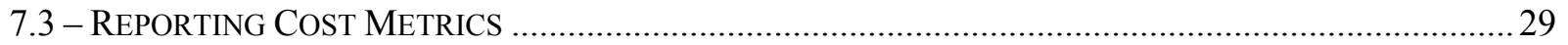

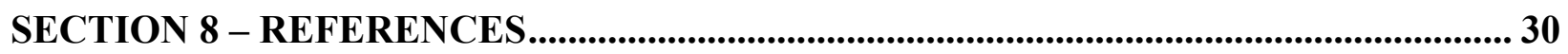

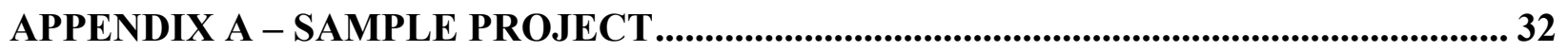

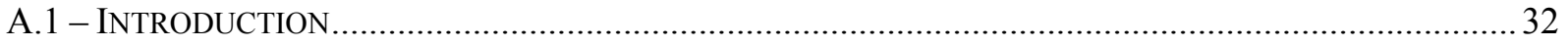

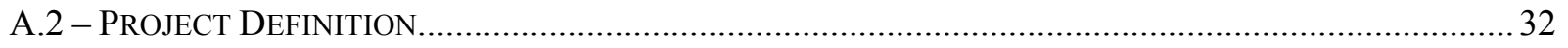

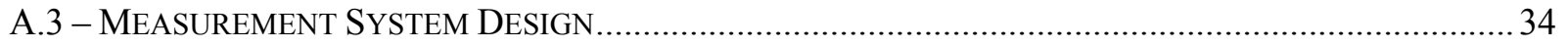

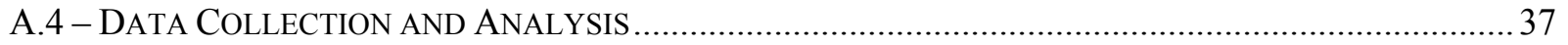

APPENDIX B - DESCRIPTION OF MONITORING EQUIPMENT ................................ 43

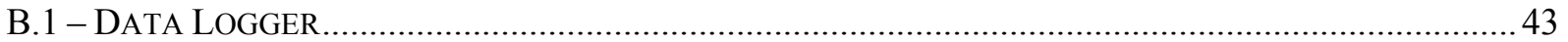

B.2 - Alternating CURRENT PoWer MEASUREMENTS .............................................................. 44

Three-Phase Power Systems ……………………………………………………….... 45

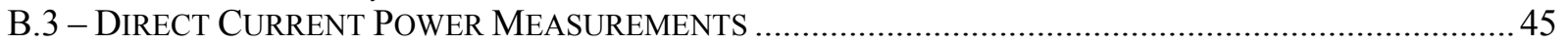

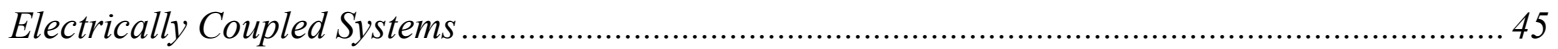

Electrically Isolated Systems................................................................................................ 45 


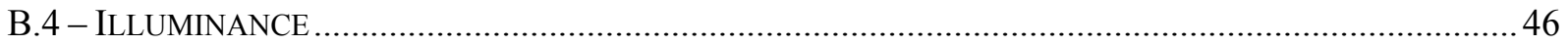

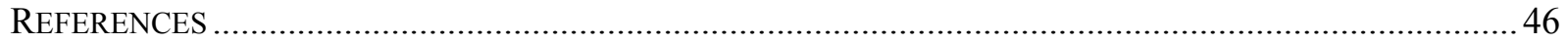

APPENDIX C - UNCERTAINTY ANALYSIS ....................................................................... 47

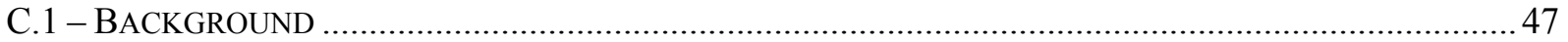

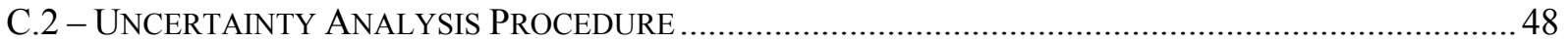

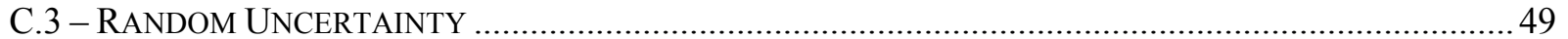

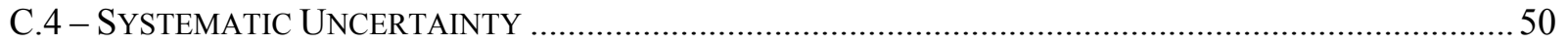

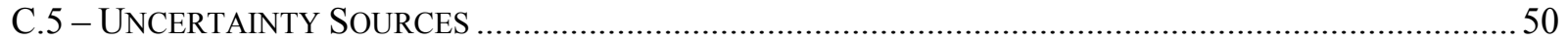

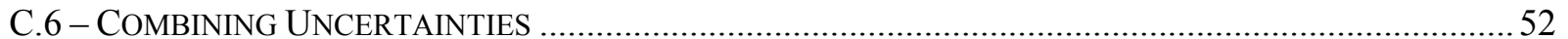

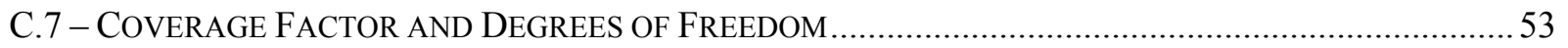

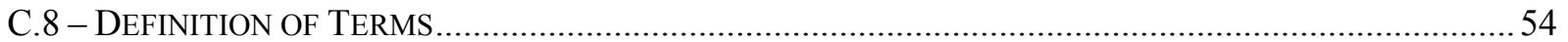

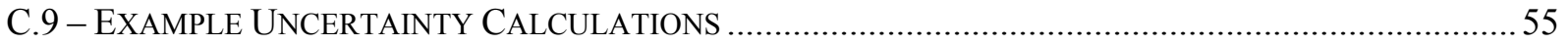

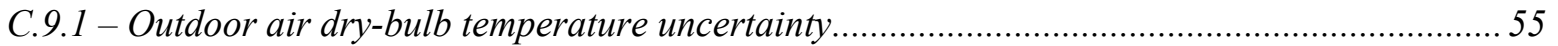

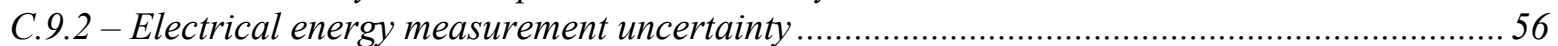

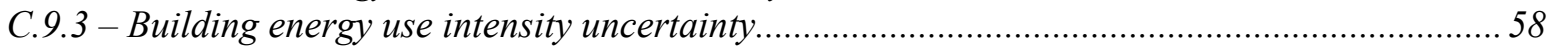

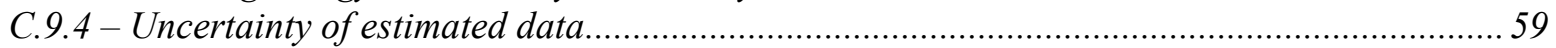

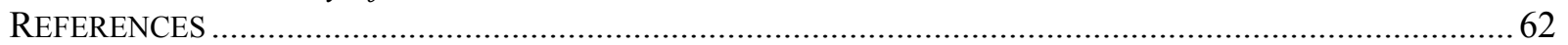




\section{Quick Reference Guide}

This document provides standard definitions of performance metrics and methods to determine them for the energy performance of interior lighting systems. It can be used for existing and proposed buildings. This procedure is primarily intended for building energy analysts and technicians who design, install, and operate data acquisition systems, and who analyze and report building energy performance data.

Typical results from the use of this procedure are the monthly and annual energy used for lighting, energy savings from occupancy or daylighting controls, and the percent of the total building energy use that is used by the lighting system. The performance metrics defined in Section 4 of this procedure are listed in Table 1. The document is not specifically intended for retrofit applications; however, it does complement measurement and verification protocols that do not provide detailed performance metrics or measurement procedures.

Table 1 Lighting Performance Metrics

\begin{tabular}{|l|l|}
\hline \multicolumn{1}{|c|}{ Performance Area } & \multicolumn{1}{|c|}{ Performance Metrics } \\
\hline Energy Cost & Lighting Energy Cost \\
\hline Energy Savings & $\begin{array}{l}\text { Daylighting and Occupancy Energy Savings } \\
\text { Lighting Design Energy Savings } \\
\text { Total Lighting Energy Savings }\end{array}$ \\
\hline Illuminance & $\begin{array}{l}\text { Global Horizontal External Illuminance } \\
\text { Horizontal Illuminance } \\
\text { Vertical Illuminance }\end{array}$ \\
\hline HVAC Interaction & Instantaneous Heat Gain from Lighting \\
\hline Lighting Energy & $\begin{array}{l}\text { Code Baseline Lighting Energy } \\
\text { Lighting Energy Use } \\
\text { Installed Baseline Lighting Energy } \\
\text { Plug-in Lighting Energy Use } \\
\text { Lighting Energy Percent of Building Energy }\end{array}$ \\
\hline Lighting Power & $\begin{array}{l}\text { Installed Lighting Power } \\
\text { Peak Lighting Power }\end{array}$ \\
\hline LPD & $\begin{array}{l}\text { Code Baseline LPD } \\
\text { Installed LPD }\end{array}$ \\
\hline
\end{tabular}

This procedure is divided into two tiers to differentiate the resolution of the results and the amount of effort required to complete the procedure. The Tier 1 procedure yields annual results and requires minimal measurement. The Tier 2 procedure gives seasonal and/or hourly results and requires on-site measurements.

This document develops a standard approach to monitoring projects that is flexible enough to handle the diversity of building energy monitoring applications. A high-level outline of the approach is as follows:

1. List the project objectives

2. Formulate specific questions to be answered by the project

3. Select the specific performance metrics to answer the questions

4. Develop a monitoring plan to determine the performance metrics

5. Implement the monitoring plan

6. Complete data collection and analysis

7. Report the results. 


\section{Foreword}

People measure and analyze the energy performance of buildings for many reasons. Comparisons of energy use may be made among nations, regions, individual buildings, or systems within a building. Policy makers, owners, designers, operators, raters, and researchers use energy performance data. Many tools (or approaches) have been developed to analyze energy performance in different ways, at different levels of effort and precision, and at different stages in the life of a building. Each tool quantifies the building energy performance to fit the users' needs. However, methods and metrics are often inconsistent with each other. In addition, performance numbers may be misrepresented or misused to predict energy savings beyond the accuracy of the numbers.

The Performance Metrics Project is a U.S. Department of Energy commercial buildings research activity whose goal is to standardize the measurement and characterization of building energy performance. Its main products are clearly defined energy performance metrics and standard procedures for determining the performance metrics; its intents are to define common language and to create standards that produce consistent results independently of the user. Therefore, the terms and techniques are clearly defined with little room for interpretation. The more opportunity there is for interpretation, the higher the probability for disparity and "gaming" of the results. These procedures focus on reporting absolute numbers and not on comparisons of energy performance. Benchmarks are included only where well-established values apply. However, benchmarking of results by others can be improved be using the clearly defined absolute metrics determined by these procedures.

Numerous other documents outline procedures for analyzing building energy performance (see references in Section 8). Some procedures are general and tend to outline the stages of project planning, management, and execution; they do not encompass the level of detail necessary to standardize specific measurements among buildings. On the other hand, the procedures that do encompass the necessary level of detail are not general enough to provide a standard basis of comparison among buildings.

The Performance Metrics Project attempts to build on this body of work and resolve differences among the various approaches. The project has worked to address the following issues that have been problems with performance monitoring in the past:

- Standardization: Standard performance metrics provide a consistent basis for comparing energy performance among buildings.

- Versatility: The analysis is customized to the facility boundaries, energy configuration, analysis goals, and analysis budget that apply to a given project.

- Economy of Effort: The data collection is carefully matched to the goals of the analysis and the study questions to avoid the common pitfalls of too few or too many data.

Each procedure in this series outlines a measurement protocol that helps to quantify standard performance metrics. The primary users for whom these documents are intended are building energy analysts and technicians who design, install, and operate data acquisition systems, and who analyze and report building energy performance data. In addition, the Metrics Definitions in Section 4 of each procedure may be useful to others who interpret and apply such data.

Two levels of effort are outlined in these procedures to meet the needs of different users and to address the goals of versatility and economy of effort in performance monitoring. In Tier 1, utility bills and other rapid, inexpensive means of data gathering are used to determine monthly and annual purchased energy, electrical demand, facility energy production, and related metrics. In Tier 2, submetering and an automated data acquisition system (DAS) are used to determine hourly or subhourly time-series data, itemized by end use. A Tier 2 analysis can require a substantial effort, and the benefits of this detailed study should be weighed against the associated costs. 


\section{Section 1 - Purpose}

Lighting serves many functions in buildings: ambient illumination, task lighting, accenting specific features, and emergency (safety and security). These systems often include a variety of lighting fixtures and daylighting and other controls to achieve energy savings while meeting the programmatic needs of the building. Lighting systems consume a significant amount of energy, and they can contribute a significant amount of heat to the building, which affects the HVAC energy use.

This document provides standard definitions and performance metrics for analysis of the energy performance of interior lighting systems. The document is not intended as a guide specifically for retrofit applications where a measurement and verification $(\mathrm{M} \& \mathrm{~V})$ protocol would be used. However, the document would complement an M\&V protocol that does not provide detailed performance metrics or measurement procedures. It is expected that the primary users of the procedure have a high-level of understanding of energy consumption in buildings. This audience includes building scientists and energy service professionals. This document may also be used as a reference to help other users have a better understanding of lighting energy consumption.

\section{Section 2 - Scope}

\section{1 - Overview}

This procedure supplies a method to determine the energy used to illuminate a building's interior and outlines methods for determining energy savings compared to the energy code and segmenting those savings (i.e., identifying savings that result from lighting design, occupancy sensors, or daylighting controls). Although this procedure is intended for use with existing buildings, certain metrics can be applied to approximate the performance of proposed lighting system designs.

This procedure is divided into two tiers to differentiate the resolution of the results and the amount of effort required to complete the procedure. The Tier 1 procedure yields annual results and requires minimal measurement. The Tier 2 procedure gives seasonal and/or hourly results and requires on-site measurements. A minimum of two weeks, but preferably one year of data collection, is typically required to obtain Tier 2 results. Shorter measurement periods will increase the uncertainties in the results.

\section{2 - What This Procedure Does}

This procedure defines performance metrics and methods for determining these metrics for the energy performance of indoor electrical lighting systems. In addition, this procedure provides a method to approximate the impact of lighting on heating and cooling loads and a suggested list of monitoring equipment. It is intended for all commercial building types.

\section{3 - What This Procedure Does Not Do}

This procedure does not address the impact of fenestration used for daylighting on the building heating and cooling loads. It is not intended to be a complete $M \& V$ plan, but has the possibility to feed into such a plan. It does not provide diagnostic support for identifying the reasons that systems are not performing as designed, nor does it give guidance on repair techniques. Finally, there is neither daylighting quality analysis nor lighting quality analysis within this procedure. 


\section{Section 3 - Definitions, Abbreviations, and Acronyms}

\section{1 - General}

Terms, abbreviations, and acronyms defined in this section apply to this procedure. The names of performance metrics are defined in Section 4 and printed in bold type throughout this document. Terms, abbreviations, and acronyms not defined in either Section 3 or Section 4 are assumed to have their ordinary definitions in the context in which they are used.

\section{2 - Definitions}

Accent Lighting

Directional lighting to emphasize a particular object or surface feature or to draw attention to a part of the field of view (IESNA 2000).

Ambient Lighting

Lighting throughout an area that produces general illumination (IESNA 2000).

Annual

A period that consists of 12 consecutive months.

Ballast

A device used with an electric-discharge lamp to obtain the necessary circuit conditions (voltage, current, and wave form) for starting and operating the lamp (IESNA 2000).

Code Lighting Power

The electrical power of all permanently installed luminaires as detailed in the appropriate energy code. This lighting power may or may not represent what is installed in a real building. This power includes the lamps, ballasts, and local control devices. Some energy codes or standards have exceptions for special application lighting. The exempted lighting in ASHRAE 90.1-2004 are the following assuming that it is an addition to general lighting and is controlled by an independent control device (ASHRAE 2004):

a. Emergency lighting that is automatically off during normal building operation

b. Lighting within living units

c. Lighting that is specifically designated as required by a health or life safety statute, ordinance, or regulation

d. Decorative gas lighting systems

e. Display or accent lighting that is an essential element for the function performed in galleries, museums, and monuments

f. Lighting that is integral to equipment or instrumentation and is installed by its manufacturer

g. Lighting specifically designed for use only during medical or dental procedures and lighting integral to medical equipment

h. Lighting integral to both open and glass-enclosed refrigerator and freezer cases

i. Lighting integral to food warming and food preparation equipment

j. Lighting for plant growth or maintenance

k. Lighting in spaces specifically designed for use by the visually impaired

1. Lighting in retail display windows, provided the display area is enclosed by ceiling-height partitions 
m. Lighting in interior spaces that have been specifically designated as a registered interior historic landmark

n. Lighting that is an integral part of advertising or directional signage

o. Exit signs

p. Lighting that is for sale or lighting educational demonstration systems

q. Lighting for theatrical purposes, including performance, stage, and film and video production

r. Lighting for television broadcasting in sporting activity areas

s. Casino gaming areas.

Data Acquisition System (DAS)

An automated data recording system that typically consists of a programmable data logger and numerous sensors and other transducers.

Daylighting

Indoor illumination provided by natural light entering the space through some type of fenestration that results in a reduction of necessary electrical lighting for ambient, accent, emergency, or task lighting.

Electric-Discharge Lamp

A lamp in which light is produced by passing an electric current through a gas (IESNA 2000).

Examples include fluorescent lamps, high intensity discharge lamps, sodium lamps, and neon lamps.

Emergency Lighting

Lighting designed to supply illumination essential to the safety of life and property in the event of failure of the normal supply (IESNA 2000).

Facility

A set of one or more buildings or outdoor applications, or both, that is defined for the purpose of an energy analysis. The boundary of the facility used in the energy analysis should be clearly defined.

Fixture Power Ratio

The ratio of the lighting fixture input power requirements and the rated lamp power. This number is used to estimate the Installed Lighting Power from a count of the lighting fixtures. For ballasted fixtures, this number can be less than one or greater than one. Refer to ballast manufacturer data for the ballast power input requirements. This number is not necessarily an indicator of the efficiency of the ballast/lamp combination because it does not include the luminous output. Some ballasts deliberately over drive the lamps to get a higher light output, which requires more power input.

Footcandle

A unit of measure of the intensity of light falling on a surface, equal to one lumen per square foot and originally defined with reference to a standardized candle burning at one foot from a given surface (IESNA 2000).

Illuminance

The area density of the luminous flux incident at a point on a surface. The metric unit of illuminance is lux, which is the number of lumens per square meter (IESNA 2000). Another unit is the footcandle, which is the number of lumens per square foot. 
Illuminance Meter

A light-sensing, solid-state device with an output signal corresponding to the amount of light incident to (falling on) the measurement surface of the device. This meter should be cosine-corrected and color-corrected to better match the human visual response (IESNA 2000).

Light Meter

A common name for an illuminance meter.

Lighted Floor Area

Floor area of spaces with installed lighting, measured from the interior face of exterior walls of the space and including the dimensions of walls interior to the space (Deru and Torcellini 2005).

\section{Lighted Hours}

The number of hours per measurement period (usually month or year) that the electric lights are on at a constant power in a lighting zone. For buildings with daylighting controls, the lighted hours should indicate what the operation would be without daylighting controls. This number should be calculated as the sum of the hourly lighting schedule values for the month or year. The lighted hours is used to estimate the lighting energy in Tier 1 analyses and theoretical buildings.

\section{Lighting Power Density (LPD)}

The lighting power divided by the lighted floor area.

\section{Lighting Schedule}

The 24-hour hourly schedule for controlling the lighting systems. There may multiple schedules for each lighting system for weekdays, weekends, holidays, and other special days. The hourly schedule values should be expressed as a number between zero and one that represents the fraction of the Installed Lighting Power that is turned on. If the lighting systems have dimming capabilities or stepped power controls other than daylighting controls, then the schedule should reflect the reduced power level as a fraction of full power. Schedules can be estimated from interviews with the building manager and occupants or the BAS for Tier 1. In Tier 2, the estimated schedules should be checked against the measured time-series data. Be sure to capture correct operation for cleaning schedules and holidays during the normal workweek. A combined set of schedules for multiple lighting systems can be produced for analyzing multiple lighting systems together. Estimating the lighting schedule is often the largest source of uncertainty in a lighting system analysis. See Sections 6.4.1 and 6.4.2 for methods of determining the lighting schedules.

Lumen

SI unit of luminous flux. Radiometrically, it is determined from the radiant power as in luminous flux. Photometrically, it is the luminous flux emitted within a unit solid angle by a point source having a uniform luminous intensity of 1 candela (IESNA 2000).

Lux

The SI unit of illuminance. One lux is one lumen per square meter $\left(\mathrm{lm} / \mathrm{m}^{2}\right)$. The equivalent English units are footcandles and the conversion between lux and footcandles is lux $=$ footcandles $\times 10.76$

(IESNA 2000).

Measure

To determine a quantity with a calibrated instrument. This includes using previously measured data such as those shown on a utility bill or engineering log. 
Metric

A standard definition of a measurable quantity.

Month

A calendar month, or a utility billing period of similar duration. (See Section 6.5.1 for details on monthly analysis.)

\section{Peak Electrical Demand}

The maximum electricity power in the building during the month averaged over a defined measurement period such as $15 \mathrm{~min}$. Refer to the applicable electric utility rate structure for the definition used for billing.

Performance Metric

A standard definition of a measurable quantity that indicates some aspect of performance. Section 4 contains definitions of the specific performance metrics used in this procedure. (See examples of Performance Metrics in Section 4.)

Plug-in Lighting

All interior lighting, including task lighting, that is plugged in and not hard wired. Typically it is circuited with other plug loads making it difficult to measure.

Procedure

A standard technique for determining one or more performance metrics, or a document (such as this one) that outlines such technique(s).

Task Lighting

Lighting directed to a specific surface or area that provides illumination for visual tasks (IESNA 2000).

Tier

A portion of a procedure that is categorized in terms of (1) the resolution of the results obtained and (2) the level of effort required obtaining the results. The particular sections of the procedure relevant to each tier within this procedure are defined in Section 6. Note that some performance metrics can be reported for each tier with different levels of resolution and/or uncertainty.

Tier 1

The most basic level of a procedure, yielding high level results. The general characteristics of Tier 1 are: (1) it generally yields only monthly and annual results; (2) it requires only existing data including building drawings and physical examination (walk-through) of the building; and (3) it is performed without installing additional metering equipment. In this procedure, the Tier 1 performance metrics are estimated from review of the building plans and walk through investigations of the building.

Tier 2

The advanced level of a procedure, yielding more precise and detailed results. Most engineers interested in a detailed examination of the performance of a building will perform both Tier 1 and Tier 2. The general characteristics of Tier 2 are that (1) it yields seasonal, daily, hourly, or subhourly (if appropriate) results; (2) it requires new data to be recorded in addition to existing building data; and (3) it involves installing advanced measurement devices and operating them throughout the year, either continuously or for multiple periods. In Tier 2 of this procedure, submetering and a DAS are used to determine hourly or subhourly time-series data. The data are recorded at the time interval 
corresponding to the electrical demand rate structure, typically every $15 \mathrm{~min}$, for a period of 2 weeks to 1 year. Using two weeks of data is acceptable in situations where the lighting load/performance

will not change noticeably throughout the year. However, for buildings with varying seasonal loads an entire year of data should be taken. For example, any building that has light dimming based on daylighting would require a year of data collection. Additionally, several assumptions from Tier 1 (such as adequate illumination being employed) are checked by taking measurements of the horizontal and vertical illuminance levels within the building.

Time Series

The data-recording interval that corresponds to the applicable electrical demand-billing scheme (typically 15-min data). If there is no applicable electrical demand-billing scheme, the recording interval should be based on the needs of the monitoring project.

Year

A period of 365 consecutive days.

\section{3 - Abbreviations and Acronyms}

ASHRAE American Society of Heating, Refrigerating, and Air-Conditioning Engineers

BAS Building Automation System

DOE U.S. Department of Energy

HVAC heating, ventilating, and air-conditioning

IESNA The Illuminating Engineering Society of North America

IPMVP International Performance Measurement and Verification Protocol

LPD lighting power density

$\mathrm{M} \& \mathrm{~V} \quad$ measurement and verification

\section{4 - Nomenclature}

$\mathrm{A}_{\mathrm{Lgt}} \quad$ lighted floor area

$\mathrm{E}_{\mathrm{Bld}} \quad$ Building Energy Use

$\mathrm{E}_{\mathrm{Lgt}, \text { code }} \quad$ Code Baseline Lighting Energy

$\mathrm{E}_{\mathrm{Lgt}}$, base $\quad$ Installed Baseline Lighting Energy

$\mathrm{E}_{\text {Lgt }} \quad$ Lighting Energy Use

LPD $D_{\text {code }} \quad$ Code Lighting Power Density

$\mathrm{LPD}_{\text {Inst }} \quad$ Installed Lighting Power Density

$\mathrm{t}_{\mathrm{Lgt}} \quad$ lighted hours

\section{Section 4 - Performance Metrics Determined in This Procedure}

This procedure covers all lighting systems in buildings. All lighting systems includes exit signs, refrigeration lighting, display lighting, and lighting integral to equipment. Ideally, all the lighting systems would be included in the measurements of lighting energy; however, this is usually not practical and some of the energy use must be estimated. It may also be the case that the user is only interested in a subset of the lighting systems. The user of this procedure should document which lighting systems are included in the analysis, which systems are measured, and which systems are estimated. The measurement and estimation techniques should also be documented.

There is a hierarchy of lighting energy saving performance metrics as shown in Figure 4-1. The Lighting Design Energy Savings represents the savings due to the installed lighting capacity relative to the allowable lighting per energy code. If the Installed Baseline Lighting Energy is greater than the Code 
Baseline Lighting Energy then there is no savings and this metric is negative. The Daylighting and Occupancy Energy Savings is the energy savings from the use of occupancy sensors to turn off lights when there is no occupancy in the space that would normally be on according to the lighting schedule, and the energy savings due to dimming the electric lights while maintaining minimum illuminance levels with available natural light. The savings from occupancy sensors and daylighting are separate effects; however, it is difficult to separate the effects with measurements in a real building and is typically not needed. The savings from daylighting should not be credited with energy savings that would normally be attributed to the lighting design or the occupancy sensors. It is possible to estimate the savings from the different effects but difficult to standardize, so it is not included in this procedure.

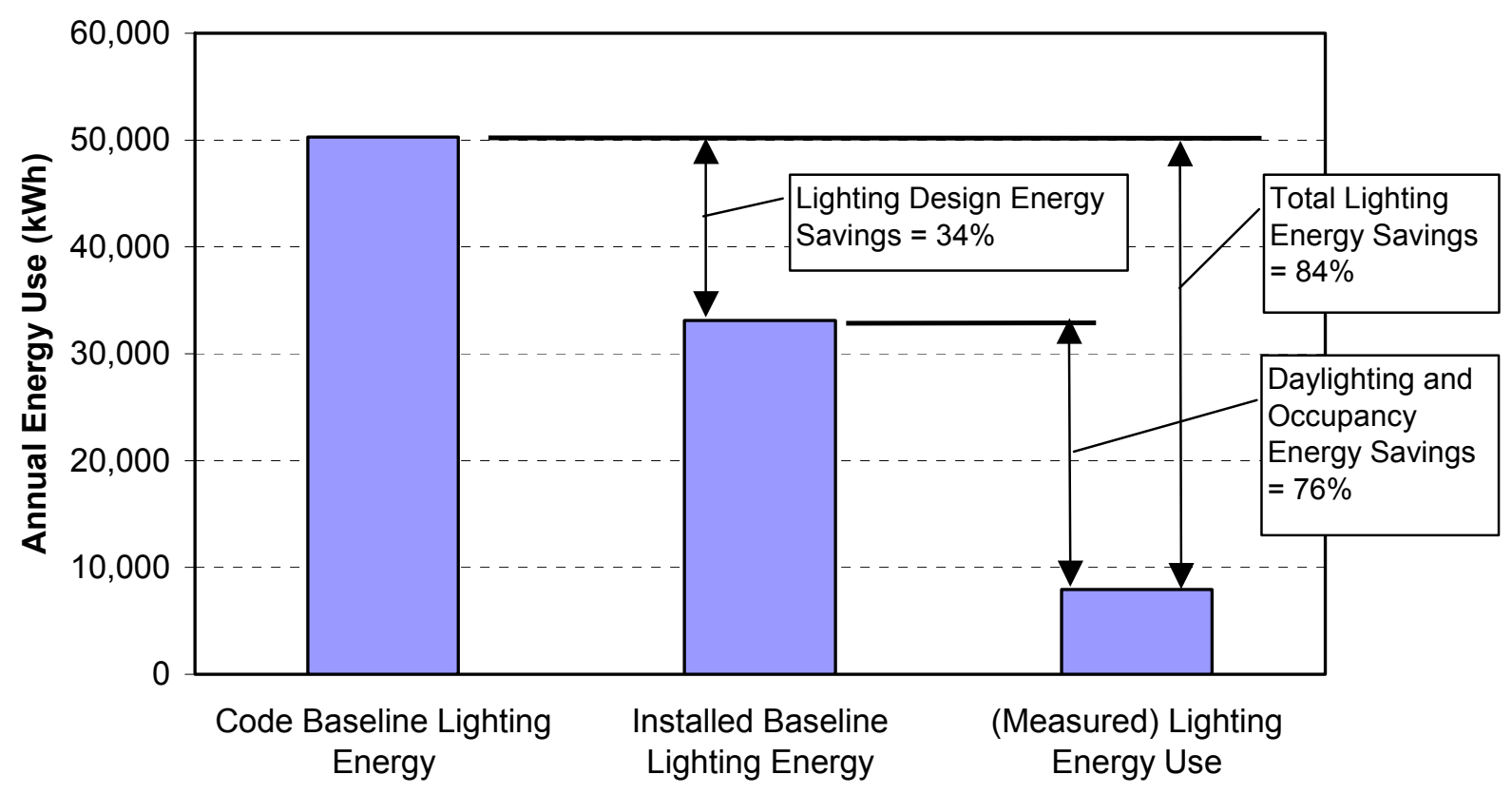

Figure 4-1 Lighting energy savings performance metrics

All the performance metrics for this procedure are listed below. They can vary in precision and methods for obtaining them based on the procedure tier being undertaken. Procedures for determining them are found in Section 6.

\section{Building Energy Use}

Energy consumed in a building for HVAC, indoor lighting, facade lighting, DHW, plug loads, people movers, and other building energy use. Many buildings have loads outside the boundaries of the building that are on the utility meter such as parking lot lighting. These loads should be removed from the utility bill totals by measurement or estimation of the loads. The appropriate uncertainty should be applied to all sources of data whether they are measured or estimated. See the Procedure for Measuring and Reporting Commercial Building Energy Performance (Barley et al. 2005) for buildings with large process loads or cogeneration systems.

Reported as: kWh, Btu, or Joules for monthly or annual total 


\section{Code Baseline Lighting Energy}

The amount of energy used for interior lighting systems using the Code Baseline LPD and the building lighting schedules. This metric is determined as the product of the lighted hours (determined from the lighting schedules), lighted floor area, and Code Baseline LPD. This metric can be determined for all lighting systems or separately for individual lighting systems.

Reported as: $\mathrm{kWh} / \mathrm{yr}, \mathrm{kWh} / \mathrm{month}$

\section{Code Baseline LPD}

The maximum amount of Installed Lighting Power for all interior lighting systems in the building or building space per square foot of lighted floor area as allowed by the appropriate building energy code or energy standard. For interior lighting systems excluded from the energy code as discussed in code lighting power, use a lighting power for a lighting system similar to the actual application. Document all sources of information and assumptions used in calculating this metric.

$$
\text { Reported as: } \mathrm{W} / \mathrm{ft}^{2} \text { or } \mathrm{W} / \mathrm{m}^{2}
$$

\section{Daylighting and Occupancy Energy Savings}

The energy saving with the occupancy sensors and daylighting controls enabled compared to the Installed Baseline Lighting Energy for the same period. The Lighting Energy Use must be measured for the entire monitoring period or estimated from a calibrated whole-building energy simulation. Document the methods and assumptions used in determining this metric. See Section 6.5.4 for a discussion of the use of energy simulations.

Reported as: \% and/ kWh monthly and/or annually

$$
\text { Calculated by: }\left[\frac{\left.E_{\text {Lgt,base }}-E_{\text {Lgt }}\right)}{E_{\text {Lgt, base }}}\right] \times 100
$$

\section{Global Horizontal External Illuminance}

Measured global illuminance on a horizontal surface external to the building. Measurements for this metric should be taken over 3 to 4 days for different seasons (preferably within 2 weeks of the summer and winter solstices and either the spring or autumnal equinox) in conjunction with the interior Horizontal Illuminance and Vertical Illuminance measurements. It is preferable to have days with different sky conditions (clear, partly cloudy, cloudy) during the 3- to 4-day measurement period; however, this may not be possible within the time and budget constraints of the monitoring project.

Reported as: graph of illuminance (fc or lux) every 15 min during days measured

\section{Horizontal Illuminance}

Measured illuminance on several horizontal surfaces within the building. The purpose of this measurement is to show the illuminance on horizontal working surfaces under various conditions throughout the year. Measurements for this metric should be taken over 3 to 4 days, preferably within 2 weeks of the summer and winter solstices and either the spring or autumnal equinox. These measurements should be taken at the same time as the Global Horizontal External Illuminance and the Vertical Illuminance. It is preferable to take measurements under different sky conditions; however, this is not always practical. 
Reported as: graph of illuminance (fc or lux) every 15 min during days measured

\section{Installed Baseline Lighting Energy}

The amount of energy used for all lighting systems with occupancy sensors disabled and daylighting controls turned off. This metric is used in the calculation of the Lighting Design Energy Savings and the Daylighting and Occupancy Energy Savings. For buildings with no occupancy sensor and/or daylighting controls, this metric is the same as the Lighting Energy Use. This metric is estimated in Tier 1 as the product of the Installed Lighting Power and the lighted hours. In Tier 2, this metric should be determined as the product of the Installed Lighting Power or measured Peak Lighting Power and the lighted hours or based on calibrated whole-building energy simulations. See Section 6.5.4 for a discussion of the use of energy simulations.

Reported as: $\mathrm{kWh} / \mathrm{yr}, \mathrm{kWh} / \mathrm{month}$, or graph of average daily lighting load profiles (see Section 6.5.3)

\section{Installed Lighting Power}

The electrical power of all installed (hard wired and plugged in) luminaires at full power, which includes the lamps, ballasts, and local control devices. Note that the ballast/lamp combination may have an operating power higher or lower than the lamp power alone. The ratio of the fixture input power to the rated lamp power is the fixture power ratio. Refer to manufacturer data for specific information regarding ballast power requirements. This performance metric can be estimated from a physical count of the lighting fixtures with the appropriate fixture power ratio. In Tier 2, this metric should be compared to the measured Peak Lighting Power. This metric can be defined by lighting type or for all lighting systems.

Reported as: $\mathrm{kW}$ by lighting type

\section{Installed LPD}

The Installed Lighting Power in the building or building space per unit of lighted floor area. This metric can be defined by lighting type or for all lighting systems.

$$
\text { Reported as: } \mathrm{W} / \mathrm{ft}^{2} \text { or } \mathrm{W} / \mathrm{m}^{2}
$$

\section{Instantaneous Heat Gain from Lighting}

The total instantaneous heat from the lighting systems (ASHRAE 2005). The equation below determines the total rate of heat load in Btu/hr based on the lamp power, the part-load lighting use factor, and the fixture power ratio. The total heat load from lighting is not instantaneously added to the building space conditioning systems, there is a delay because some of the energy is absorbed in the building materials and released at a later time. The actual peak load to the space conditioning system can be estimated with methods such as the radiant time series method (ASHRAE 2005) or an hourly whole building energy simulation, which is outside the scope of this procedure.

$$
\begin{aligned}
& \text { Reported as: Btu/h, W } \\
& \text { Calculated by: } \mathrm{q}_{\mathrm{el}}=3.412 \times \mathrm{W} \times \mathrm{F}_{\mathrm{ul}} \times \mathrm{F}_{\mathrm{sa}} \\
& \text { Where: } \\
& \mathrm{q}_{\mathrm{el}}=\text { Heat gain }(\mathrm{Btu} / \mathrm{h}) \\
& 3.412=\text { Conversion factor from } \mathrm{W} \text { to } \mathrm{Btu} / \mathrm{h} \\
& \mathrm{W}=\text { Total lamp power }(\mathrm{W})
\end{aligned}
$$


$\mathrm{F}_{\mathrm{ul}} \quad$ = Lighting use factor (part-load adjustment)

$\mathrm{F}_{\mathrm{fpr}} \quad=$ Fixture power ratio (lighting special allowance factor in ASHRAE Handbook of Fundamentals) - This factor is the ratio of the fixture power to the rated lamp power and primarily accounts for the ballast operation. This value can be more or less than one. Ballast manufacturer data should be used for the ballast input power. See ASHRAE Handbook of Fundamentals, Table 2 Chapter 30, Nonresidential Cooling and Heating Load Calculations, for more details (ASHRAE 2005).

Heat transfer from a lighting fixture consists of convection, radiation, and a negligible amount of conduction. The convective portion is the instantaneous heat gain to the air. The radiative portion can be divided into infrared radiation and visible light. The radiative heat transfer raises the temperature of surrounding surfaces (assuming they are cooler than the lamp), and is released at a later time by those surfaces. Some of the convective and radiative heat gain may go to the plenum space for recessed fixtures. For suspended, unvented fluorescent fixtures, the energy is $67 \%$ radiant and $33 \%$ convective. For recessed fluorescent fixtures vented to the return air, the energy is $59 \%$ radiant and $41 \%$ convective (ASHRAE 2005). The distribution of energy depends strongly on the lamp type and fixture design and installation configuration. Refer to manufacturer's data for more information.

\section{Lighting Design Energy Savings}

The difference between the Code Baseline Lighting Energy and the Installed Baseline Lighting Energy. For a percentage savings, this metric can be calculated as the difference between the Code Baseline LPD and the Installed LPD. This metric will be negative if the Installed LPD is greater than the Code Baseline LPD. Document the methods and assumptions used in determining this metric.

Reported as: \% and/ kWh monthly and/or annually

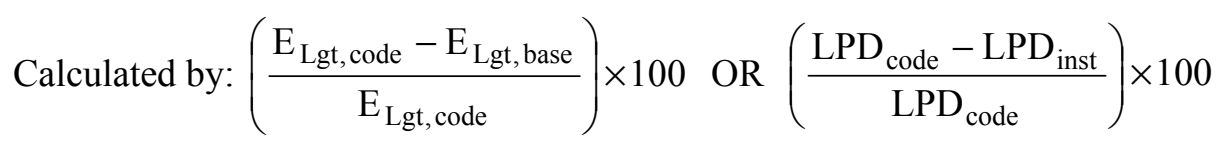

\section{Lighting Energy Cost}

The total energy cost for the interior lighting systems, including all types of lighting systems. This metric includes energy, demand, and a portion of the taxes and fixed utility bill costs. This performance metric can be estimated from short-term measurements of the lighting energy if all the lights have fixed schedules and there are no occupancy sensors or daylighting controls. This approach can lead to large errors because of the difficulty in determining the portion of the building demand charges and the lighting schedule; therefore, it is not recommended. The best result is obtained from a continuous measurement of the Lighting Energy Use and the Building Energy Use on the same interval as the utility demand charges; however, it is difficult to match the demand interval of the utility company exactly. The demand charge is estimated from the lighting energy portion of the building energy during the peak electrical demand periods.

Reported as: currency year $_{\text {/ }}$ time period monthly and/or annually (e.g., US $\$_{2003} /$ month) (see Section 7.3 for explanation) 


\section{Lighting Energy Percent of Building Energy}

The percent of the Building Energy Use that is consumed by the interior lighting systems.

Reported as: \% monthly and/or annually

$$
\text { Calculated by: }\left(\frac{E_{\text {Lgt }}}{E_{\text {Bld }}}\right) \times 100
$$

\section{Lighting Energy Use}

The amount of energy used for all interior lighting systems or for individual lighting types. This metric can be approximated in Tier 1 with estimates of lighting schedules and Installed Lighting Power. A Tier 2 approximation can be obtained with estimates of lighting schedules and short-term measurements of the Peak Lighting Power. These approximation methods can lead to large errors because of the difficulty in determining the lighting schedules, and they are only appropriate if there are no occupancy sensors or daylighting controls. The best method is by continuous measurement of the Lighting Energy Use for the entire monitoring period. See Plug-in Lighting Energy Use to estimate the energy used by lights that are plugged in and not on permanently installed circuits. In the case with no occupancy sensors or daylighting controls, this metric is equal to the Installed Baseline Lighting Energy.

Reported as: $\mathrm{kWh} / \mathrm{yr}, \mathrm{kWh} / \mathrm{month}$, or graph of average daily lighting load profiles (see Section 6.5.3)

\section{Peak Lighting Power}

The peak lighting power measured on all lighting circuits averaged over the data recording period, typically 15 minutes or one hour, recorded over a period of one week, one month, or one year. If the value is based on measurements taken over one week or one month and the value is used to calculate energy use over a longer period, then the user must verify that changes in operating conditions do not cause the peak lighting power to change over the longer period. When measuring this metric, ensure that all the light circuits are on and that there are not significant numbers of lamps burned out. Note the conditions during the measurement period.

Reported as: $\mathrm{kW}$

\section{Plug-in Lighting Energy Use}

Energy consumed in all indoor lighting fixtures that are not connected to a dedicated lighting circuit, estimated as described in Section 6.5.2. This may include task lighting, accent lighting, or other types of lighting plugged into outlets.

Reported as: $\mathrm{kWh} / \mathrm{yr}, \mathrm{kWh} / \mathrm{month}$, or graph of average lighting load profile (see Section 6.5.3)

\section{Total Lighting Energy Savings}

This metric is the energy savings of the Lighting Energy Use compared to the Code Baseline Lighting Energy. This metric does not account for the secondary effects of the lighting energy on the HVAC energy. The HVAC energy use may go up or down depending on the amount of heating and cooling energy required in the building.

Reported as: \% and/or kWh monthly and/or annually 
Calculated by: $\left[\frac{\left.\mathrm{E}_{\text {Lgt, code }}-\mathrm{E}_{\mathrm{Lgt}}\right)}{\mathrm{E}_{\mathrm{Lgt}, \text { code }}}\right] \times 100$

\section{Vertical Illuminance}

Measured illuminance on several vertical surfaces within the building. The purpose of this measurement is to show the illuminance on vertical working surfaces under various conditions throughout the year. Measurements for this metric should be taken over 3 to 4 days, preferably within 2 weeks of the summer and winter solstices and either the spring or autumnal equinox. These measurements should be taken at the same time as the Global Horizontal External Illuminance and the Horizontal Illuminance. It is preferable to take measurements under different sky conditions; however, this is not always practical.

Reported as: graph of illuminance (fc or lux) every 15 min during days measured

\section{Section 5 - Required Additional References}

To complete the steps described in this procedure, the following additional references may be required:

- The Procedure for Measuring and Reporting Commercial Building Energy Performance (Barley et al. 2005) details how to determine the Building Energy Use that applies to the Lighting Energy Percent of Building Energy metric.

- The IESNA Lighting Handbook: Reference and Applications 2000 (IESNA 2000) provides appropriate illuminance levels for each type of space.

- The ASHRAE Handbook of Fundamentals (ASHRAE 2005) provides methods to calculate the contribution of lighting to the heating load of the space.

- The applicable energy code for defining maximum LPDs such as the applicable version of ASHRAE Standard 90.1, Energy Standard for Buildings Except Low-Rise Residential Buildings (ASHRAE 1999, 2001, 2004).

\section{Section 6 - Description of Procedure}

\section{1 - General}

This section details the steps for completing the interior lighting procedure. An overview of the procedure in Table 6-1 demonstrates the basic process. Explanations of each step are provided in the sections indicated in the outline. Depending on the reasons for conducting the procedure, different groups of metrics will need to be determined and the user may need to perform the quicker, simpler Tier 1 procedural steps or the more extensive Tier 2 analysis. 
I. Project Definition (Section 6.2)
A. Identify project goals.
B. List questions to be answered.
C. Determine boundaries of the analysis.
D. Select Tier 1 or Tier 2 analysis.
E. Specify desired accuracy of results.
F. Estimate budget for project.
G. Identify period of analysis.
$\mathrm{H}$. Assemble basic building data.
I. Obtain pre-existing performance data.

II. Measurement System Design (Section 6.3)
A. Select performance metrics to be measured.
B. Identify data required for each metric.
C. Specify physical location of each measurement.
D. Specify frequency of each measurement.
E. Specify measurement equipment.
F. Determine practicality of measurements.
G. Estimate cost of DAS equipment and operation.
$\mathrm{H}$. Calculate uncertainty of measurements.
I. Resolve cost and uncertainty with expectations (Steps I.E and I.F).

\section{Data Collection and Analysis (Section 6.4)}
A. Monitor data for quality control.
B. Assemble data for the period of analysis.
C. Calculate monthly metrics.
D. Calculate annual metrics.

\section{Reporting Results}

(See reporting formats in Section 7)

\section{2 - Project Definition}

The form shown in Table 6-2 serves as a guide for the Project Definition stage of the procedure. Steps I.A through I.I, as shown in Table 6-1, are identified in Table 6-2. Explanations of these steps follow. 


\section{Project Name:}

Building Address:

All Facility/Procedure Related Contacts:

(Names, organization, title, contact information)

(I.A) Goals of the Analysis:

(I.B) Questions to Be Answered:

(I.C) Facility Definition and Boundaries:

(I.D) Analysis Tier (Tier 1 or Tier 2):

(I.E) Desired Accuracy of Results:

$\left( \pm \_\%\right.$, or other criteria)

(I.F) Estimated Budget For Performance Analysis:

(I.G) Dates of:

Site visits:

Monitoring period:

(I.H) Basic Building Data:

Building description:

(Floor plan, floors, space uses, typical occupancy patterns)

Principal Building Function(s):

Principal building types are classified according to the commercial activities, which are types of business, commerce, or function carried on within each building (based on EIA 2003). Indicate percent floor area for all that apply:

\begin{tabular}{|c|c|c|c|c|}
\hline Education & Health Care & Office & Religious & Parking \\
\hline Food & Lodging & Public & Other Service & Other \\
\hline $\begin{array}{l}\text { Food } \\
\text { Service }\end{array}$ & Mercé & $\begin{array}{l}\text { Public Order } \\
\text { and Safety }\end{array}$ & $\begin{array}{l}\text { Warehouse } \\
\text { and Storaqe }\end{array}$ & \\
\hline
\end{tabular}

Utility Company(s) and Rate Schedule(s):

(Attach to this form)

All relevant Building Drawings: (e.g., floor plans, elevations, electrical panel layouts, lighting plans)

(Obtain at this time)

(I.I) Pre-Existing Performance Data (Obtain at this time) 
Step I.A: Identify project goals. Summarize the purpose for conducting the performance analysis. Some examples of project goals are to

- Determine the energy used by the lighting systems

- Compare lighting energy use in this building to that in other buildings or to the energy code

- Reduce lighting energy use and contribution to building demand

- Win an energy conservation award.

Step I.B: List specific performance questions to be answered. Some examples of questions are

- How much energy is used for interior lighting?

- How effectively are the daylighting controls?

- Has the amount of energy necessary for lighting changed from previous years?

- How does the actual lighting energy use compare to the energy that would be used to meet the minimum lighting requirements of the energy code?

Step I.C: Determine the boundaries of the analysis. Define which lighting systems will be included in the analysis and the length of time for the analysis.

Step I.D: Select Tier 1 or Tier 2 analysis. This procedure is divided into two tiers to differentiate the resolution of the results and the amount of effort typically required to complete the procedure. Tier 1 provides estimates of the annual lighting energy and lighting design energy savings, based on building drawings, a physical examination (walk-through) of the building, and additional data in some cases. Tier 2 yields time-series results, in addition to monthly and annual results, based on submetering and a DAS.

For a Tier 1 analysis of an existing building, the necessary data can be determined with a review of the drawings and a detailed walk-through of the building, so the procedure may be completed in a matter of days. For a Tier 2 analysis, the data collection will necessarily take at least 1 month and often 1 year to complete.

The primary metrics that can be determined in a Tier 1 analysis are:

- Code Baseline Lighting Energy

- Code Baseline LPD

- Installed Baseline Lighting Energy

- Installed Lighting Power

- Installed LPD

- Instantaneous Heat Gain from Lighting

- Lighting Design Energy Savings

- Lighting Energy Use (estimated with no daylighting or occupancy controls)

For the Tier 1 analysis, occupancy levels and schedules must be approximated from a physical inspection and surveys of the building managers and occupants. Additionally, in Tier 1, it is assumed that adequate light levels exist in all work areas. In Tier 2, this is verified by measuring the illuminance in various areas throughout the building.

Tier 2 metrics are itemized by end use and recorded as time-series data with a DAS, for a period of 1 month to 1 year depending on the variability of the lighting performance and the influence of daylighting. If the lighting loads are constant, one month of data is adequate to capture building use patterns. From the time-series data, monthly and annual totals are also determined. All the metrics that are determined in a Tier 2 analysis are listed in Table 6-4. 
Step I.E: Specify desired accuracy of results. More precise measurements will require more expensive monitoring equipment. Refer to the project goals (Step I.A) and project questions (Step I.B) to help put this into perspective.

Step I.F: Develop estimated budget for performance analysis. The budget may dictate the appropriate level of effort, the necessary level of effort may dictate the budget, or the trade-off between the two may be considered. In the budget, include:

- The Project Definition effort

- The DAS purchase, installation, and operation (data collection), if used

- The analysis and reporting effort.

Step I.G: Identify period of analysis. For a Tier 1 analysis, this should generally correspond to the walk-through period of the building. For a Tier 2 analysis, it might be based on the time required to design, install, and commission a DAS, and then operate it for an appropriate period (several weeks for some buildings and up to a year for a building with daylighting, for example). In any case, select the period(s) that is representative of the normal, occupied function(s) of the facility.

Step I.H: Gather basic building data. Specific information about the building, which should be gathered before the Measurement System Design phase begins, is detailed in the Project Definition Form in Table 6-2. The lighting fixture count should be expressed in a lighting table such as Table 6-3. The date of the most recent lamp replacement should be included.

Table 6-3 Survey of Building Lighting Fixtures

\begin{tabular}{|c|c|c|c|c|c|c|c|}
\hline Space & Fixture Type & $\begin{array}{c}\text { Control } \\
\text { Type }^{1}\end{array}$ & $\begin{array}{c}\text { Fixture } \\
\text { Power } \\
\text { Ratio }\end{array}$ & Qty & $\begin{array}{l}\text { Lamps } \\
\text { per } \\
\text { Fixture }\end{array}$ & $\begin{array}{l}\text { Lamp } \\
\text { Power } \\
\text { (W) }\end{array}$ & Total (W) \\
\hline Retail space & Pendant - CFL & BAS/DL & 1.0 & 60 & 8 & 42 & 20,160 \\
\hline Office 1 & T-8 Fluor. & BAS & 0.9 & 6 & 4 & 32 & 691 \\
\hline Office 2 & T-8 Fluor. & BAS & 0.9 & 8 & 4 & 32 & 922 \\
\hline Office 3 & T-8 Fluor. & BAS & 0.9 & 2 & 4 & 32 & 230 \\
\hline Office 4 & T-12 Fluor. & man & 1.2 & 2 & 2 & 40 & 200 \\
\hline Restroom & T-8 Fluor. & occ & 0.9 & 1 & 2 & 32 & 115 \\
\hline Restroom & T-8 Fluor. & occ & 1.0 & 4 & 2 & 25 & 200 \\
\hline Total Building & & & & & & & 22,518 \\
\hline
\end{tabular}

${ }^{1}$ Control types: Building Automation System (BAS), Daylighting (DL), Occupancy (occ), Manual (man)

Step I.I: Obtain pre-existing performance data. Obtain any pre-existing performance data that are available, including utility bills, installed metering, and engineering records.

\section{3 - Measurement System Design}

The purpose of the measurement plan is to assure that the set of data collected will correspond to the desired analysis and results. This should help to eliminate two of the most common problems in building analysis: (1) insufficient data to complete the desired analysis, and (2) extraneous data that is collected but never used. 
Step II.A: Select performance metrics. Review the list of performance metrics defined in this procedure, which are listed in the Performance Metric column in Table 6-4, and ascertain which ones apply to the analysis at hand. Cross out any metrics corresponding to features that do not exist at the site and any metrics for which results are not desired.

User-Defined Metrics: If any additional measurements, not defined in this document, are indicated by goals of the analysis, these metrics should be included as additional items in the Performance Metrics column, so that the Measurement Plan will support them.

Step II.B: Review necessary data. For each item remaining in the checklist, note the data needed to compute the metric. Table 6-4 lists the metrics and necessary data for each. In some cases, the data may consist of other items in the checklist.

Step II.C: Determine points of measurement. For each necessary data point, note the physical location at the site where this data will be measured. This process may include reviewing the building drawings, and specifications, walk-through inspections, and interviewing the building engineer and building occupants (see Table A-3 for an example of recording this information).

Step II.D: Specify measurement frequency. For each required measurement, specify the measurement frequency. Many Tier 2 analysis variables require short time steps, which will be determined by the needs of the project.

Step II.E: List measurement equipment. For each required measurement, list the measurement device(s) to be used. (See Appendix B for guidance on equipment selection.)

Step II.F: Determine practicality of measurements. The practicality of making the measurements with the specified equipment in the specified locations should be verified. Project goals, the tier level, accuracy requirements, or the list of included performance metrics may have to be modified based on the practicality of measurements. Three important tasks are:

- Verify configurations. Inspect the building wiring and other measurement points to verify that the physical configuration matches the drawings or assumptions on which the plan is based and that it enables the planned measurements. Examples of features to check include circuit breaker configuration, access to wiring for measurement purposes, and clearances for installing measurement devices.

- Verify code conformity. Review the measurement system design with the local building department or any other authority that has jurisdiction, to verify that the measurement devices and the planned location of measurement devices will not violate code restrictions. If necessary, an exception to the code should be obtained before installing the measurement equipment.

- Check warranty concerns. Ensure that the placement of measurement devices in particular pieces of equipment does not void manufacturers' warranties. 
Table 6-4 Performance Metrics and Necessary Data

\begin{tabular}{|c|c|c|}
\hline Performance Metric & Data Needed & $\begin{array}{l}\text { Measurement } \\
\text { Location or } \\
\text { Source of Data } \\
\end{array}$ \\
\hline Building Energy Use & total building energy use & \\
\hline $\begin{array}{l}\text { Code Baseline Lighting } \\
\text { Energy }\end{array}$ & $\begin{array}{l}\text { Code Baseline LPD, lighting schedules, and lighted floor } \\
\text { area }\end{array}$ & \\
\hline Code Baseline LPD & $\begin{array}{l}\text { function of each space and LPDs for each space from the } \\
\text { applicable energy code }\end{array}$ & \\
\hline $\begin{array}{l}\text { Daylighting and } \\
\text { Occupancy Energy } \\
\text { Savings }\end{array}$ & $\begin{array}{l}\text { Lighting Energy without Controls and Lighting Energy } \\
\text { with Daylighting }\end{array}$ & \\
\hline $\begin{array}{l}\text { Global Horizontal } \\
\text { External Illuminance }\end{array}$ & measured external illuminance & \\
\hline Horizontal Illuminance & measured interior horizontal illuminance at several points & \\
\hline $\begin{array}{l}\text { Installed Baseline } \\
\text { Lighting Energy }\end{array}$ & $\begin{array}{l}\text { Lighting Energy Use with occupancy sensors disabled and } \\
\text { daylighting controls turned off - measured or estimated with } \\
\text { Installed Lighting Power and lighted hours }\end{array}$ & \\
\hline Installed Lighting Power & Installed LPD and lighted floor area & \\
\hline Installed LPD & $\begin{array}{l}\text { Installed lighting capacity (W) in each space by type } \\
\text { (ambient, accent, etc.) and lighted floor area for each space }\end{array}$ & \\
\hline $\begin{array}{l}\text { Instantaneous Heat Gain } \\
\text { from Lighting }\end{array}$ & $\begin{array}{l}\text { Number and types of fixtures, lighting power by fixture type, } \\
\text { and fixture power ratios for each lighting type }\end{array}$ & \\
\hline $\begin{array}{l}\text { Lighting Design Energy } \\
\text { Savings }\end{array}$ & Code Baseline LPD and Installed LPD & \\
\hline Lighting Energy Cost & $\begin{array}{l}\text { Time-series energy data for Lighting Energy Use and } \\
\text { Building Energy Use, the lighting contribution to electrical } \\
\text { demand charge, and the utility rate structure }\end{array}$ & \\
\hline $\begin{array}{l}\text { Lighting Energy Percent } \\
\text { of Building Energy }\end{array}$ & Lighting Energy Use, Building Energy Use & \\
\hline Lighting Energy Use & $\begin{array}{l}\text { Tier 1: Fixture type, power per fixture, fixture power ratio, } \\
\text { fixture counts for all lighting types, and lighting schedules } \\
\text { Tier 2: Measured monthly Lighting Energy Use }\end{array}$ & \\
\hline Peak Lighting Power & Subhourly lighting energy data & \\
\hline $\begin{array}{l}\text { Plug-in Lighting Energy } \\
\text { Use }\end{array}$ & Estimated energy use of plug-in lighting (see Section 6.5.2) & \\
\hline $\begin{array}{l}\text { Total Lighting Energy } \\
\text { Savings }\end{array}$ & $\begin{array}{l}\text { Code Baseline LPD, measured lighting schedule, lighted } \\
\text { floor area, and Lighting Energy Use }\end{array}$ & \\
\hline Vertical Illuminance & measured vertical illuminance & \\
\hline
\end{tabular}

Step II.G: Estimate cost of DAS equipment and operation. If any new measurements are needed, the following items should be included when estimating the cost of implementing the measurement plan:

- The measurement equipment listed in Step II.E.

- A data logger or other means of recording all of the required measurements

- Installation and commissioning of the above equipment 
- The data collection effort: In addition to designing and installing DAS hardware that is capable of collecting the required data, it is also necessary to provide technical staff to operate the DAS. Experience has shown that hardware failures do occur, and these can result in a significant loss of data if any problems are not promptly detected and remedied. Thus, the following questions should be answered at this stage:

- Who will be responsible for data collection and quality control?

- How many hours per week will the responsible party(s) spend on this task?

- How will the data be collected and reviewed?

- How often will the data be checked?

It cannot be recommended strongly enough that the data logging operation should be automated. Weekly, automated data downloads are recommended, and daily is better if there is a concern about losing data. Weekly review is the recommended minimum frequency, but daily review is better, especially during the DAS installation and commissioning. Software that checks the data continuously and sends fault alarms to the technical staff is recommended, along with a telephone modem or network connection for remote monitoring.

Step II.H: Calculate uncertainty of measurements. Calculating the uncertainty of the measurements according to the methods presented in Appendix C.

Step II.I: Resolve cost and uncertainty with expectations. Before purchasing any DAS equipment, the estimated cost (Step II.G) and measurement uncertainty (Step II.H) should be compared to the expectations that were set in the Project Definition phase (Steps I.E and I.F). Resolve any disparities by modifying the estimated budget, the expected accuracy, or the design of the measurement system.

\section{4 - Data Collection and Analysis}

The task of data collection consists of purchasing, installing, commissioning, and operating the DAS specified in the Measurement System Design phase, and monitoring the data for quality control. Conduct analysis (e.g., determining the monthly values of all the applicable metrics) concurrently with data collection, to verify that the data set is complete and that it yields credible results.

The data analysis task consists of determining values of all the applicable performance metrics based on the collected data. Some recommended practices are as follows:

- Energy Balances. In cases where one metric is the sum (or difference) of several other metrics, the recommended practice is to measure each metric individually and use the summation as a check on the consistency of the data. Any inconsistencies should be reconciled (corrected, or at least understood and reported).

- Unmeasurable Metrics. In cases where it is not practical to measure a metric directly, it may be possible and necessary to determine that metric based on a sum or difference of other metrics. However, this practice sacrifices the benefit of energy balance checking, as described above.

- Missing Data. Maintain a log of all missing data and the method(s) used to reconcile the missing data. Apply one of the following approaches for intervals of missing data:

- Extend the period of data collection, so that a complete year of data is obtained, and modify the period of analysis to make use of the complete year of data.

- Report "Missing Data" in lieu of metrics for the periods affected.

- Apply the best available method for estimating the missing data, and include the uncertainty introduced by this method in the reported measurement uncertainty. (Note: Large, continuous gaps are more difficult to restore than intermittent lapses.) 


\subsubsection{Tier 1 Metric Procedure Recommendations}

The energy use and savings in a Tier 1 analysis of the interior lighting is based on LPDs and approximated schedules. As level of effort is minimal, the accuracy of the results is not very good and should be used with caution. Follow the steps below to complete tier 1 analysis.

1. Determine the lighted floor area for each occupied space in the building and use the local energy code or ASHRAE Standard 90.1 (1999, 2001, 2004) to determine the Code Baseline LPD for each space that falls within a different usage category.

2. Determine the Installed LPD. For an existing building, determine the amount of installed lighting and plug-in lighting within the building with a physical inspection.

Make an accurate count of each type of light fixture within each space of the building. Task (plug-in) lighting also needs to be accurately counted and documented for each room, including determining the approximate use schedule. For a proposed building, use the building drawings and architectural notes to determine the planned LPD for the building. The power of the auxiliary equipment (primarily lighting ballasts) must also be included. Note that ballasts can increase or decrease the fixture power above or below the rated lamp power depending on the type and the operating scheme. Ratios of power input to rated lamp power (fixture power ratio) can range from 0.7 to 1.4 . Refer to the manufacturer data for rated operating power.

3. Approximate the lighting schedules during one or more physical inspections of the building. Interview the building manager and one or more employees to help determine the typical lighting levels and on/off periods for the building. Make sure to account for holidays and cleaning schedules. Cleaning crews often work before or after the normal working day and turn all or most of the lights on in a building. Estimating the lighting schedules can be difficult and can introduce significant uncertainty in the results.

4. Approximate the Installed Baseline Lighting Energy by type and total for the building with the lighting schedules and Installed Lighting Power. If there are no occupancy sensors and daylighting controls, the Installed Baseline Lighting Energy is an approximation for the Lighting Energy Use. If there are occupancy sensors and daylighting controls, then the Lighting Energy Use must be measured in a Tier 2 analysis.

5. Determine the Lighting Design Energy Savings from the definition.

\subsubsection{Tier 2 Metric Procedure Recommendations}

Complete the necessary steps from Tier 1 and from below to satisfy the goals of the project.

1. Obtain the time-series data of the Lighting Energy Use and Building Energy Use (if included in the monitoring plan) continuously for the desired collection period. If the building and lighting circuits are not already monitored, install equipment (see Appendix B) to take hourly or subhourly measurements of the electricity use. Include as many of the lighting circuits as possible in the monitoring equipment. It may be necessary to estimate the energy use of some lighting circuits and add it to the total lighting energy. The energy use for lighting circuits that are on a timer control and no occupancy sensors or daylighting controls can be estimated with the use of one-time measurements of the Installed Lighting Power and logged run-time hours of the lighting systems or the lighting schedules. This method is not as accurate as the continuous measurements because the Installed Lighting Power may change with lamp burn out, and the estimated lighting schedules may change with manual control of the lighting. Document the lighting circuits included and not included in the measurements and the methods used to estimate those circuits not measured. 
2. Determine the Plug-in-Lighting Energy Use, which includes task lighting, with a physical walkthrough combined with the approximate task lighting schedule for each zone (See Section 6.5.2).

3. Examine the time-series energy data to see if it matches expectations. Unexpected results should be examined and explained in the project report. Compare the estimated lighting schedules from Tier 1 with the time-series data. Compare lighting levels, starting and stopping times, cleaning schedules, and holidays. Modify the lighting schedules if necessary to better match the measured data.

4. Determine the Peak Lighting Power from the time-series data as the maximum lighting energy. Compare this metric with the Installed Lighting Power determined from a survey of the lighting fixtures. Document and explain the differences. The measured maximum lighting power is often lower than the estimated maximum power. Some reasons for the differences include lighting circuits that are not included in the measurements, burned out lamps, the control system never turns on all the lights at the same time, and the fixture power ratio was over estimated. The timing of the last lamp replacement should be recorded in the monitoring report.

5. Approximate the Code Baseline Lighting Energy and the Installed Baseline Lighting Energy with the lighting schedules, Code Baseline LPD, Installed Lighting Power or the Peak Lighting Power. It is preferable to use the Peak Lighting Power because this is a measured value.

6. Determine the Lighting Design Energy Savings, Daylighting and Occupancy Energy Savings, and Total Lighting Energy Savings. It is possible for any or all of these numbers to be negative, which means that the baseline energy use is less than the building lighting energy use.

7. The Lighting Energy Cost may consist of demand charges, energy charges, fixed billing charges, fees, and taxes. Find the monthly peak demand periods from the time-series data of the Building Energy Use and compare these values with the demand on the utility bills. Determine the portion of the demand resulting from the lighting system for each month and apply the demand charge and appropriate percentage-based fees (e.g., taxes) to determine the demand charges for lighting. The energy charge for the lighting system is the total lighting energy times the energy rate and appropriate percentage based fees. For time-of-use rate structures, total the lighting energy for each rate period. Divide fixed monthly utility charges (e.g., metering and billing) among the energy end uses by the fractions of the total building energy consumption. Divide the taxes, fees, and other charges among the energy end uses by the fraction of the total energy consumption or total energy costs depending if the charge is $\$ / \mathrm{kWh}$ or a $\%$ of costs.

8. Measure the typical horizontal and vertical illuminances within the building on working surfaces and the exterior illumination continuously for 3-5 day periods in three seasons. These measurements should be taken within two weeks of the summer solstice, winter solstice, and one equinox (Artif et al. 1997, Pless and Torcellini 2004). Take additional hand held illuminance measurements in the general working areas on a grid layout or along a cross-section of the space. These measurements provide finer detail than the continuous measurements for the distribution of light in the space. During these measurements, note the illumination on the horizontal and vertical work surfaces without the influence of daylight, which means the measurements must be taken after sunset with all the lights on. To perform these measurements, use photometers as described in Appendix B. Compare the measured horizontal and vertical illuminance with the appropriate minimum levels as found in the IESNA handbook (2000). This step in the procedure is to make sure that comfort and safety are not sacrificed for energy savings. 


\section{5 - Special Instructions}

\subsubsection{Monthly Analysis}

The following procedures should be used to account for months that may vary in length, and for various utility billing periods.

Identify Analysis Months

Standard months are January through December, corresponding to the Gregorian calendar.

Nonstandard months may be any 12 approximately equal divisions of a year. For example, nonstandard months may correspond to a utility billing cycle, provided it consists of 12 consecutive, approximately equal intervals that cover approximately 365 days. They may be named January, February, and so on, according to the standard month in which most of the days occur. Alternatively, they may be named Month 1, Month 2, etc., or another convenient designation.

For a Tier 1 analysis, in which the primary source of energy use data is utility bills, the analysis months should be chosen to correspond to the utility billing cycle. If more than one utility is used, and they are on different billing cycles, the one with the highest annual use should be favored. This approach

minimizes errors caused by estimating the portion of the utility use that occurs within the analysis month (see Accommodate Nonsynchronous Utility Billing Periods, below).

Use Average Daily Values

Monthly metrics should be reported as average daily values for the month to prevent the weighting of metrics by the number of days per month, which may vary slightly from one month to another.

Identify the Analysis Year

Annual totals are determined by summing 12 consecutive monthly totals and adjusting for the number of included days. An analysis year consists of 365 consecutive days, whether or not the data were collected during a leap year. ${ }^{1}$ In the event that the 12 consecutive months amount to slightly more or fewer than 365 days, the total should be adjusted by adding or subtracting average daily values symmetrically at the beginning and end of the analysis year.

\section{Examples:}

1. Standard months in a leap year.

A sum of energy totals for January through December includes 366 days. This is adjusted to 365 days by subtracting one half of the average daily value for January and one half of the average daily value for December.

2. Utility billing periods that cover fewer than 365 days.

Utility meter readings occur on or about the 10th of each month; the date varies slightly from month to month. The period from approximately January 10 to February 10 is called "January," because most of the days occur during that month. The analysis year consists of "April" through "March." Variations in the meter reading dates cause these 12 consecutive months to cover only 361 days. Thus, the annual total is adjusted to 365 days by adding two times the average daily value for "April" and two times the average daily value for "March."

\footnotetext{
${ }^{1}$ This is to avoid a slight bias in annual metrics measured in leap years versus nonleap years.
} 


\subsubsection{Special Instructions for Plug-in Lighting Energy Use}

When plug-in lighting fixtures are present in a building, some method should be used to either measure or estimate this metric as accurately as is practical. The following two methods are recommended.

- Instrumented Audit (preferred method)

If the number of plug-in lighting fixtures is small, it may be practical to use individual meters to measure the energy usage of each fixture. For example, plug-in meters are available that tally the energy used by one or two plug loads. Such instruments may be read monthly, either by visual inspection or modem connection, to indicate monthly values of the energy use.

If a large number of identical plug-in lighting fixtures are used in a consistent manner (i.e., similar usage schedules), it may be practical to monitor a sample of them in the manner described above, and then scale the results to estimate the energy usage of all the fixtures.

In either case, take care to ensure that the period of measurement is a good representation of the period of analysis. For example, take seasonal variations and vacation schedules into account. The recommended procedure is to continue the measurements for 1 year, unless it is obvious that a shorter period of measurement is a good representation of the entire year.

- Uninstrumented Audit (alternate method)

When an instrumented audit is not practical, the following procedure is recommended as an alternate approach.

- Determine the amount of plug-in lighting present in a zone by a walk-through inspection. During the walk through, count the number of each type of fixture and note the power consumption of each type.

- Determine the usage schedule of the plug-in lighting by visually inspecting the zone during a period of occupancy. In addition, conduct an oral or written survey of either (a) one person who has knowledge of the usage schedules in the zone, or (b) a sample of the zone occupants who use the plug-in lighting. In the survey, address seasonal variations, vacation schedules, and any other variations in the usage schedule.

- Estimate the Plug-in Lighting Energy Use based on the amount of installed power and the usage schedules, as determined above.

When dissimilar zones are present, conduct this type of audit for each type of zone. When numerous zones of the same type are present, conduct an audit for one zone and apply it to the other similar zones.

\subsubsection{Special Instructions for Average Daily Lighting Load Profile}

The average daily lighting load profile by month or season (summer, winter, spring/fall) is created by plotting the average power of each measurement period (15 minutes or 1 hour) over a 24 -hour period in the month or season. If there are no monthly or seasonal variations, then only one graph is required. For buildings that have very different use patterns for different days of the week (like weekdays versus weekends), separate profiles for the different use periods may be appropriate. Figures 7-3 and A-5 show examples lighting load profiles. 


\subsubsection{Discussion of the Use of Energy Simulations}

Hourly energy simulations of buildings are extremely useful in detailed energy performance studies. They allow the user to make relatively quick assessments of complex systems over long periods. However, the simulation results are only as good as the input data and the models. The program must be accepted, the model inputs carefully entered, and the model calibrated with measured data. The use of energy simulations is beyond the scope of this procedure. The user is referred to ASHRAE Guideline 14 (ASHRAE 2002), ASHRAE Standard 90.1-2004 (ASHRAE 2004), IPMVP Volume III (IPMVP 2003) for more information about the use of energy simulations.

\section{Section 7 - Reporting Format}

To facilitate comparisons among various projects, this section gives a set of standard formats for reporting on the results of this procedure in a consistent manner. The final report for this procedure should include the items outlined in sections 7.1 and 7.2 that apply to your project.

\section{1 - Tier 1}

- General Project Data form, provided in Table 6-2

- Table of one-time performance metrics and a table of monthly and annual performance metrics (Table 7-1).

- A Lighting Design Layout for all floors of the building or a detailed table of lighting type by space (Figure 7-1 and Table 7-3).

\section{2 - Tier 2}

- General Project Data, using form provided in Table 6-2

- A Lighting Design Layout for all floors of the building or a detailed table of lighting types by space (Figure 7-1 and Table 7-3)

- Diagram of measurement scheme, showing locations of measurements (Figure 7-2)

- Table of monthly and/or annual performance metrics, including all metrics listed in the Measurement Plan similar to the example in Table 7-2

- Graphs of average daily lighting energy profiles (Figure 7-3)

- Bar graph of monthly daily average energy use by lighting type (Figure 7-4)

- Bar graph showing the lighting energy savings by type and control (Figures 4-1 and 7-5)

- Graphs of daily illumination levels during the measurement periods.

Table 7-1 Table of Tier 1 Monthly and Annual Metrics

\begin{tabular}{|c|c|c|c|c|c|c|c|c|c|c|c|c|c|}
\hline \multirow{2}{*}{ Metric } & \multicolumn{12}{|c|}{ Month } & \multirow{2}{*}{ Annual } \\
\hline & 1 & 2 & 3 & 4 & 5 & 6 & 7 & 8 & 9 & 10 & 11 & 12 & \\
\hline $\begin{array}{l}\text { Code Baseline } \\
\text { Lighting Energy }\end{array}$ & & & & & & & & & & & & & \\
\hline $\begin{array}{l}\text { Installed Baselin } \\
\text { Lighting Energy }\end{array}$ & & & & & & & & & & & & & \\
\hline $\begin{array}{l}\text { Lighting Energy } \\
\text { Use (estimated) }\end{array}$ & & & & & & & & & & & & & \\
\hline
\end{tabular}


Table 7-2 Table of Tier 2 Monthly and Annual Metrics

\begin{tabular}{|c|c|c|c|c|c|c|c|c|c|c|c|c|c|}
\hline \multirow{2}{*}{ Metric } & \multicolumn{12}{|c|}{ Month } & \multirow{2}{*}{ Annual } \\
\hline & 1 & 2 & 3 & 4 & 5 & 6 & 7 & 8 & 9 & 10 & 11 & 12 & \\
\hline $\begin{array}{l}\text { Code Baseline } \\
\text { Lighting Energy }\end{array}$ & & & & & & & & & & & & & \\
\hline $\begin{array}{l}\text { Daylighting and } \\
\text { Occupancy } \\
\text { Energy Savings }\end{array}$ & & & & & & & & & & & & & \\
\hline $\begin{array}{l}\text { Installed Baselin } \\
\text { Lighting Energy }\end{array}$ & & & & & & & & & & & & & \\
\hline $\begin{array}{l}\text { Lighting Energy } \\
\text { Cost }\end{array}$ & & & & & & & & & & & & & \\
\hline $\begin{array}{l}\text { Lighting Energy } \\
\text { Percent of } \\
\text { Building Energy }\end{array}$ & & & & & & & & & & & & & \\
\hline $\begin{array}{l}\text { Lighting Energy } \\
\text { Use }\end{array}$ & & & & & & & & & & & & & \\
\hline $\begin{array}{l}\text { Peak Lighting } \\
\text { Power }\end{array}$ & & & & & & & & & & & & & \\
\hline $\begin{array}{l}\text { Total Lighting } \\
\text { Energy Savings }\end{array}$ & & & & & & & & & & & & & \\
\hline
\end{tabular}

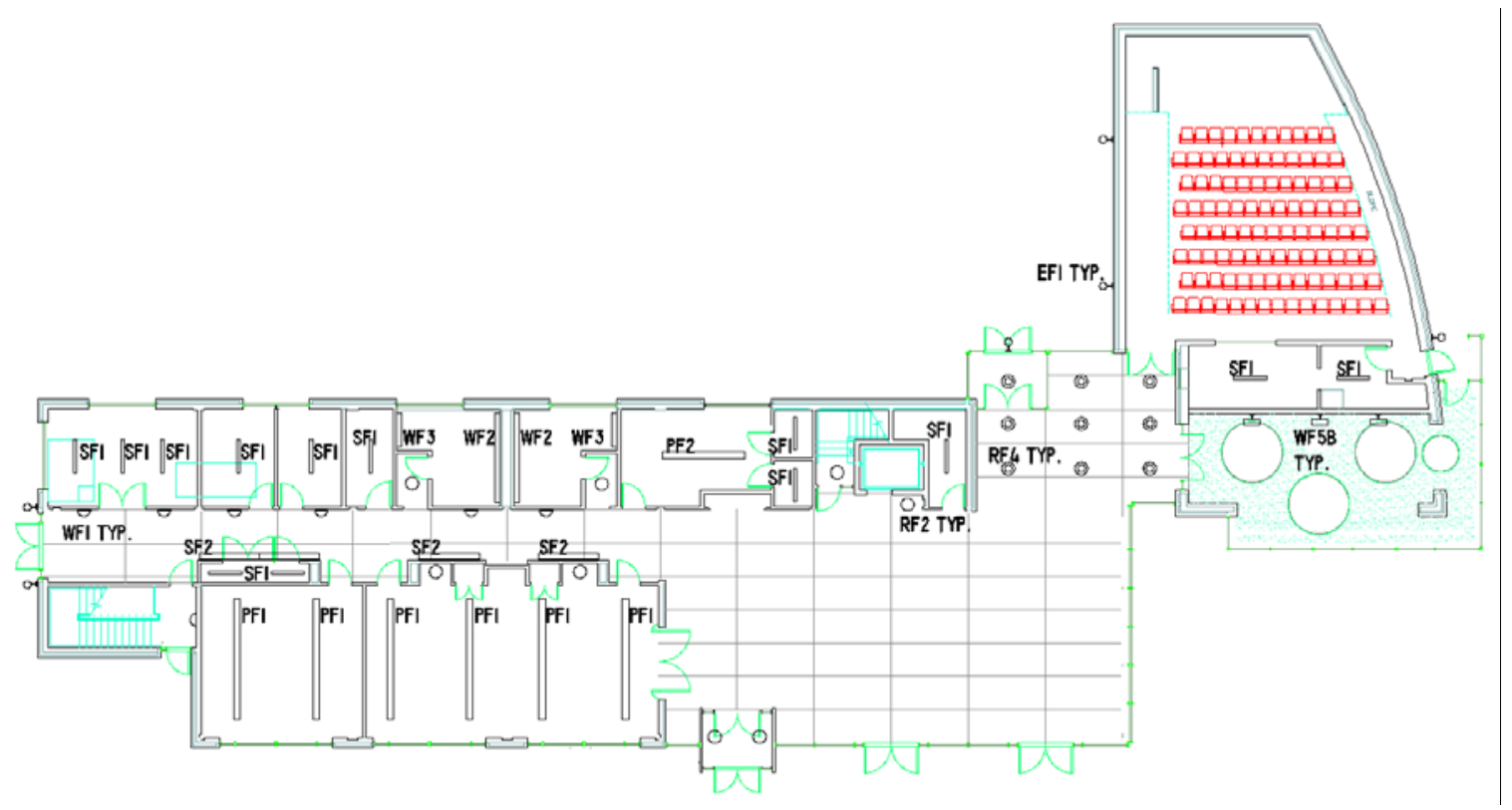

Figure 7-1 A Lighting Design Layout for all floors of the building. The fixture schedule should also include the number of lamps, the lamp type and ballast type 
Table 7-3 Lighting schedule including location and power

\begin{tabular}{|c|c|c|c|c|c|}
\hline Type & Description & Mounting & $\begin{array}{c}\text { Fixture } \\
\text { Power } \\
\text { Ratio }\end{array}$ & Lamps & Lamp Type \\
\hline A & vandal resistant lensed fluorescent & wall-surface & 0.9 & 2 & $\mathrm{FO} 32 / 35 \mathrm{~K}$ \\
\hline B1 & $\begin{array}{l}\text { 4' fluorescent - asymmetric } \\
\text { distribution }\end{array}$ & wall mounted & 0.9 & 1 & $\mathrm{~T} 8-32$ \\
\hline B2 & $\begin{array}{l}\text { 3' fluorescent - asymmetric } \\
\text { distribution }\end{array}$ & wall mounted & 0.9 & 1 & T8 - 25 \\
\hline $\mathrm{C}$ & 2' $\times 2$ ' parabolic fluorescent & ceiling-lay in & 1.0 & 2 & FB031/35K \\
\hline $\mathrm{D}$ & fluorescent uplight & pendant & 1.0 & 1 & $\mathrm{~F} 032$ / 35K \\
\hline$E$ & keyless porcelain lamp holder & ceiling - surface & 1.0 & 1 & F13DTT/D835 \\
\hline $\mathrm{F}$ & compact fluorescent track light & ceiling - track & 1.1 & 2 & 27 W BIAX \\
\hline G & under cabinet fluorescent & cabinet surface & 0.9 & 1 & $\mathrm{FO} 32 / 35 \mathrm{~K}$ \\
\hline $\mathrm{H}$ & high abuse wraparound fluorescent & ceiling - surface & 1.1 & 2 & $\mathrm{FO} 32 / 35 \mathrm{~K}$ \\
\hline 1 & vandal resistant fluorescent & ceiling - surface & 0.9 & 2 & $\mathrm{FO} 2 / 35 \mathrm{~K}$ \\
\hline $\mathrm{J}$ & compact fluorescent track light & ceiling - track & 1.0 & 1 & $39 \mathrm{~W}$ T5 \\
\hline $\mathrm{K}$ & $\begin{array}{l}\text { fluorescent uplight lensed wet } \\
\text { location fluorescent }\end{array}$ & deck - surface & 1.1 & 1 & FO32 / 35K \\
\hline $\mathrm{L}$ & wall washer & ceiling recessed & 1.1 & 2 & F13DTT/D835 \\
\hline M1 & metal halide monopoint & ceiling - surface & 1.15 & 1 & 35 W PAR38 \\
\hline M2 & suspended cable fluorescent uplight & ceiling - pendant & 1.0 & 1 & F32 T8 M3 1 \\
\hline M3 & low voltage mini - floodlight & beam surface & 1.0 & 1 & 13WTFM 3DTT \\
\hline $\mathrm{X} 1$ & finished area exit light & wall - surface & 1.0 & 2 & LED \\
\hline $\mathrm{X} 2$ & finished area emergency light & wall - surface & 1.0 & 1 & DS N080 \\
\hline $\mathrm{x} 3$ & finished area exit light & pendant wall & 1.0 & 2 & LED \\
\hline
\end{tabular}




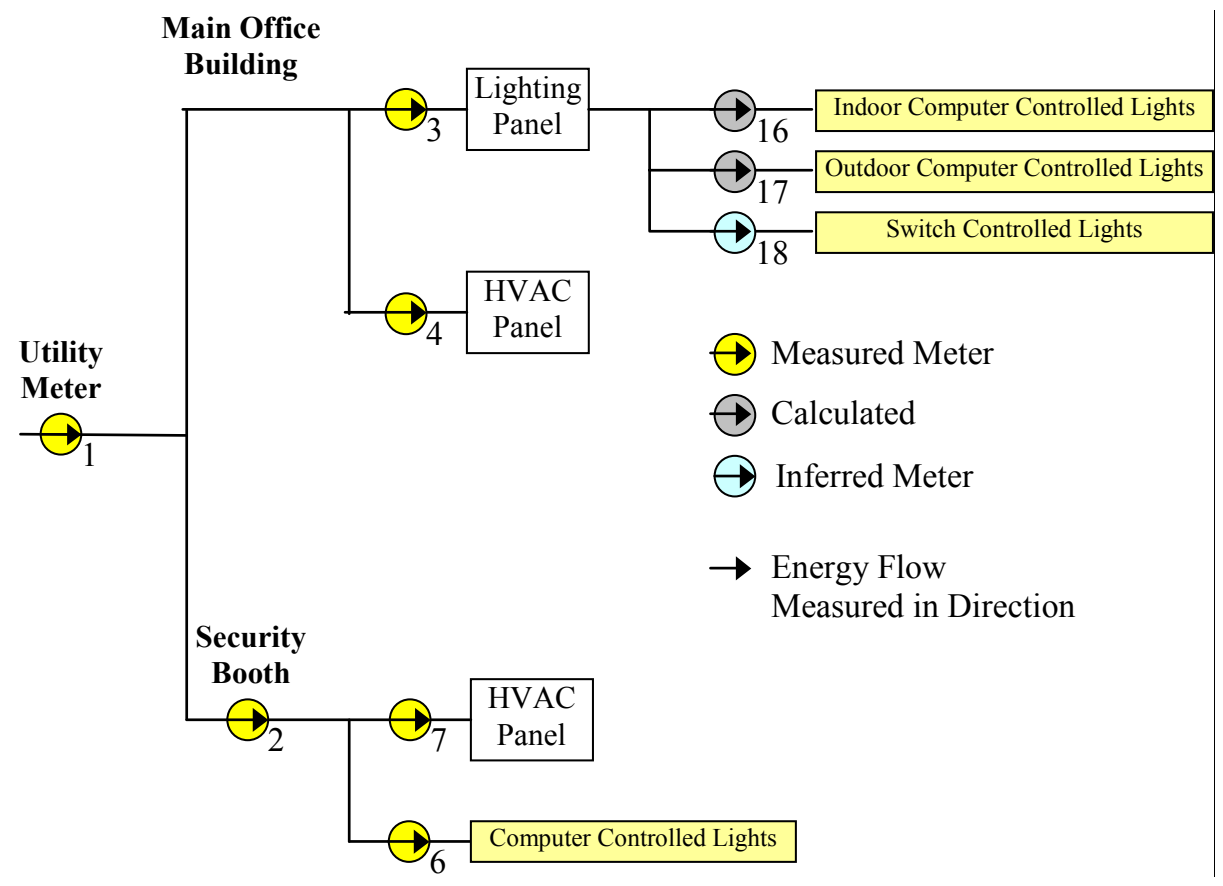

Figure 7-2 Diagram of measurement scheme, showing locations of measurements

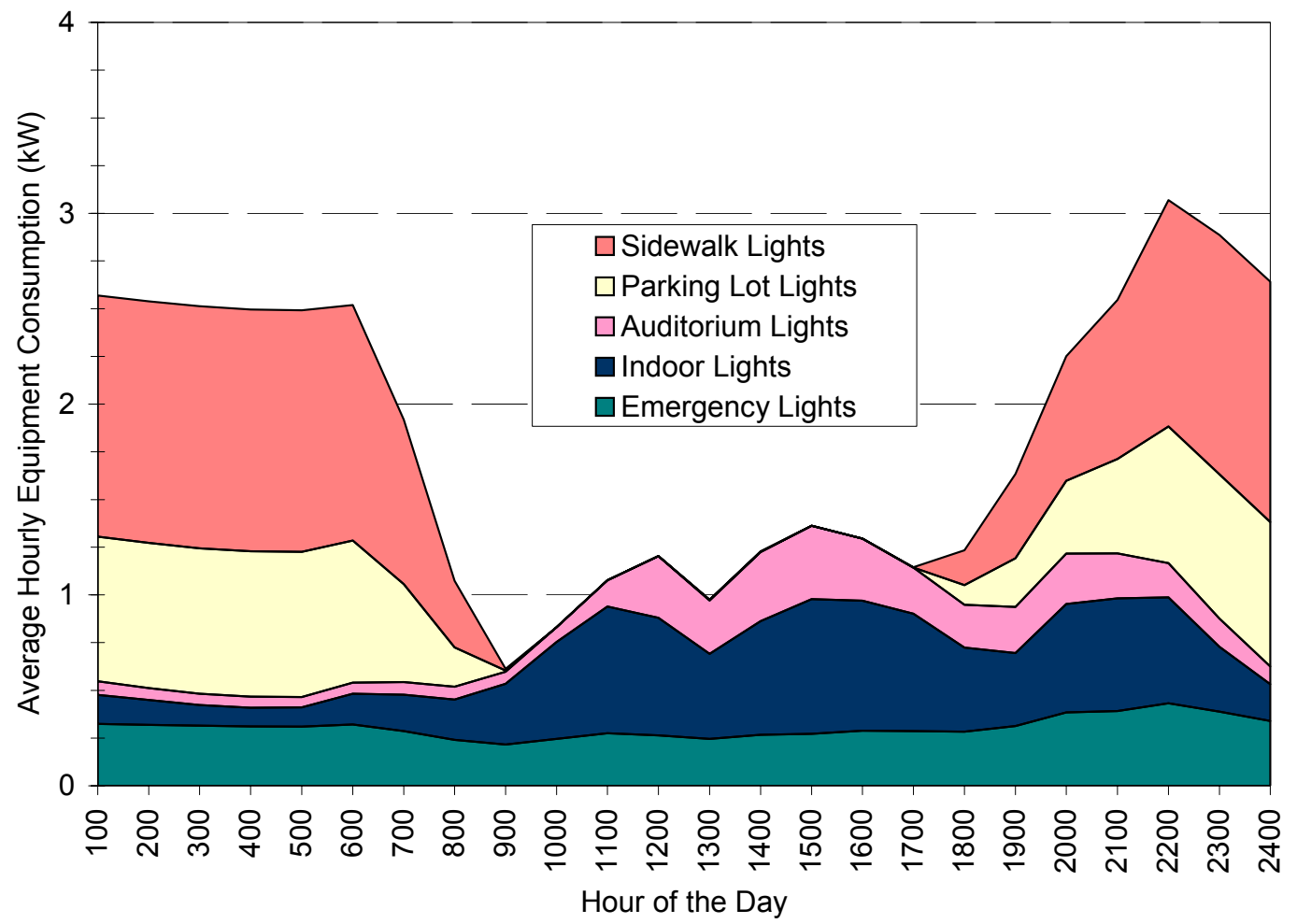

Figure 7-3 Average Daily Lighting Load Profile 


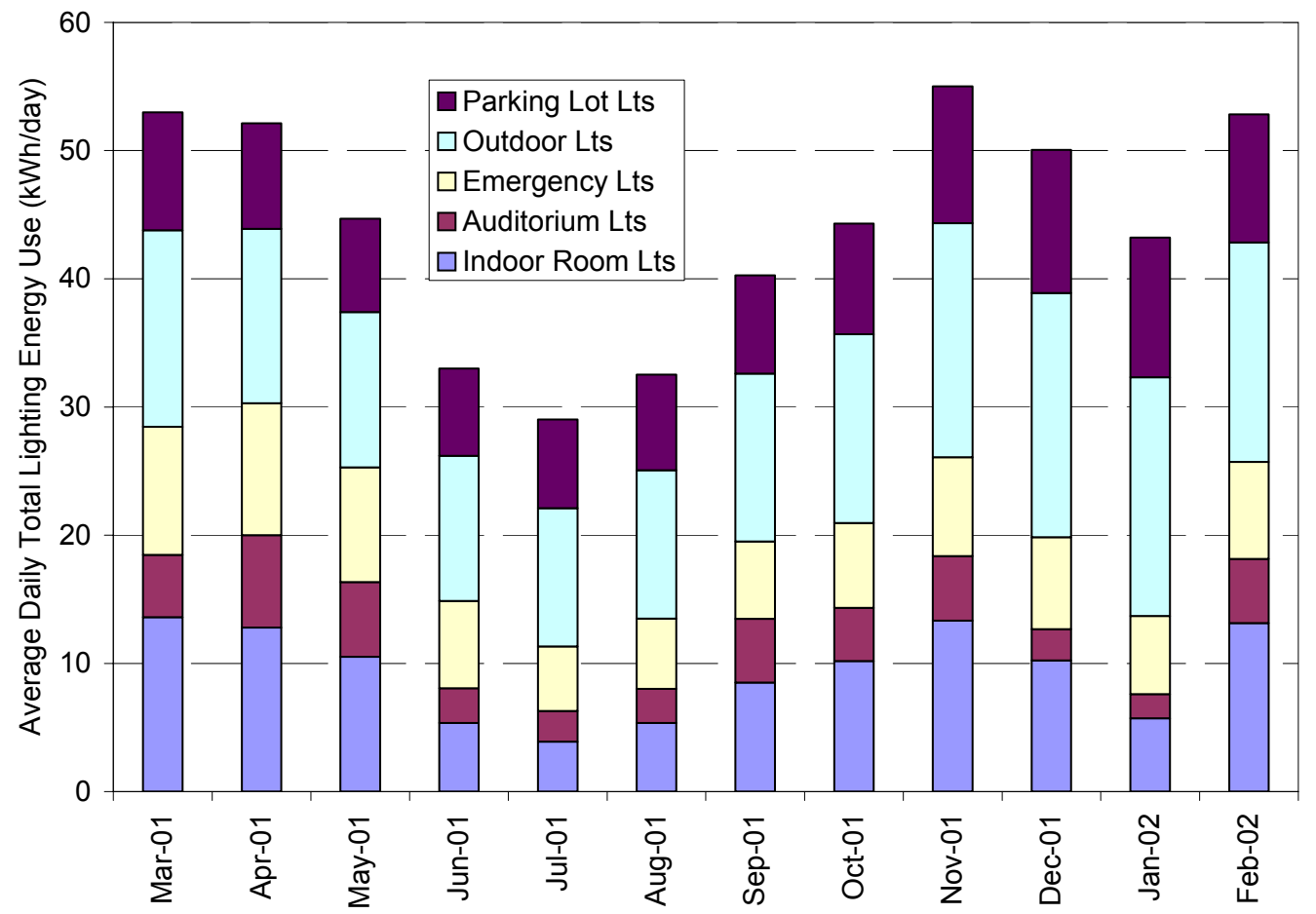

Figure 7-4 Monthly average daily lighting energy end use

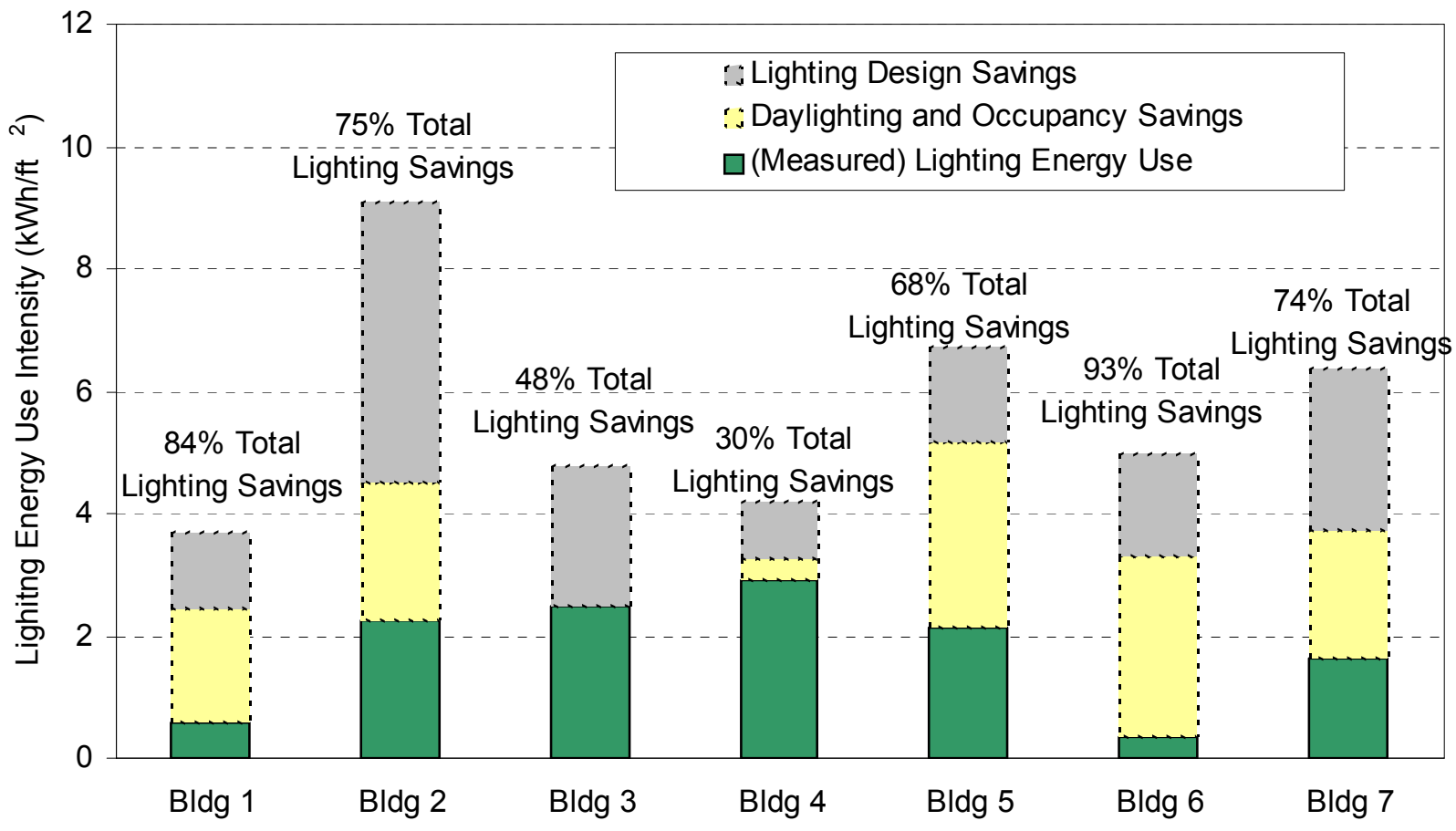

Figure 7-5 Lighting energy savings percent of total 


\section{3 - Reporting Cost Metrics}

When energy costs are compared between two projects that have been analyzed at different times or in different places, several factors may bias the comparison:

- Changes in energy prices over time

- Differences in energy prices from place to place

- General inflation that occurs during the time interval

- Exchange rates between different currency units, which vary over time.

It is beyond the scope of this procedure to develop a system for normalizing all these effects. However, the following procedures should be used to report cost metrics in a way that will facilitate their interpretation.

In cases where currency units are used, the year during which the expenditures occurred should be noted. If the analysis year extends over two calendar years, the calendar year during which most of the expenditures occurred should be cited.

Example: $\quad$ Lighting Energy Cost $=\mathrm{US}_{2001} 6,500 / \mathrm{yr}$ 


\section{Section 8 - References}

ASHRAE. (1999). Energy Standard for Buildings Except Low-Rise Residential Buildings.

ANSI/ASHRAE/IESNA Standard 90.1-1999. Atlanta, GA: American Society of Heating, Refrigerating, and Air Conditioning Engineers.

ASHRAE. (2001). Energy Standard for Buildings Except Low-Rise Residential Buildings.

ANSI/ASHRAE/IESNA Standard 90.1-2001. Atlanta, GA: American Society of Heating, Refrigerating, and Air-Conditioning Engineers.

ASHRAE. (2002). Measurement of Energy and Demand Savings. ASHRAE Guideline 14-2002. Atlanta, GA: American Society of Heating, Refrigerating, and Air-Conditioning Engineers.

ASHRAE. (2004). Energy Standard for Buildings Except Low-Rise Residential Buildings.

ANSI/ASHRAE/IESNA Standard 90.1-2004. Atlanta, GA: American Society of Heating, Refrigerating, and Air-Conditioning Engineers.

ASHRAE. (2005). ASHRAE Handbook of Fundamentals. Atlanta, GA: American Society of Heating, Refrigerating, and Air-Conditioning Engineers.

ASME. (1985). Measurement Uncertainty: Instruments and Apparatus. ANSI/ASME Standard PTC 19.185 (R 1990). New York: American Society of Mechanical Engineers.

Atif, M. R.; Love, J. A.; Littlefair, P. (1997). Daylighting Monitoring Protocols and Procedures for Buildings. A Report of IEA Task 21 / Annex 29 Daylight in Buildings. T21/D2.1/97-01. Ottawa, Ontario, Canada: Institute for Research in Construction.

Barley, C.D.; Deru, M.; Pless, S.; Torcellini, P. (2005). Procedure for Measuring and Reporting Commercial Building Energy Performance. Technical Report NREL/TP-550-38601. Golden, CO: National Renewable Energy Lab (http://www.nrel.gov/publications/).

Deru, M.; Torcellini, P.; Pless, S. (2005). Energy Design and Performance Analysis of the BigHorn Home Improvement Center. 120 pp.; NREL Report No. TP-550-34930. Golden, CO: National Renewable Energy Laboratory. www.nrel.gov/docs/fy05osti/34930.pdf

Deru, M.; Torcellini, P. (2005). Standard Definitions of Building Geometry for Energy Evaluation Purposes. Technical Report NREL/TP-550-38600. Golden, CO: National Renewable Energy Lab (http://www.nrel.gov/publications/).

EIA. (2003). Description of CBECS Building Types. Available at http://www.eia.doe.gov/emeu/cbecs/building_types.html. Last modified January 23, 2003; accessed September 24, 2003. Washington, DC: Energy Information Administration.

Haberl, J.; Lopez, R.; and Sparks, R. (1992). LoanSTAR Monitoring and Analysis Program: Building Energy Monitoring Workbook. submitted to the Texas Governor's Energy Office. Energy Systems Laboratory Report No. ESL-TR-92/06-03, College Station, TX: Texas A\&M University.

Haberl, J.; Reddy, T.; Claridge, D.; Turner, D.; O'Neal, D.; and Heffington, W. (1996). Measuring Energy-savings Retrofits: Experiences from the Texas LoanSTAR Program, Energy Systems Laboratory, Texas A\&M University. ORNL/Sub/93-SP090/1, Oak Ridge, TN: Oak Ridge National Laboratory. 
IESNA. (2000). The IESNA Lighting Handbook; Reference \& Applications 2000. New York: Illuminating Engineering Society of North America.

IPMVP. (2002). International Performance Measurement \& Verification Protocol Concepts and Options for Determining Energy and Water Savings, Volume I. DOE /GO-102002-1554. Washington D.C.: Efficiency Valuation Organization. www.ipmvp.org/info/downloads.html. (Accessed April 2003).

IPMVP. (2003). International Performance Measurement \& Verification Protocol Concepts and Options for Determining Energy Savings in New Construction, Volume III. Washington D.C.: Efficiency Valuation Organization. www.ipmvp.org/info/downloads.html. (Accessed September 2005).

Pless, S.D.; Torcellini, P.A. (2004). Energy Performance Evaluation of an Educational Facility: The Adam Joseph Lewis Center for Environmental Studies, Oberlin College, Oberlin, Ohio. 155 pp.; NREL/TP-550-33180.Golden, CO: National Renewable Energy Laboratory. 


\section{Appendix A - Sample Project}

\section{A.1 - Introduction}

This sample project is provided as an illustrative example of the "Project Definition" and "Measurement System Design" stages of the procedure presented in Section 6.

This example measurement plan corresponds to a hardware store and lumberyard. The building includes a retail/office area of $18,400 \mathrm{ft}^{2}$ and a $24,000-\mathrm{ft}^{2}$ warehouse/lumber yard. This monitoring project looked at the whole building and all of the subsystems. The monitoring and analysis of the interior lighting was extracted for this example (Deru et al. 2005).

Lighting system energy features include:

- Extensive daylighting design with light levels controlled by an building automation system

- Pendant style luminaires with eight $42-\mathrm{W}$ compact fluorescent lights that can be controlled two lamps at a time

- Occupancy sensors in the restrooms.

The construction was completed in April 2000.

\section{A.2 - Project Definition}

Project Name: Ace hardware store and lumber yard

Building Address:

2000 Hwy 12

Silverthorne, CO

All Site/Procedure Related Contacts:

(Names, organization, title, contact info)

Building Manager: John Smith -

Energy Consultants: Ace Energy -

(I.A) Goals of the Analysis:

The lighting systems were evaluated to determine the energy saving and to evaluate the quality of the light delivered by the lighting design. The goals of the monitoring plan were to:

1. Analyze the operation of the lighting design and optimize its performance.

2. Quantitatively assess the quality of the lighting and daylighting designs.

3. Document the successes and weakness of the lighting design.

(I.B) Questions to be Answered:

1. What is the total lighting energy use of the building?

2. How much energy is saved by the lighting design?

3. How effective is the daylighting system?

4. Are minimum light levels being met in each zone?

5. How could the lighting system be improved? 


\section{(I.C) Site Definition and Boundaries:}

The site is defined from the outside edge of building, which excludes façade lighting and parking lot lighting.

\section{(I.D) Analysis Tier (Tier 1 or Tier 2):}

Tier 1 and 2 will need to be implemented to reach the goals set for the project.

(I.E) Desired Accuracy of Results:

The desired accuracy is $\pm 5 \%$ for energy consumption on a monthly basis.

(I.F) Estimated Budget For Performance Analysis:

DAS equipment \& installation: $\$ 5,000$

Staff time: $\quad 500$ hours

Travel expense: $\$ 600$

\section{(I.G) Dates of:}

Site Visits: $\quad$ Ten site visits were made between April 2000 and August 2003.

Monitoring Period: $\quad$ Energy measurements continued from August 2000 until August 2003.

\section{(I.H) Basic Building Data:}

Building Description:

The building serves as a hardware store and lumberyard. The building includes a retail/office area of $18,400 \mathrm{ft}^{2}$ and a 24,000- $\mathrm{ft}^{2}$ warehouse/lumber yard.

Lighting system energy features include:

- Extensive daylighting design with light levels controlled by an building automation system

- Pendant style luminaires with eight 42-W compact fluorescent lights that can be controlled two lamps at a time

- Occupancy sensors in the restrooms. 
Table A-1 Lighting Schedule Table

\begin{tabular}{|l|c|c|c|c|c|c|r|}
\hline \multicolumn{1}{|c|}{ Space } & Fixture Type & $\begin{array}{c}\text { Control } \\
\text { Type }^{1}\end{array}$ & $\begin{array}{c}\text { Fixture } \\
\text { Power } \\
\text { Ratio }\end{array}$ & Qty & $\begin{array}{c}\text { Lamps } \\
\text { per } \\
\text { Fixture }\end{array}$ & $\begin{array}{c}\text { Lamp } \\
\text { Power } \\
\text { (W) }\end{array}$ & Total (W) \\
\hline Retail space & Pendant - CFL & BAS/DL & 1.0 & 60 & 8 & 42 & 20,160 \\
Office 1 & T-8 Fluor. & BAS & 0.9 & 6 & 4 & 32 & 691 \\
Office 2 & T-8 Fluor. & BAS & 0.9 & 8 & 4 & 32 & 922 \\
Office 3 & T-8 Fluor. & BAS & 0.9 & 2 & 4 & 32 & 230 \\
Office 4 & T-12 Fluor. & man & 1.2 & 2 & 2 & 40 & 200 \\
Restroom & T-8 Fluor. & occ & 0.9 & 1 & 2 & 32 & 115 \\
Restroom & T-8 Fluor. & occ & 1.0 & 4 & 2 & 25 & 200 \\
\hline Total Building & & & & & & & $\mathbf{2 2 , 5 1 8}$ \\
\hline
\end{tabular}

${ }^{1}$ Control types: Building Automation System (BAS), Daylighting (DL), Occupancy (occ), Manual (man)

Principal Building Function:

The principal building type is classified according to the principal commercial activity, which is the primary business, commerce, or function carried on within each building (CBECS http://www.eia.doe.gov/emeu/cbecs/building types.html). The building can be divided into two buildings: mercantile and warehouse. The analysis will treat the two spaces and separate buildings.

(I.I) Pre-Existing Performance Data: None available.

\section{A.3 - Measurement System Design}

Step II.A and II.B: Select Performance Metrics and Review necessary data: The performance metrics and data required are shown in Table A-2.

Step II.C, D, and E: Determine point of measurement, specify measurement frequency, and list measurement equipment: The measurement equipment details are listed in Table A-3 and the location of the measurements is shown in Figure A-1. This project includes monitoring all the building loads; however, only the meters used for the whole building and lighting loads are shown in Table A-3.

Step II.F: Determine practicality of measurements. During the first site visit, it was found that the actual configuration of circuit breakers was adequate to install the DAS; however, after monitoring the building for six months, it was discovered that some lighting circuits were not labeled and were located in different power panels. These circuits did not have daylighting or occupancy controls. It was decided to measure these circuits one time and adjust the data accordingly.

Step II.G: Estimate cost of DAS equipment and operation. The estimate determined in Step I.F is realistic.

Step II.H: Calculate uncertainty of measurements. The pretest uncertainty analysis follows from Example C.9.2 in Appendix C, and we expect the uncertainty of the electrical energy measurements to be $\pm 1 \%$. The posttest uncertainty analysis is completed in more detail at the end of this section. 
Step II.I: Resolve cost and uncertainty with expectations (Steps I.E and I.F). The uncertainty is within the accuracy requirements.

Table A-2 Metrics and Data

\begin{tabular}{|c|c|}
\hline Performance Metric & Data Needed \\
\hline Building Energy Use & total building energy use \\
\hline Code Baseline LPD & $\begin{array}{l}\text { function of each space and LPDs for each space from the applicable } \\
\text { energy code }\end{array}$ \\
\hline $\begin{array}{l}\text { Daylighting and } \\
\text { Occupancy Energy } \\
\text { Savings }\end{array}$ & Lighting Energy without Controls and Total Lighting Energy \\
\hline Installed LPD & $\begin{array}{l}\text { Installed lighting capacity (W) in each space by type (ambient, accent, } \\
\text { etc.) and lighted floor area for each space }\end{array}$ \\
\hline $\begin{array}{l}\text { Lighting Design Energy } \\
\text { Savings }\end{array}$ & Code Baseline LPD and Installed LPD \\
\hline Lighting Energy Cost & $\begin{array}{l}\text { Time-series energy data for lighting and the building, and the utility } \\
\text { rate structure to determine lighting contribution to electrical demand } \\
\text { charge }\end{array}$ \\
\hline $\begin{array}{l}\text { Lighting Energy Percent } \\
\text { of Building Energy }\end{array}$ & Lighting Energy Use, Building Energy Use \\
\hline Lighting Energy Use & $\begin{array}{l}\text { Tier 1: Fixture type, power per fixture, and fixture counts for each of } \\
\text { the } 4 \text { lighting types } \\
\text { Tier 2: Measured monthly lighting energy use }\end{array}$ \\
\hline $\begin{array}{l}\text { Lighting Energy with } \\
\text { Daylighting }\end{array}$ & $\begin{array}{l}\text { Measured Lighting Energy Use with daylighting controls turned on } \\
\text { and occupancy controls enabled. }\end{array}$ \\
\hline $\begin{array}{l}\text { Lighting Energy without } \\
\text { Controls }\end{array}$ & $\begin{array}{l}\text { Lighting Energy Use with the occupancy and daylighting controls } \\
\text { turned off - measured or estimated with Installed LPD, lighted hours, } \\
\text { and lighted floor area. }\end{array}$ \\
\hline $\begin{array}{l}\text { Total Lighting Energy } \\
\text { Savings }\end{array}$ & $\begin{array}{l}\text { Code Baseline LPD, measured lighting schedule, Lighted Floor Area, } \\
\text { and Lighting Energy Use }\end{array}$ \\
\hline Horizontal Illuminance & measured horizontal illuminance \\
\hline Vertical Illuminance & measured vertical illuminance \\
\hline
\end{tabular}


Table A-3 Data Monitored for Energy Performance Evaluation

\begin{tabular}{|r|l|l|l|l|l|}
\hline No & \multicolumn{1}{|c|}{ Data } & $\begin{array}{c}\text { Measurement } \\
\text { Point }\end{array}$ & \multicolumn{1}{|c|}{$\begin{array}{c}\text { Monitoring } \\
\text { Equipment }\end{array}$} & Frequency & $\begin{array}{c}\text { Recording } \\
\text { Channel }\end{array}$ \\
\hline \hline 1 & Building Total & MDP (WM1) & $\begin{array}{l}9-100 \text { amp CT } \\
1-\text { Wh trans. }\end{array}$ & 15 minute & $\begin{array}{l}\text { SDM-SW8A } \\
\text { ch-8 }\end{array}$ \\
\hline 2 & Electrical Energy & PP-A (WM2) & $\begin{array}{l}3-50 \text { amp CT } \\
1-\text { Wh trans. }\end{array}$ & 15 minute & $\begin{array}{l}\text { SDM-SW8A } \\
\text { ch-7 }\end{array}$ \\
\hline 5 & Retail Lighting & PP-B (WM5) & $\begin{array}{l}6-100 \text { amp CT } \\
1-\text { Wh trans }\end{array}$ & 15 minute & $\begin{array}{l}\text { SDM-SW8A } \\
\text { ch-5 }\end{array}$ \\
\hline 6 & Lighting Display & PP-B (WM6) & $\begin{array}{l}6-30 \text { amp CT } \\
1-W h \text { trans }\end{array}$ & 15 minute & $\begin{array}{l}\text { SDM-SW8A } \\
\text { ch-1 }\end{array}$ \\
\hline 7 & Warehouse Lighting & PP-C (WM7) & $\begin{array}{l}6-100 \text { amp CT } \\
1-W h \text { trans }\end{array}$ & 15 minute & $\begin{array}{l}\text { SDM-SW8A } \\
\text { ch-6 }\end{array}$ \\
\hline
\end{tabular}

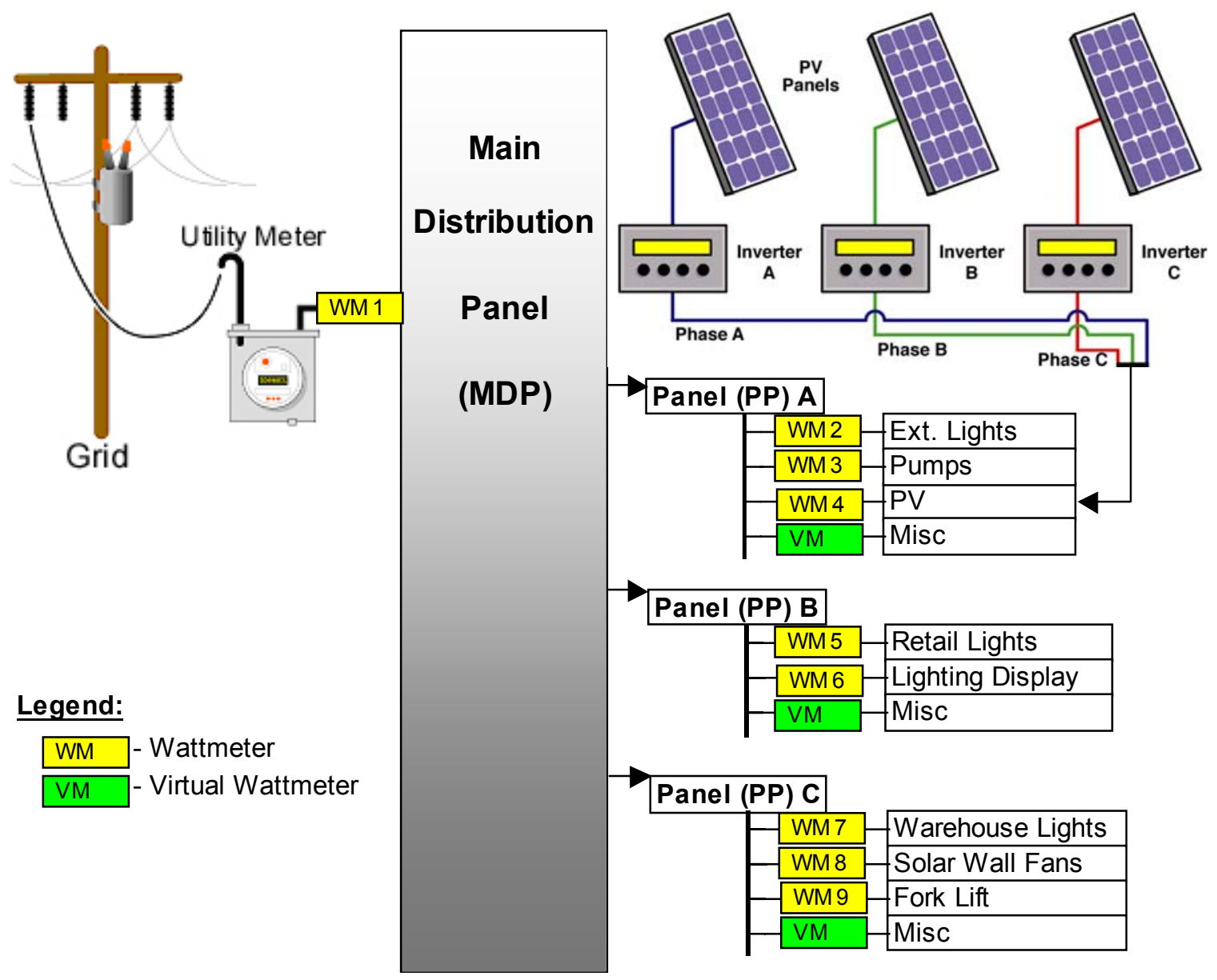

Figure A-1 Electrical diagram and data monitoring points 


\section{A.4 - Data Collection and Analysis}

The data were automatically downloaded two times per week via a cellular telephone modem. A program was written to check the data for missing or bad data. Fortunately, there was no missing data during the two monitoring years.

The layout of the electrical loads in the power panels was not well organized, which made submetering all the loads difficult. Some loads were divided between two panels and some were labeled incorrectly. The miscellaneous loads account for all the loads that could not be monitored separately. The miscellaneous loads were calculated as the total building load [purchased energy plus the PV supplied energy (WM1+WM4)] minus the sum of the submetered loads (all other WMs). However, this includes some loads that belong in the retail lights, lighting display, and exterior lights. The miscellaneous loads were adjusted to account for these other loads to more accurately reflect the distribution of energy. The adjustments were estimated from analyzing plots of the time-series data and noting the change in the miscellaneous loads with changes in the other loads. These manual adjustments introduce higher uncertainties in the final results.

The illuminance levels were measured on three occasions: June 22-28, 2000; September 15-19, 2000; and December 31, 2000, to January 2, 2001. The results for the measurement in the retail area from September are shown in Figures A-2 to A-4. These graphs show a comparison of a clear day with a partly cloudy day. The measured illuminance levels for September 16 in Figure A-3 were adjusted to subtract out the electric light contribution. The electric light levels were determined from the data measured after sunset. The daylighting controls were disabled during the measurement periods. The electric lights were not used on September 17; therefore, no adjustments were made to the measured values. The exterior photometer was shaded early in the morning, which is evident on the clear day. The morning of the partly cloudy day was mostly diffuse light, so the shading by the building is not as evident in the measurements.

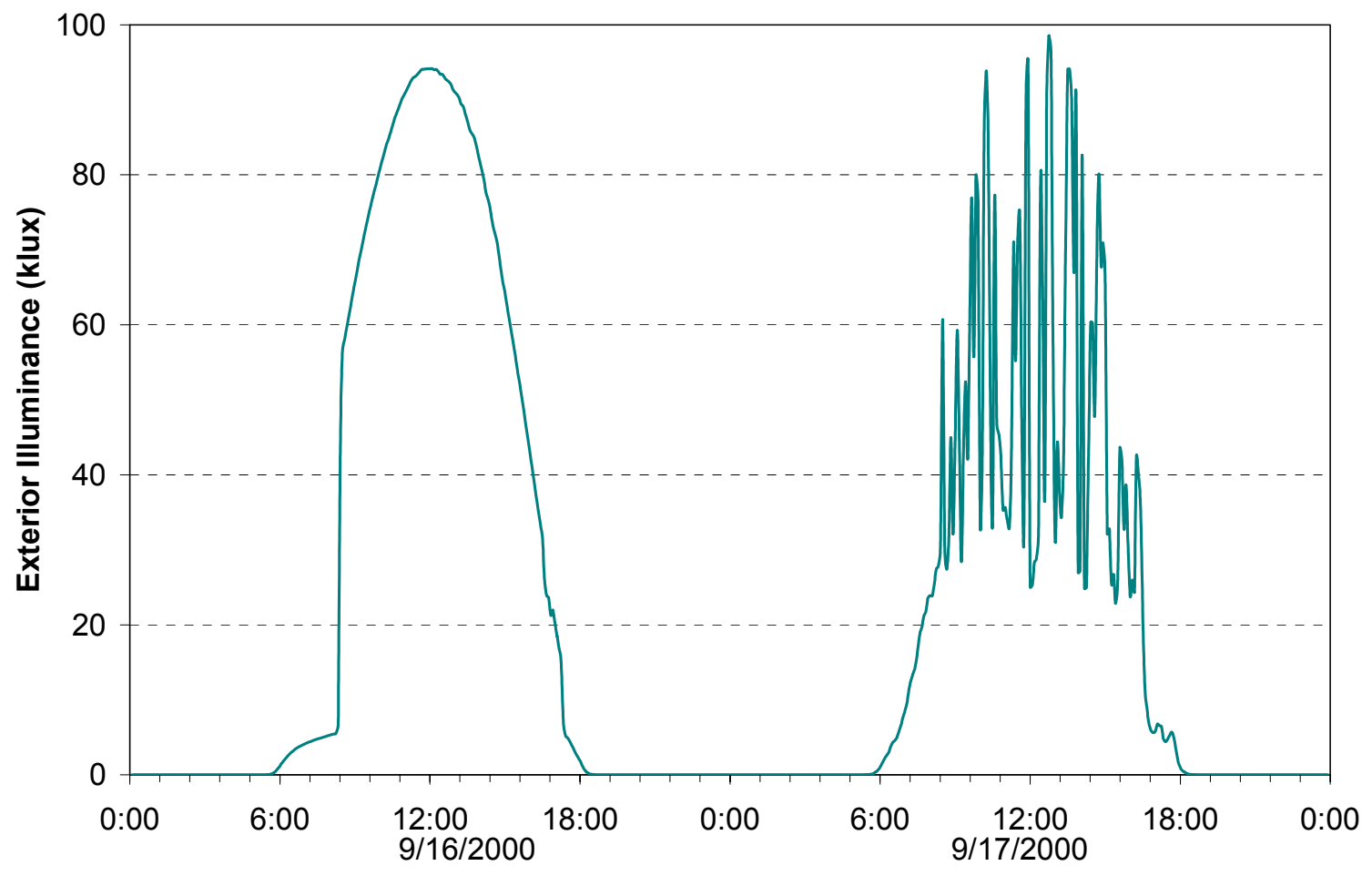

Figure A-2 Exterior illuminance for September 16 and 17, 2000 


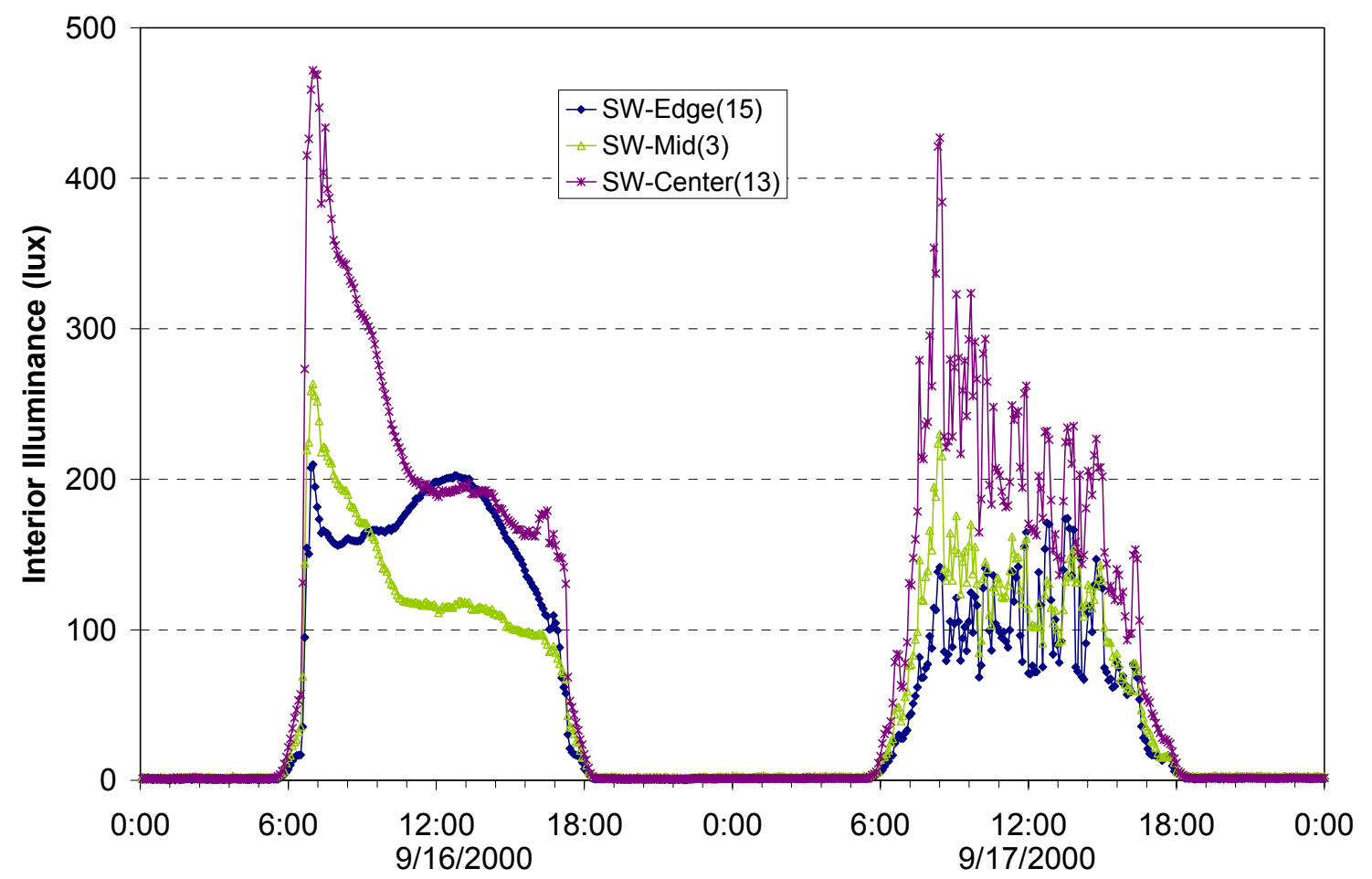

Figure A-3 Daylight levels on the south side of the retail area for clear and partly cloudy autumn days (September 16 and 17, 2000)

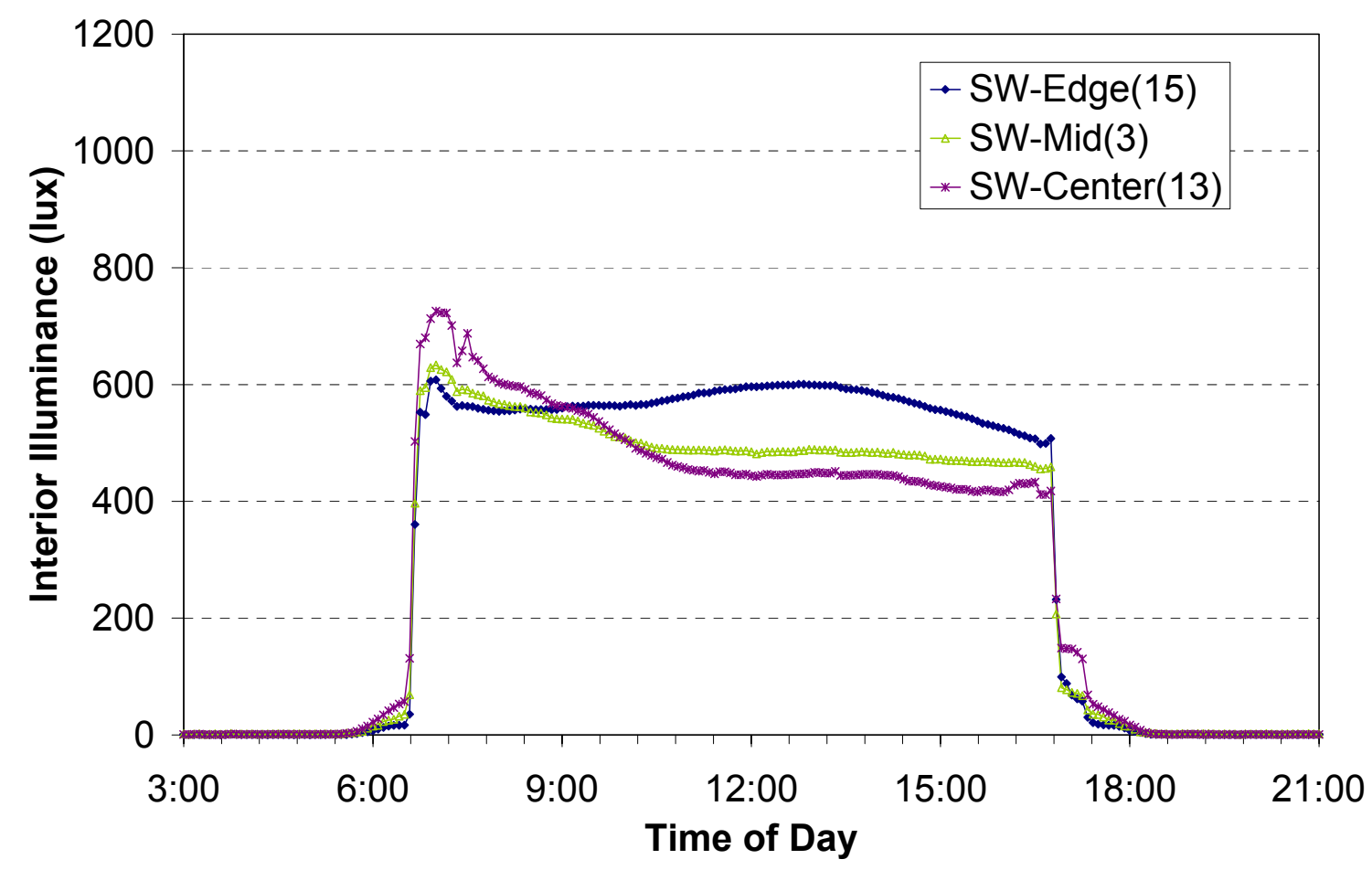

Figure A-4 Light levels from daylight and electric lights on the south side of the retail area on September 16, 2000 
The rate structures for the utility company are summarized in Table A-4 and Figure A-5. The charges for electricity consist of a fixed charge, an energy rate charge, a demand charge, two to four energy rate charge adjustments, a franchise fee, and sales tax. All the charges remained fixed during the monitoring period except for the energy rate charge adjustments, which varied from month to month. Energy rate adjustments doubled the total electrical energy rate charge from the beginning to the end of the monitoring period; however, the electrical demand charge did not change. The energy rate adjustment charges are included to account for such things as changes in primary fuel costs and air quality improvement costs.

Table A-4 Summary of Utility Charges

\begin{tabular}{|c|c|}
\hline Category & $\begin{array}{c}\text { Actual Costs } \\
\text { Throughout Monitoring }\end{array}$ \\
\hline \hline Natural Gas & \\
\hline Total Rate Charge (\$/therm) (\$/GJ) & $\begin{array}{c}\$ 0.34546 \text { to } \$ 0.85546 \\
(\$ 3.27 \text { to } \$ 8.11)\end{array}$ \\
\hline Metering and Billing & $\$ 15.35$ to $\$ 17.29$ \\
\hline Franchise Fee (\% of subtotal) & $3.0 \%$ \\
\hline Sales Tax (\% of total) & $7.65 \%$ \\
\hline & \\
\hline Electricity & $\$ 15.30$ \\
\hline Service and Facility Charge & $\$ 0.01455$ to $\$ 0.03004$ \\
\hline Total Rate Charge (\$/kWh) & $\$ 12.55$ \\
\hline Demand Charge (\$/kW) & $3.0 \%$ \\
\hline Franchise Fee (\% of subtotal) & $7.65 \%$ \\
\hline Sales Tax (\% of total) & \\
\hline
\end{tabular}

A detailed analysis of the electricity costs was undertaken to determine the relative energy costs, understand the impacts of the demand charges. The electrical demand charges and associated taxes constitute a significant part (59\%-80\%) of the monthly electricity bills. The demand charge, including taxes, is $\$ 13.92 / \mathrm{kW}$ based on the maximum 15 -minute integrated kilowatt demand used during the billing month. The impact of demand charges on electricity costs was estimated by examining the electrical energy end use from the 15-minute data. The demand charges were divided among the end uses by determining their fraction of the total load at the time of the monthly peak demand.

The annual energy use and estimated energy cost for the interior lighting systems and the building (excluding the exterior lights) are listed in Table A-5. For the September 2002 to August 2003 period, the lighting systems accounted for $29 \%$ of the electrical energy use, $36 \%$ of the electrical energy cost, and $26 \%$ of the total energy cost. 


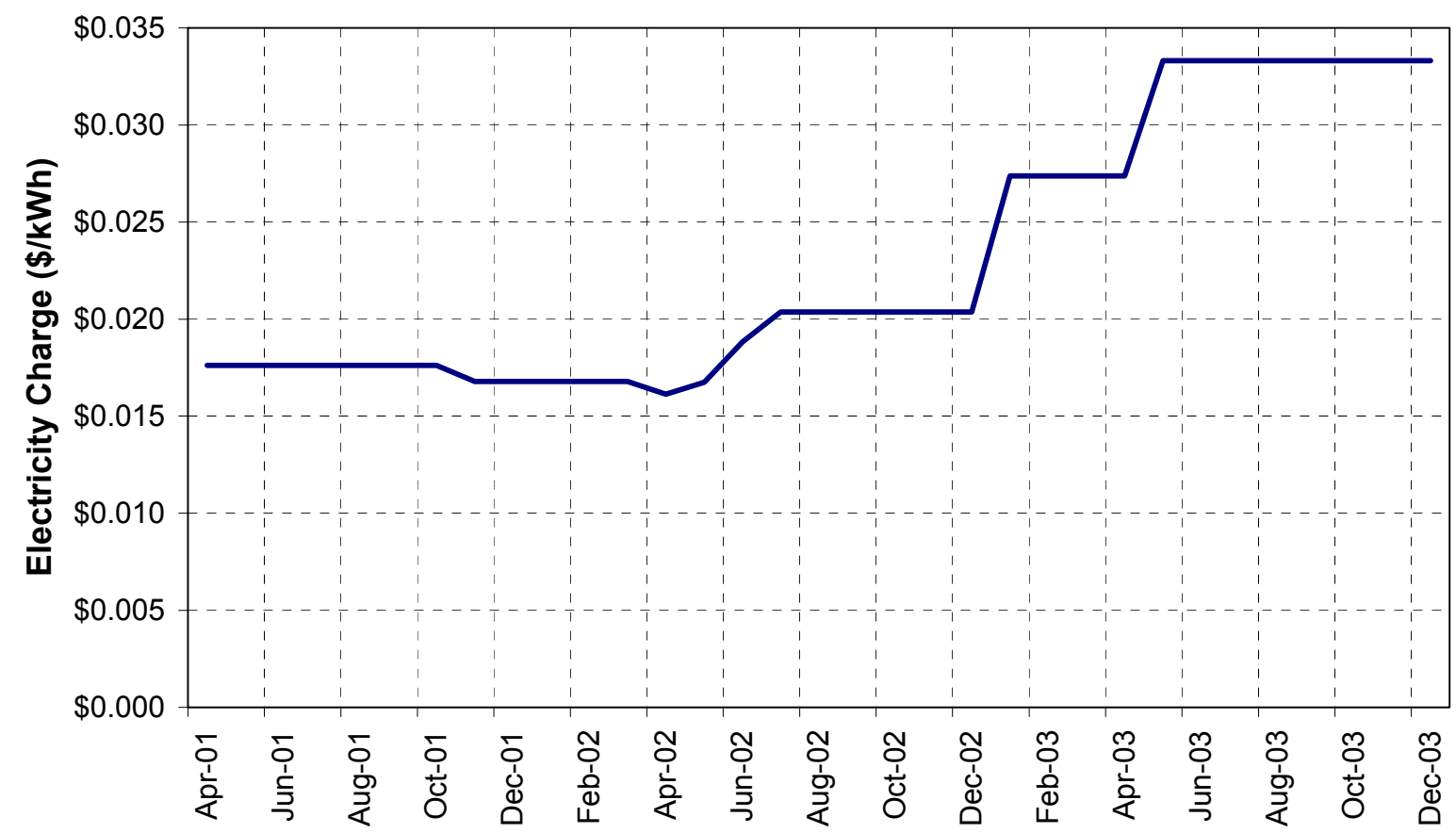

Figure A-5 Total utility electricity rate charges

Table A-5 Lighting Energy Use and Lighting Energy Cost of Interior Lighting Systems

\begin{tabular}{|c|c|c|c|c|}
\hline \multirow[b]{2}{*}{ Load } & \multicolumn{2}{|c|}{ Energy Use MWh (GJ) } & \multicolumn{2}{|c|}{ Estimated Energy Cost } \\
\hline & $\begin{array}{l}9 / 1 / 2001- \\
8 / 31 / 2002\end{array}$ & $\begin{array}{l}9 / 1 / 2002 \\
8 / 31 / 2003\end{array}$ & $\begin{array}{l}9 / 1 / 2001- \\
8 / 31 / 2002\end{array}$ & $\begin{array}{l}9 / 1 / 2002 \\
8 / 31 / 2003\end{array}$ \\
\hline Retail Lights & $\begin{array}{r}44.1 \\
(159)\end{array}$ & $\begin{array}{r}39.3 \\
(141)\end{array}$ & $\$ 3,145$ & $\$ 3,037$ \\
\hline Warehouse Lights & $\begin{array}{r}3.7 \\
(13)\end{array}$ & $\begin{array}{r}8.4 \\
(30)\end{array}$ & $\$ 757$ & $\$ 1,307$ \\
\hline Total Lighting Energy Use & $\begin{array}{r}47.8 \\
(172) \\
\end{array}$ & $\begin{array}{r}47.7 \\
(172) \\
\end{array}$ & $\$ 3,872$ & $\$ 4,344$ \\
\hline Building Site Electrical Energy Use & $\begin{array}{r}147 \\
(529) \\
\end{array}$ & $\begin{array}{r}166 \\
(598) \\
\end{array}$ & $\$ 10,162$ & $\$ 11,907$ \\
\hline $\begin{array}{l}\text { Lighting Energy Percentage of } \\
\text { Building Electrical Energy }\end{array}$ & $33 \%$ & $29 \%$ & $38 \%$ & $36 \%$ \\
\hline
\end{tabular}

Although the lighting systems represent a significant fraction of the building energy consumption, they do exhibit considerable savings compared to the energy code. Table A-6 presents the LPDs and savings for the retail/office area and warehouse. The retail/office area LPD for ASHRAE 90.1 was calculated as the area weighted average of the LPDs of each space in the retail and office areas. The measured energy savings are shown in Table A-7 calculated by two methods. 
Table A-6 Lighting Design Energy Savings

\begin{tabular}{|l|c|c|c|}
\hline \multicolumn{1}{|c|}{ Space } & $\begin{array}{c}\text { ASHRAE 90.1 } \\
\text { W/ft }^{2}\left(W / m^{2}\right)\end{array}$ & $\begin{array}{c}\text { Installed } \\
\mathbf{W}^{2} / \mathrm{ft}^{2}\left(W / m^{2}\right)\end{array}$ & Saving \\
\hline Retail/Office Area & $1.63(17.5)$ & $1.25(13.5)$ & $23 \%$ \\
\hline Warehouse & $1.2(12.9)$ & $0.79(8.5)$ & $34 \%$ \\
\hline Whole Building & $1.39(15.0)$ & $1.0(10.8)$ & $28 \%$ \\
\hline
\end{tabular}

Table A-7 Total Lighting Energy Savings

\begin{tabular}{|l|r|r|c|}
\hline \multicolumn{1}{|c|}{ Space } & $\begin{array}{c}\text { ASHRAE 90.1 } \\
\text { MWh (GJ) }\end{array}$ & $\begin{array}{c}\text { As-Built } \\
\text { MWh (GJ) }\end{array}$ & Savings \\
\hline \hline $\begin{array}{l}\text { Method \#1: } \\
\text { Code vs. Measured Data }\end{array}$ & & & \\
\hline Retail/Office Area & $125.2(451)$ & $39.3(141)$ & $69 \%$ \\
\hline Warehouse & $120.1(432)$ & $8.4(30)$ & $93 \%$ \\
\hline Whole Building & $245.3(883)$ & $47.7(172)$ & $81 \%$ \\
\hline $\begin{array}{l}\text { Method \#2: } \\
\text { Simulated Comparison }\end{array}$ & & & \\
\hline Retail/Office Area & $123.7(445)$ & $41.1(148)$ & $67 \%$ \\
\hline Warehouse & $119.4(430)$ & $7.9(28)$ & $93 \%$ \\
\hline Whole Building & $243.1(875)$ & $49.0(176)$ & $80 \%$ \\
\hline
\end{tabular}

The average daily electrical load profiles by season for the retail/office lighting are shown in Figure A-6. The profiles are similar in shape from season to season. The winter profile shows the need for additional light in the mornings and late afternoons because of the limited daylight. The fall profile shows a slight increase in the late afternoons caused by the change from daylight saving time in late October. The light use in the evening (after 18:00) is from the cleaning crew, who typically turn on most of the lights. This represents a higher light use than during normal operating hours. The average profile is lower than the total because the crew is only in the store two or three days per week. 


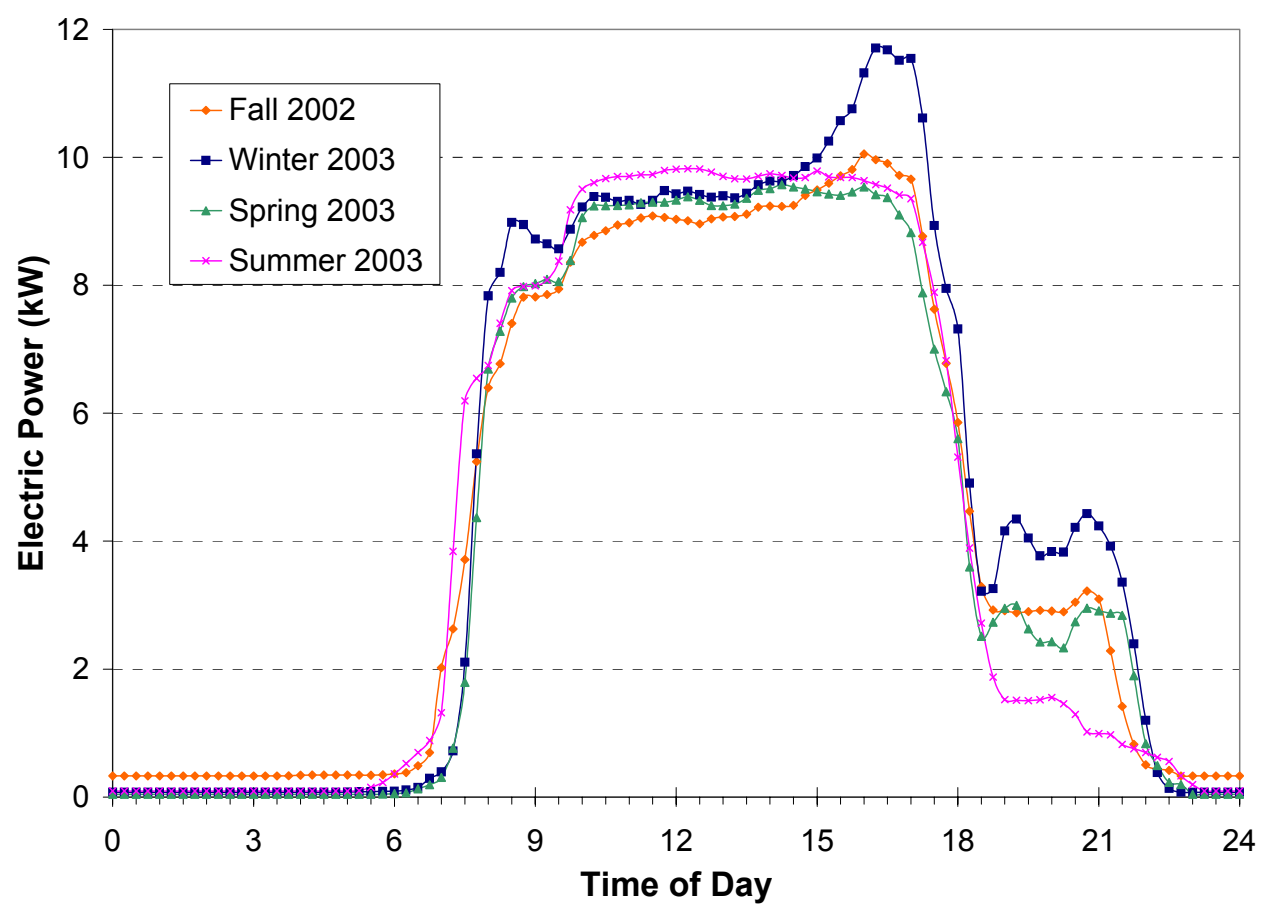

Figure A-6 Seasonal average daily profile of lighting power 


\section{Appendix B - Description of Monitoring Equipment}

This appendix contains a brief introduction to measurement techniques and equipment - it is not meant to be a definitive source of information. The reader is encouraged to conduct further research into these techniques and equipment if there are additional questions after reading this section. For additional information on building energy monitoring equipment and methods, see the ASHRAE Handbook of Fundamentals (2005), ASHRAE Guideline 14 (2002), and International Performance Measurement and Verification Protocol, Volume I (2002).

Maintain the calibration of all instruments according to the manufacturers' recommendations. Some instruments must be field calibrated after installation. Instruments may require recalibration or replacement during long monitoring periods. Maintain a record of all instrument calibrations during the monitoring period.

\section{B.1 - Data Logger}

The data logger is the most important piece of equipment in the data acquisition system (DAS). The options are usually to use small, self-contained units that house the sensors and data logger, or to use one or more central data loggers. Although the self-contained units are easy to install, they do not allow remote access to the data, they must be synchronized with other units, and they generate multiple data files. A central data logger can be expensive; however, it will usually pay for itself in saved time during data collection and analysis. Some building automation systems (BAS) can log and store data, but their use as data loggers should be analyzed carefully. Most BAS are not designed to be data loggers; therefore, problems with precision, scan rate, storage, retrieval, or reliability may arise. The following features are key in a central data logger:

- Reliability: The data logger must be dependable and robust. If the data logger fails, all the data will be lost for that period; the data collected up to the point of failure may be lost as well. A reliable data logger usually pays for itself by reducing maintenance costs and avoiding lost data.

- Memory: The data logger must be able to store the collected data for long periods in case there are times when the data cannot be retrieved. Recording time-series data can create large data files. Ideally, a data logger should be able to store many months of data without running out of memory.

- Communications: Most data loggers have, at a minimum, an RS232 port for direct connection to a computer. For long-term data monitoring, remote communication capabilities that allow data retrieval, data logger programming, and data logger troubleshooting are usually preferable. For building applications, remote access is usually through a telephone modem, a cell phone modem, or an Internet connection.

- Data Storage Format: The format of the data storage should be straightforward and easy to work with. Some systems have storage formats that are difficult to process and may even result in lost data. The easiest format is usually a comma-delimited text file with a date and time stamp for each set of readings.

- Versatility: A good data logger will be flexible enough to handle many types of sensors and ranges of inputs. Sensor outputs may be voltage, current, or pulses. The data logger should also be able to supply excitation outputs to power sensors. Its scan rate should be an order of magnitude greater than the dynamics of the system being monitored. The data logger should also be able to expand to handle many inputs.

- Programmability: Many data loggers include built-in functions for converting signals from sensors into convenient engineering units. Examples include simple mathematical expressions, complex thermocouple (TC) conversions, and combining flow and temperatures to calculate 
energy flow (e.g. "Btu meter"). Programming the data logger to perform these tasks reduces the amount of data post processing and facilitates quick data assessments.

- Capability for Backup Power: The data logger should be able to operate for at least 2-4 weeks on backup power in case of a power outage or if it is inadvertently unplugged.

\section{B.2 - Alternating Current Power Measurements}

In alternating current (AC) systems, the voltage and current waveforms vary with time over a cycle. Thus, the power is also cyclic, and the desired measurement is the average power over a cycle. The type of equipment needed to measure $\mathrm{AC}$ power depends on the current waveform, i.e., whether it is a sine wave and whether it is in phase with the voltage waveform. A power transducer is a device that can accurately measure the average power in any situation, regardless of the type of current waveform. However, in some cases a simpler method is recommended. Generally there are three cases to consider, depending on the type of load.

1. Case 1: Resistive loads. In loads that behave as resistors (with $\mathrm{E}=\mathrm{I} \cdot \mathrm{R}$ ), such as incandescent lights and electrical resistance heaters (water heater, duct heater, electric baseboard, etc.), the current is a sinusoid in phase with the voltage. In this case, the recommended measurement scheme is to monitor the root mean square (RMS) ${ }^{2}$ voltage and RMS current, and compute the power as

Power $=($ RMS voltage $) \times($ RMS current $)$.

2. Case 2: Sinusoid out of phase. If the current is a sinusoid that is out of phase with the voltage, such as electric motors (blower, pump, compressor, etc.) and electronic ballasted light fixtures, the formula for the power is: ${ }^{3}$

Power $=($ RMS voltage $) \times($ RMS current $) \times($ power factor $)$.

If the power factor were a constant, it would be sufficient to measure the power factor once, monitor the RMS voltage and RMS current, and use this formula. However, any changes in the loading of a motor, such as dirt buildup on an air filter, corrosion of pipes, or changes in heat pump operating temperatures, can cause the power factor to vary. Therefore, the recommended measurement scheme is to use a power transducer.

3. Case 3: Nonsinusoidal current. If the current is an irregular (nonsinusoidal) waveform, such as fluorescent lights, dimmer controls, or other loads, a power transducer must be used.

$\mathrm{AC}$ current can be measured by a split core CT that fits around an existing wire without interrupting it (the wire does not need to be cut to install the device). When a power transducer is used, a similar type of $\mathrm{CT}$ is attached to the power transducer, along with a voltage connection. If electrical energy flows in both directions in the same wire, two sets of unidirectional CTs and watt-hour transducers, or one bidirectional device, may be required. The CTs should be sized for maximum expected load and not the breaker size. Breakers usually have a higher rating than the maximum load on the circuit. Oversized CTs will lower the accuracy of the measurements. Many CTs have a linear range of response between $10 \%$ and $130 \%$ of their rated capacity.

$\mathrm{AC}$ voltage should be monitored continuously with an $\mathrm{AC}$ voltage transducer if it is required for power calculations. Even though the grid voltage has a fixed nominal value, the actual voltage varies significantly with changing load conditions. A typical bus voltage variation is $\pm 5 \%$. The electric utility company may quote a more specific tolerance.

\footnotetext{
${ }^{2}$ RMS is the square root of the average value of the square of the quantity. This is a special type of average that applies in power calculations. Devices are available that measure RMS voltage and RMS current.

${ }^{3}$ The power factor is the cosine of the phase angle between the voltage and current waveforms, when both waveforms are sinusoids.
} 


\section{Three-Phase Power Systems}

If three-phase electrical power needs to me measured, it will require three-phase power transducers. The power transducer should be selected based on the wiring configuration (three-phase/three-wire or threephase/four-wire). Various three-phase power transducer models feature watt, volt-ampere, power factor, and watt-hour outputs; various response times; and the ability to accommodate chopped or distorted voltage and current waveforms within the accuracy specifications.

\section{B.3 - Direct Current Power Measurements}

$\mathrm{CTs}$, and thus the type of power transducer that is recommended for AC power measurements (Section B.2), do not work with direct current (DC). Two general classes of alternative methods are available:

- Electrically coupled. The DAS shares a common electrical ground with the system being monitored. Measurement apparatus is relatively inexpensive.

- Electrically isolated. The DAS is electrically isolated from the system being monitored. Measurement apparatus is more expensive. This requirement may occur, for example, in a gridconnected photovoltaic (PV) system, where the design of the inverter requires that the DC power circuitry be isolated from ground.

When DC voltage and current are measured separately, the instantaneous DC power is the product of the current times the voltage. Often, the DC power will have some periodic components or other fluctuations in it because of the pulsating nature of current or voltage waveforms in DC systems introduced by rectifiers, inverters, and so on. In such cases, the sampling rate must be high enough to capture and analyze the fluctuations, and the average DC power can be calculated for any desired averaging period.

\section{Electrically Coupled Systems}

A voltage divider is recommended to measure DC voltage in electrically coupled systems. This consists of a simple network of two precision resistors in series, which reduces the range of voltages in the system to the range of voltages accepted by the DAS. The corresponding conversion factor is used to interpret the measurements for data analysis.

A shunt resistor is recommended to measure DC current in electrically coupled systems. A precision lowresistance resistor is placed in series with the circuit to be monitored. The resistance value is chosen to convert the range of currents in the system to the range of voltages accepted by the DAS. The power rating of resistor must also be chosen to accommodate the amount of power consumed (and thus heat generated) in the shunt resistor.

\section{Electrically Isolated Systems}

One type of DC watt transducer employs an external Hall-effect ${ }^{4}$ current sensor to measure the DC power. In some cases, for low current systems (up to $20 \mathrm{~A}$ ) there is no need for an external current sensor because the watt transducer comes with its own internal current sensors. Hall-effect current sensors are more complex and expensive than simple current shunts. However, the Hall-effect technology is a noncontact method of current measurement that provides electrical isolation. For the same reason, electrically isolated voltage transducers are much safer to use than inexpensive voltage dividers. The lack of electrical isolation may damage the DAS in case of overvoltage events, lightning strikes, and other mishaps. Among other benefits, the Hall-effect current sensors come in a split-core configuration. This allows the power measurement equipment to be installed in just a few minutes without breaking the existing power lines. In field applications, problems have been experienced with maintaining the calibration of Hall-effect sensors. One problem is the temperature sensitivity of the calibration.

\footnotetext{
${ }^{4}$ Hall-effect current measurement is a noncontact technique that measures the magnetizing effects of current flowing in a conductor.
} 
Another option is to use DC voltage and current transducers that achieve electrical isolation without the use of the Hall effect. Some are unidirectional and some are bidirectional. Typical accuracies are $\pm 0.25 \%-1 \%$ of full scale plus $0.25 \%$ of reading. As of this writing, prices are about $\$ 200-\$ 400$ per sensor.

\section{B.4 - Illuminance}

Illuminance is a measurement of radiation as sensed by the human eye. Every human eye senses radiation slightly differently, but a standard spectral response curve is defined by the Commission Internationale de Eclairage (CIE, International Commission on Illumination). Photodiodes are the most common sensors for illuminance measurements. They have a nearly linear output and are very stable. The output is corrected to match the standard human eye spectral response curve.

\section{References}

ASHRAE (2002). Measurement of Energy and Demand Savings. ASHRAE Guideline 14-2002. Atlanta, GA: American Society of Heating, Refrigerating and Air-Conditioning Engineers, Inc.

ASHRAE (2005). ASHRAE Handbook of Fundamentals. Atlanta, GA: American Society of Heating, Refrigerating and Air-Conditioning Engineers, Inc.

IPMVP (2002). International Performance Measurement and Verification Protocol Concepts and Options for Determining Energy and Water Savings. Volume I. DOE /GO-102002-1554. Available at www.ipmvp.org/info/downloads.html. (Accessed April 18, 2003.) Washington, DC: U.S. Department of Energy. 


\section{Appendix C - Uncertainty Analysis}

\section{C.1 - Background}

Estimating uncertainty is an important step in data reduction and expression of results. This section introduces uncertainty analysis and provides an uncertainty analysis method for this procedure. The approach outlined here contains many simplifications from a rigorous uncertainty analysis. Our intent is to provide a practical approach without losing the essential uncertainty effects. This procedure is compatible with standard International and U.S. practices from the International Organization for Standardization (ISO 1995), National Institute of Standards and Technology (NIST 1994), American Society of Mechanical Engineers (ASME 1998), and the Instrument Society of America (Dieck 1997).

Uncertainty analysis in building monitoring projects is often neglected either because the practitioner knows that the uncertainty will be small, or because the practitioner does not know how to complete the uncertainty analysis and is overwhelmed by the complexities of rigorous uncertainty analysis. If the correct size instruments are used and they are installed and operated properly, the uncertainty is usually small and within the desired accuracy for building monitoring projects. Nevertheless, this does not relieve the practitioner from having to understanding error and uncertainty.

There is often confusion between error and uncertainty. Error is the difference between the true value, which we do not know, and the measured value; therefore, the error is unknowable. Uncertainty is an estimate of the limits of the error. The terms have different meanings and should not be confused. Every step in the process of making a measurement and reducing the data can introduce an error. The practitioner must be careful to recognize and minimize the sources of error to develop a reasonable estimate of the measurements' uncertainty.

Error is often described as having random and systematic components. The effects of random errors arise from unpredictable temporal or spatial variations in repeated observations of the measurand. All other errors are classified as systematic errors (also called bias errors). All errors should be minimized or adjusted for as practical by careful experimental design, sensor selection, sensor placement, calibration, data acquisition, and data reduction.

The ISO guideline divides uncertainty by the method used to determine it and not by the source. Type A evaluation of uncertainty is from statistical analysis of a series of observations, and Type B evaluation of uncertainty includes all other analysis that is not Type A. ASME (1998) and Dieck (1997) use a slightly different approach by dividing the uncertainties by the effect. Effects that cause scatter in the results are classified as random uncertainties; all others are systematic uncertainties. This procedure follows the ISO approach for classifying uncertainties, but applies the terms random and systematic to the Type A and Type B uncertainties.

Uncertainties are generally combined as the square root of the sum of the squares. The random and systematic uncertainties are treated separately, then combined to arrive at the final uncertainty. A coverage factor $k$ is sometimes used to provide the desired confidence interval. For example, the following uncertainties have coverage factors of 1.7 for $90 \%$ confidence and 2 for $95 \%$ confidence, and assume adequate degrees of freedom.

$$
\begin{aligned}
& \mathrm{U}_{90}=1.7\left[\mathrm{U}_{\mathrm{B}}^{2}+\mathrm{U}_{\mathrm{A}}^{2}\right]^{1 / 2} \\
& \mathrm{U}_{95}=2.0\left[\mathrm{U}_{\mathrm{B}}^{2}+\mathrm{U}_{\mathrm{A}}^{2}\right]^{1 / 2}
\end{aligned}
$$

These equations assume that (1) the uncertainties $U_{A}$ and $U_{B}$ have symmetric and normal distributions; (2) the uncertainties are at the standard deviation confidence level (68\% coverage); and (3) the uncertainties have a large degrees of freedom $(\geq 30)$. In this procedure, we make these assumptions unless we have 
specific information to the contrary. The value of the coverage factor $(\mathrm{k}=1.7)$ comes from the $\mathrm{t}-$ distribution for $90 \%$ confidence with a degree of freedom greater than 30 , as shown in Table C-3. The $90 \%$ confidence interval (sometimes stated as 90\% coverage) means that 9 of 10 observations should satisfy $x=\bar{x} \pm U_{90}$. This procedure requires that uncertainties be reported at the $90 \%$ confidence level unless project requirements dictate otherwise. If the confidence levels of uncertainties from outside this procedure are not known, a knowledgeable estimate will have to be made.

Uncertainty analysis should be completed before (pretest) and after (posttest) a monitoring project. The purpose of the pretest uncertainty analysis is to determine whether the designed approach will fit within the accuracy and cost constraints of the monitoring project. The research plan may have to be altered to find the best balance between accuracy, cost, and effort. The uncertainty analysis should be repeated following the monitoring exercise with the actual sensor and measurement data to determine the uncertainty of the final result and whether the uncertainty is within the accuracy requirements. In addition, the pretest and posttest uncertainty analyses should be compared with each other and any major discrepancies corrected.

\section{C.2 - Uncertainty Analysis Procedure}

As every building energy-monitoring project is different, so is every uncertainty analysis. However, general steps should be followed, and Table C-1 provides an outline of an uncertainty analysis procedure. The procedure represents a balance between rigorous and practical approaches. 
Table C-1 Uncertainty Analysis Procedure

\begin{tabular}{|c|c|}
\hline Step & Reference \\
\hline $\begin{array}{l}\text { 1. Define Measurement Problem } \\
\text { - List measurements, instruments, accuracies, and } \\
\text { equations used in analysis }\end{array}$ & \\
\hline $\begin{array}{l}\text { 2. Identify Error Sources } \\
\text { - List potential sources of error and estimated } \\
\text { uncertainties }\end{array}$ & $\begin{array}{l}\text { Table C-2 } \\
\text { Section C.5 }\end{array}$ \\
\hline $\begin{array}{l}\text { 3. List Uncertainties } \\
\text { - List uncertainties in a table format by type (random or } \\
\text { systematic) }\end{array}$ & Sections C.3, C.4, and C.5 \\
\hline $\begin{array}{l}\text { 4. Determine Sensitivity Coefficients } \\
\text { - Determine the sensitivity coefficients from functions } \\
\text { used in the analysis and enter in the table }\end{array}$ & $\begin{array}{l}\text { Section C. } 6 \\
\text { Equations C. } 6 \text { and C.7 }\end{array}$ \\
\hline $\begin{array}{l}\text { 5. Determine the Degrees of Freedom and Coverage Factor } \\
\text { - List degrees of freedom in the table } \\
\text { - Determine the effective degrees of freedom } \\
\text { - Determine the desired coverage factor }\end{array}$ & $\begin{array}{l}\text { Section C. } 7 \\
\text { Equations C.10 and C.11 } \\
\text { Table C-3 }\end{array}$ \\
\hline $\begin{array}{l}\text { 6. Combine the Uncertainties } \\
\text { - Combine random and systematic uncertainties } \\
\text { separately then combine and apply the appropriate } \\
\text { coverage factor }\end{array}$ & $\begin{array}{l}\text { Section C. } 6 \\
\text { Equations C. } 8 \text { and C.9 }\end{array}$ \\
\hline $\begin{array}{l}\text { 7. Report the Uncertainties } \\
\text { - Report the final result with the uncertainty and } \\
\text { confidence interval }\end{array}$ & \\
\hline
\end{tabular}

\section{C.3 - Random Uncertainty}

Unpredictable variation or scatter that is apparent in repeated observations of an event under the same conditions is called random error. Measurements in buildings are rarely repeated under constant conditions; however, random error may result from regression analysis or be assigned to sensor calibrations.

The uncertainty approximation of the random error in a sample of $n$ observations is estimated from the sample standard deviation as in Equation C.3. Usually we are interested in the mean value of a sample of measurements, and the random uncertainty of the mean value is estimated as the standard deviation of the mean as given by Equation C.4. The sample standard deviation is the random uncertainty of each measurement; the standard deviation of the mean is the random uncertainty of the mean of all the measurements. The degree of freedom $v$ is equal to $n-1$.

$$
\begin{aligned}
& S_{x}=\left[\sum_{i=1}^{n}\left(x_{i}-\bar{x}\right)^{2} /(n-1)\right]^{1 / 2} \\
& S_{\bar{x}}=S_{x} / \sqrt{n}
\end{aligned}
$$

Uncertainties from instrument calibration, data acquisition, and round off errors can also contribute to the random uncertainty. If the instrument calibration does not provide enough information to estimate the 
division between random and systematic uncertainty, this procedure assumes all uncertainty to be systematic.

Regression models are sometimes used to correlate measured energy variables with a driving force like outdoor dry-bulb temperature. The resulting function can be used to estimate energy data for periods when it was not measured. For example, the functional expression can be used to fill missing data or estimate data for periods outside the measurement period. However, the function should be used judiciously and not beyond the range of data used to determine the function.

The residual standard deviation $\mathrm{S}_{\mathrm{Y} / \mathrm{X}}$ is a measure of how well the function fits the measured data and is calculated as shown in Equation C.5 and Example C.9.4. However, it is not an absolute test of "fit" and can be misleading. Higher order relationships can sometimes provide a good fit to the data but contain oscillations between data points. A visual inspection of the function and the measured data can help determine how well the function fits the data.

$$
\mathrm{S}_{\mathrm{Y} / \mathrm{X}}=\left[\frac{\sum_{\mathrm{i}=1}^{\mathrm{n}}\left(\mathrm{y}_{\mathrm{i}}-\hat{\mathrm{y}}_{\mathrm{i}}\right)^{2}}{(\mathrm{n}-\mathrm{p})}\right]^{1 / 2}
$$

The measured dependent variables are $y_{i}$ and the function values are $\hat{y}_{i}$. The degrees of freedom is $v=(n$ $-\mathrm{p}$ ), where $\mathrm{n}$ is the number of observations used to determine the functional relationship and $\mathrm{p}$ is the number of parameters in the function. Section C.7 provides more discussion on degrees of freedom.

\section{C.4 - Systematic Uncertainty}

Systematic uncertainties are from all error sources that are not classified as random. Estimated values of the systematic uncertainties come from experience, engineering judgment, and careful analysis of the results. Instrument drift can increase the systematic uncertainty, which can be a problem for long-term monitoring projects. All instruments should be calibrated or replaced according to the manufacturers' recommendations, or sooner if problems are suspected.

Most systematic uncertainties are assumed to have equal positive and negative magnitude and probability. Furthermore, unless more information is known, the systematic uncertainties are assumed to have a normal distribution and a 95\% confidence interval (ASME 1998). If more details are known, they should be used to handle the systematic uncertainties. If the calibration history is not well known, a more conservative approach is to assume $68 \%$ coverage $\left(\mathrm{U}_{\mathrm{B}}=\mathrm{s}\right)$. If the physical characteristics of the measurement dictate that the systematic uncertainties are not symmetric about the expected value, the positive and negative uncertainties should be calculated separately.

\section{C.5 - Uncertainty Sources}

The first goal of uncertainty analysis is to reduce the possible sources of uncertainty as much as practical. Grouping the sources of potential uncertainties is a helpful, but not necessary, step in uncertainty analysis. Grouping helps identify and track uncertainty sources. Table C-2 summarizes the sources of uncertainties and how to deal with them in this procedure. All standard uncertainties, either random $U_{A}$ or systematic $\mathrm{U}_{\mathrm{B}}$, are estimated at the level of confidence of the standard deviation. For a normal distribution, the standard deviation provides an uncertainty with a confidence interval of approximately $68 \%$ (i.e., $68 \%$ of the observations are expected to lie within $\bar{X} \pm S_{x}$ ). 
Table C-2 Summary of Uncertainty Sources

\begin{tabular}{|c|c|c|c|c|}
\hline Source & Type & Uncertainty & $\begin{array}{l}\text { Degrees of } \\
\text { Freedom }\end{array}$ & Comments \\
\hline $\begin{array}{l}\text { Repeated } \\
\text { Observations }\end{array}$ & Random & $\mathrm{U}_{\mathrm{A}}=\mathrm{S}_{\overline{\mathrm{x}}}$ & $v=n-1$ & Equations C. 3 and C.4 \\
\hline $\begin{array}{l}\text { Regression } \\
\text { Analysis }\end{array}$ & Random & $\mathrm{U}_{\mathrm{A}}=\mathrm{S}_{\mathrm{Y} / \mathrm{X}}$ & $v=n-p$ & Equation C.5 \\
\hline $\begin{array}{l}\text { Sensor } \\
\text { Calibration } \\
\text { Accuracy, s }\end{array}$ & Systematic & $U_{B}=S / 2$ & $v>30$ & $\begin{array}{l}\text { If there is confidence in the sensor and } \\
\text { the calibration, assume (1) symmetric } \\
\text { and normal distribution, (2) } 95 \% \\
\text { coverage, and (3) large degree of } \\
\text { freedom (>30). }\end{array}$ \\
\hline $\begin{array}{l}\text { Sensor } \\
\text { Calibration } \\
\text { Accuracy, s }\end{array}$ & Systematic & $U_{B}=S$ & $v>30$ & $\begin{array}{l}\text { If there is limited confidence in and } \\
\text { information about the sensor calibration, } \\
\text { assume (1) symmetric and normal } \\
\text { distribution, (2) } 68 \% \text { coverage, and (3) } \\
\text { large degree of freedom }(>30) \text {. }\end{array}$ \\
\hline $\begin{array}{l}\text { Sensor } \\
\text { Calibration } \\
\text { Accuracy, s }\end{array}$ & $\begin{array}{l}\text { Systematic } \\
\text { and } \\
\text { Random }\end{array}$ & $\begin{array}{l}\text { Estimate } \\
U_{A} \& U_{B} \\
\text { from } S\end{array}$ & & $\begin{array}{l}\text { If detailed information is known about the } \\
\text { sensor accuracy, it can be used to } \\
\text { estimate } U_{A}, U_{B} \text {, and } v \text {. }\end{array}$ \\
\hline $\begin{array}{l}\text { Resolution } \\
\text { and Round } \\
\text { Off Error }\end{array}$ & Systematic & $U_{B}=a / \sqrt{ } 3$ & $v \rightarrow \infty$ & $\begin{array}{l}\text { Assume (1) rectangular distribution with } \\
\text { equal probability and }(2) \text { half width of } \\
\text { distribution } a=\left(a^{-}+a^{+}\right) / 2 \text {. }\end{array}$ \\
\hline $\begin{array}{l}\text { Measurement } \\
\text { \& Analysis } \\
\text { Methods }\end{array}$ & Systematic & Estimated & $\begin{array}{l}\text { Equation } \\
\text { C. } 10\end{array}$ & $\begin{array}{l}\text { Uncertainty is based on best engineering } \\
\text { judgment and degrees of freedom is } \\
\text { based on an assumed reliability of the } \\
\text { estimated uncertainty. }\end{array}$ \\
\hline Other & & & & $\begin{array}{l}\text { Use best engineering judgment along } \\
\text { with other references where appropriate. }\end{array}$ \\
\hline
\end{tabular}


ASME (1998) and Dieck (1997) provide the following general uncertainty groups:

- $\quad$ Calibration uncertainties are from the limited precision of instruments. Instruments are calibrated to achieve a small combination of systematic uncertainty of the standard instrument and the random uncertainty of the comparison. The magnitude of this uncertainty can be obtained from the manufacturers' specifications or field calibrations. If there is not enough information to estimate the division between random and systematic uncertainty, this procedure assumes that all uncertainty is systematic. Most calibration uncertainties will be assumed to have symmetric and normal distributions and to have $95 \%$ coverage $\left(\mathrm{U}_{\mathrm{B}}=\mathrm{s} / 2\right)$. If the calibration history is not well known, a more conservative approach is to assume $68 \%$ coverage $\left(\mathrm{U}_{\mathrm{B}}=\mathrm{s}\right)$.

- Data acquisition uncertainties include limitations in sensing and recording signals, signal conditioning, and the sensors. These uncertainties can be reduced by overall measurement system field calibrations. The data logger error may be stated as a percent of the measurement at the data logger (usually a current or voltage). There may also be a resolution error when the analog signal is rounded off because only a limited number of digits can be stored and transmitted. These uncertainties also include those introduced by manual reading and recording data. Manually read meters sometimes have low resolution and can be misread.

- $\quad$ Data reduction uncertainties come from processing raw data. Computational round off errors are usually very small and are neglected. However, errors from curve fits to measured data can be significant. Regression models are often used to relate a dependent variable to independent variables, such as energy consumption to outdoor temperature. Regression models can be used to fill in missing data or extrapolate beyond the measurement period. The simplest estimate of the modeling uncertainty is given by the residual standard deviation as shown in Equation C.5. Uncertainty should also be estimated for all data from sources that are not directly measured.

- $\quad$ Uncertainties due to methods are from the techniques in the measurement process. Examples of these uncertainties include those embedded in calculations such as constants or material properties; obtrusive disturbance of a medium by the sensors; spatial averaging of discrete points; environmental effects such as convection, conduction, and radiation; and instability and hysteresis in the sensor. Installation effects should be minimized with careful planning and field calibration of the measurement systems. Even with careful placement, they represent the largest potential uncertainties for measurement of physical phenomena such as temperatures and fluid flows. For example, consider the temperature measurement of a fluid in a pipe by inserting a thermocouple (TC) probe in a thermal well in the pipe. Probe errors will result from thermal resistance between the fluid and the TC and from conduction along the thermal well and thermal couple to the surrounding environment. Spatial errors will result from measuring the fluid temperature in one spot in the pipe and assigning this value to be the average of all the fluid in the cross section of pipe. Another spatial error that may be significant is that the sensor may be at a different location along the length of the pipe relative to the desired point of measurement.

\section{C.6 - Combining Uncertainties}

In general, uncertainties are combined as the square root of the sum of the squares. To combine uncertainties, they must be at the same level of confidence. Combining uncertainties is usually done at the standard deviation level of confidence, which is $68 \%$. Random (Type A) and systematic (Type B) uncertainties should be summed separately until the end of the analysis.

The final result we are interested in is often derived from a function of measured and constant values such as $R=f\left(X_{1}, X_{2}, X_{3}, \ldots X_{m}\right)$. The effects of the uncertainty in each term (measured and constant) on the result are not the same. The most common approach to determine the relative effects of uncertainties on a result is by the use of a Taylor series expansion of the function. The first-order terms from the Taylor series expansion are the sensitivity coefficients. If the uncertainties are independent, the absolute $\theta_{\mathrm{i}}$ and 
relative $\theta_{\mathrm{i}}^{\prime}$ sensitivity coefficients can be calculated analytically or approximated numerically as shown in Equations C.6 and C.7.

$$
\begin{aligned}
& \theta_{\mathrm{i}}=\frac{\partial \mathrm{R}}{\partial \mathrm{X}_{\mathrm{i}}} \approx \frac{\Delta \mathrm{R}}{\Delta \mathrm{X}_{\mathrm{i}}} \\
& \theta_{\mathrm{i}}^{\prime}=\frac{\mathrm{X}_{\mathrm{i}}}{\mathrm{R}} \frac{\partial \mathrm{R}}{\partial \mathrm{X}_{\mathrm{i}}} \approx \frac{\mathrm{X}_{\mathrm{i}}}{\mathrm{R}} \frac{\Delta \mathrm{R}}{\Delta \mathrm{X}_{\mathrm{i}}}
\end{aligned}
$$

The uncertainties (treating random and systematic separate) of the result $\mathrm{R}$ can then be combined as

$$
\mathrm{U}=\left[\sum_{\mathrm{i}=1}^{\mathrm{n}}\left(\theta_{\mathrm{i}} \mathrm{U}_{\mathrm{X}_{\mathrm{i}}}\right)^{2}\right]^{1 / 2}
$$

Finally, the combined uncertainty is the combination of the random and systematic uncertainties

$$
\mathrm{U}_{\mathrm{C}}=\mathrm{k}\left[\mathrm{U}_{\mathrm{B}}^{2}+\mathrm{U}_{\mathrm{A}}^{2}\right]^{1 / 2}
$$

Where $\mathrm{k}$ is the coverage factor that provides appropriate confidence interval $\mathrm{C}$ in the final expression of uncertainty. Section C.7 and Table C-3 provide more information about the coverage factor and degrees of freedom.

Equation C. 8 assumes that the systematic uncertainties are independent. If the uncertainties are correlated, the covariance term from the Taylor series expansion should be included in the uncertainty calculations. The covariance term contains the cross products of the uncertainties and the sensitivity coefficients. ASME (1998) and ISO (1995) contain more information on correlated uncertainties.

\section{C.7 - Coverage Factor and Degrees of Freedom}

Dieck (1997) defines the degrees of freedom $v$ as the freedom left in a data set for error or variability. For example, in the calculation of the sample standard deviation $S_{x}$, the sample mean $\bar{x}$ is calculated, and one degree of freedom is lost, therefore $v=(n-1)$. In the calculation of the residual standard deviation from a regression curve fit, $v=(n-p)$, where $n$ is the number of measured observations used to establish the correlation and $\mathrm{p}$ is the number of constants determined in the correlation.

For building monitoring projects, some systematic uncertainties and the degrees of freedom must be estimated. The degrees of freedom can be thought of as a measure of how good the estimated uncertainty is (or more precisely, the estimated variance). The degrees of freedom can be estimated from the following equation (ISO 1995).

$$
\mathrm{v} \approx \frac{1}{2}\left[\frac{\Delta \mathrm{u}(\mathrm{x})}{\mathrm{u}(\mathrm{x})}\right]^{-2}
$$

The term in the brackets is the relative uncertainty of the estimated uncertainty $u(x)$. It can be thought of as the reliability of the estimated uncertainty $\mathrm{u}(\mathrm{x})$. For example, if an estimated uncertainty $\mathrm{u}(\mathrm{x})$ of an instrument is believed to be reliable to within $\pm 25 \%$ (or the relative uncertainty is $\pm 25 \%$ ), then $v \approx 1 / 2$ $(0.25)^{-2}=8$.

The degrees of freedom is used to determine the coverage factor $\mathrm{k}$, which is used to determine the uncertainty band for different confidence levels. For example, if the degrees of freedom are greater than 30 and the data follow a normal distribution, the t-distribution for $95 \%$ confidence is approximately 2 and 1.7 for $90 \%$ confidence. Therefore, the data should lie within the bounds of $\bar{x} \pm 2 \mathrm{U} 95 \%$ of the time. The 
t-distribution is shown in Table C-3 for different confidence levels (ASHRAE 2002 and ISO 1993). Uncertainties calculated in this procedure should be estimated at a $90 \%$ confidence level unless requirements of the analysis call for a different level. The use of $90 \%$ confidence intervals for building energy measurements follows requirements in ASHRAE (2002) and IPMVP (2002) guidelines.

When two or more uncertainties are combined, the distribution can be approximated by the t-distribution with the effective degrees of freedom calculated by the Welch-Satterthwaite formula:

$$
v_{\text {eff }}=\frac{\left(\sum_{i=1}^{n} S_{i}^{2}\right)^{2}}{\sum_{i=1}^{n} \frac{S_{i}^{4}}{v_{i}}}
$$

Table C-3 t-Distribution

\begin{tabular}{|l|l|l|l|l|}
\hline $\begin{array}{c}\text { Degrees of } \\
\text { Freedom }\end{array}$ & $\begin{array}{c}\mathbf{6 8 \%} \\
\text { Confidence }\end{array}$ & $\begin{array}{c}\mathbf{8 0 \%} \\
\text { Confidence }\end{array}$ & $\begin{array}{c}\mathbf{9 0 \%} \\
\text { Confidence }\end{array}$ & $\begin{array}{c}\mathbf{9 5 \%} \\
\text { Confidence }\end{array}$ \\
\hline \hline 1 & 1.84 & 3.08 & 6.31 & 12.71 \\
\hline 2 & 1.32 & 1.89 & 2.92 & 4.30 \\
\hline 3 & 1.20 & 1.64 & 2.35 & 3.18 \\
\hline 4 & 1.14 & 1.53 & 2.13 & 2.78 \\
\hline 5 & 1.11 & 1.48 & 2.02 & 2.57 \\
\hline 10 & 1 & 1.37 & 1.81 & 2.23 \\
\hline 15 & 1 & 1.34 & 1.75 & 2.13 \\
\hline 20 & 1 & 1.33 & 1.73 & 2.09 \\
\hline 25 & 1 & 1.32 & 1.71 & 2.06 \\
\hline$\geq 30$ & 1 & 1.3 & 1.7 & 2.0 \\
\hline$\infty$ & 1 & 1.28 & 1.65 & 1.96 \\
\hline
\end{tabular}

\section{C.8 - Definition of Terms}

Combined Uncertainty - $\left(\mathrm{U}_{\mathrm{c}}\right)$ Combination of all uncertainties, usually by the positive square root of the sum of the squares at confidence interval $\mathrm{c}$.

Covariance - A measure of the dependence of two random variables.

Coverage Factor - (k) multiplier used with the standard uncertainty to expand the uncertainty for the desired confidence. For example, the standard deviation is multiplied by a coverage factor of 2 for $95 \%$ confidence (or coverage), assuming that the degree of freedom is $\geq 30$. The coverage factor is typically based on the t-distribution (Table $\mathrm{C}-3$ ).

Error - The difference between the true value, which is not known, and the measured value.

Measurand - The quantity being measured.

Random Error - Error from unpredictable sources that are apparent in repeated observations.

Random (Type A) Uncertainty - $\left(\mathrm{U}_{\mathrm{A}}\right)$ Uncertainty obtained from a statistical evaluation of a series of observations that form an observed probability density function. 
Residual Standard Deviation - $\left(\mathrm{S}_{\mathrm{Y} / \mathrm{X}}\right)=$ An estimate of the scatter of data about a curve fit through the data. It is analogous to the standard deviation for the scatter of data about a mean.

Standard Deviation - $\left(\mathrm{S}_{\mathrm{x}}\right)$ A measure of the scatter of data about the mean equal to the positive square root of the variance. For a normal probability distribution and an infinite number of observations, approximately $68 \%$ of the observations will be contained in the interval $\bar{x} \pm S_{x}$. It is taken as the sample standard deviation (n-1 denominator) and not the population standard deviation ( $\mathrm{n}$ denominator).

Standard Uncertainty $(\mathrm{U})$ - Uncertainty at the standard deviation level of confidence, which is $68 \%$.

Systematic Error - Error effects that are not attributed to random error. Systematic errors should be minimized through proper calibration and experimental design.

Systematic (Type B) Uncertainty - $\left(\mathrm{U}_{\mathrm{B}}\right)$ Uncertainty estimated by means other than statistical. This uncertainty is based on an assumed probability density function (e.g., normal, rectangular, or triangular).

Uncertainty - An estimation of the bounds of the error.

Variance - $\left(\mathrm{S}_{\mathrm{x}}{ }^{2}\right)$ A measure of dispersion equal to the sum of the square of the difference between the measurements and the mean divided by one less than the number of measurements.

\section{C.9 - Example Uncertainty Calculations}

\section{C.9.1 - Outdoor air dry-bulb temperature uncertainty}

Estimate the uncertainty in the measurement of the outdoor air dry-bulb temperature by a type-T shielded TC. The TC is connected to a data logger that contains a built-in thermistor reference temperature and calculates the temperature from the measured voltages. The temperature sensors are scanned every $15 \mathrm{~s}$ and the average value is recorded every $15 \mathrm{~min}$.

The significant error sources are sensor error, reference junction temperature sensor error, data acquisition error, and environmental errors. Uncertainties are assumed to be systematic with normal distributions, have $95 \%$ coverage (i.e., $U_{B}=U_{95} / 2$ ), and have a large degree of freedom $(\geq 30)$, unless otherwise noted.

- TC sensor uncertainty: Assume that the reference temperature junction is maintained at $20^{\circ} \mathrm{C}$ and the minimum $\mathrm{T}_{\mathrm{db}}$ is $-20^{\circ} \mathrm{C}$ for a maximum temperature differential of $-40^{\circ} \mathrm{C}$. The maximum error limits established by ANSI for Type-T TCs are $\pm 1.0^{\circ} \mathrm{C}$ from $-100^{\circ} \mathrm{C}$ to $100^{\circ} \mathrm{C}$ or $1.5 \%$, whichever is larger. However, practical experience has shown that this is extremely conservative for the midrange. A more reasonable estimation is to use $1.5 \% \mathrm{x}$ $40^{\circ} \mathrm{C}= \pm 0.6^{\circ} \mathrm{C}$. Therefore, $\mathrm{U}_{\mathrm{B}, \mathrm{I}}= \pm 0.6^{\circ} \mathrm{C} / 2= \pm 0.3^{\circ} \mathrm{C}$.

- Reference junction temperature uncertainty $= \pm 0.2^{\circ} \mathrm{C}$ (from data logger manufacturer). Therefore, $\mathrm{U}_{\mathrm{B}}= \pm 0.2^{\circ} \mathrm{C} / 2= \pm 0.1^{\circ} \mathrm{C}$.

- $\mathrm{TC}$ polynomial voltage temperature conversion uncertainty $= \pm 0.001^{\circ} \mathrm{C}$ (data logger manufacturer). Therefore, $\mathrm{U}_{\mathrm{B}}= \pm 0.001^{\circ} \mathrm{C} / 2= \pm 0.0005^{\circ} \mathrm{C}$.

- Reference junction temperature to voltage conversion uncertainty $= \pm 0.001^{\circ} \mathrm{C}$ (data logger manufacturer). Therefore, $\mathrm{U}_{\mathrm{B}}= \pm 0.001{ }^{\circ} \mathrm{C} / 2= \pm 0.0005^{\circ} \mathrm{C}$.

- Data acquisition voltage measurement uncertainty $= \pm 0.1 \%$ full scale reading $(\mathrm{FSR})=$ $\pm 0.0025 \mathrm{mV}$ for $\pm 2.5 \mathrm{mV}$ range, which is $\pm 0.06^{\circ} \mathrm{C}$ at $45^{\circ} \mathrm{C}$ (from data logger manufacturer)

- Data acquisition resolution uncertainty $=0.00033 \mathrm{mV}$ for the $\pm 2.5 \mathrm{mV}$ range. This is much smaller than the other uncertainties and is neglected.

- Environmental uncertainty is estimated from experience to be $\pm 0.5^{\circ} \mathrm{C}$ at $95 \%$ confidence with an estimated reliability of $25 \%$. The degrees of freedom from Equation C. 10 is $v=8$; 
therefore, the t-statistic for $95 \%$ is 2.3 and $\mathrm{U}_{\mathrm{B}}= \pm 0.5^{\circ} \mathrm{C} / 2.3=0.22$. The uncertainty is mainly due to radiation to the surroundings and convective thermal resistance around the TC.

Assuming that the uncertainties are uncorrelated, the maximum expected uncertainty in taking a single measurement is calculated in Table C-4. The effective degrees of freedom is calculated from Equation C. 11 to be 39 and the coverage factor for $90 \%$ confidence is 1.7 .

Table C-4 Uncertainty Analysis for a TC

\begin{tabular}{|l|l|l|l|l|l|}
\hline \multicolumn{1}{|c|}{$\begin{array}{c}\text { Uncertainty } \\
\text { Source }\end{array}$} & Units & $\begin{array}{c}\text { Standard } \\
\text { Systematic } \\
\text { Uncertainty } \\
\mathbf{U}_{\mathrm{B}}\end{array}$ & $\begin{array}{c}\text { Standard } \\
\text { Random } \\
\text { Uncertainty } \\
\mathbf{U}_{\mathrm{A}}\end{array}$ & $\begin{array}{c}\text { Degrees of } \\
\text { Freedom }\end{array}$ & $\begin{array}{c}\text { Sensitivity } \\
\text { Coefficient }\end{array}$ \\
\hline \hline TC Limits of Error & ${ }^{\circ} \mathrm{C}$ & 0.3 & 0.0 & 30 & 1 \\
\hline Ref. Junction & ${ }^{\circ} \mathrm{C}$ & 0.1 & 0.0 & 30 & 1 \\
\hline TC Voltage Conversion & ${ }^{\circ} \mathrm{C}$ & 0.0005 & 0.0 & 30 & 1 \\
\hline Ref. Junction conversion & ${ }^{\circ} \mathrm{C}$ & 0.0005 & 0.0 & 30 & 1 \\
\hline TC Voltage Measurement & ${ }^{\circ} \mathrm{C}$ & 0.03 & 0.0 & 30 & 1 \\
\hline Environmental & ${ }^{\circ} \mathrm{C}$ & 0.22 & 0.0 & 8 & 1 \\
\hline & \multicolumn{7}{|l|}{ Effective degrees of freedom $=$} & 39 & \\
\hline
\end{tabular}

\begin{tabular}{|l|l|l|l|l|}
\hline Uncertainty & Units & $\begin{array}{c}\text { Standard } \\
\text { Systematic } \\
\text { Uncertainty } \\
\sqrt{\sum\left(\theta \mathrm{U}_{\mathrm{B}}\right)_{\mathrm{i}}^{2}}\end{array}$ & $\begin{array}{c}\text { Standard } \\
\text { Random } \\
\text { Uncertainty }\end{array}$ & $\begin{array}{c}\text { Combined Uncertainty } \\
\sqrt{\sum\left(\theta \mathrm{U}_{\mathrm{A}}\right)_{\mathrm{i}}^{2}}\end{array}$ \\
\hline Thermocouple & ${ }^{\circ} \mathrm{C}$ & 0.39 & 0.0 & 0.66 \\
\hline
\end{tabular}

The uncertainty is therefore $\mathrm{U}_{90}= \pm 0.7^{\circ} \mathrm{C}$ with 41 degrees of freedom. Over the course of a long-term monitoring project, most of the temperature measurements would be within $20^{\circ} \mathrm{C}$ of the reference junction temperature, which would reduce the TC uncertainty to $\mathrm{U}_{95} \pm 0.3^{\circ} \mathrm{C}$ and the overall uncertainty, $\mathrm{U}_{90}= \pm 0.5^{\circ} \mathrm{C}$.

\section{C.9.2 - Electrical energy measurement uncertainty}

Calculate the uncertainty in electrical energy measurements made on a 480 VAC (phase-to-phase) threephase circuit with 100-amp current transformers (CTs) on each phase and a watt-hour meter (WHM). The CTs have a stated accuracy of $\pm 1 \%$ of the reading between $10 \%$ and $130 \%$ of rating, and the accuracy of the WHM is $\pm 0.45 \%$ of the reading $\pm 0.05 \%$ of full scale. The WHM output pulses with a full-scale frequency of $4 \mathrm{~Hz}$ and is connected to a pulse counter with a sampling frequency of $500 \mathrm{~Hz}$. A data logger scans the pulse counter every $15 \mathrm{~s}$. The WHM calculates the energy by the following equation

$$
\mathrm{E}=\frac{\mathrm{nCTs} \times \mathrm{VAC} \times \mathrm{CTamps} \times \text { Pulses }}{\mathrm{FSHz} \times 3,600}
$$

where $\mathrm{E}$ is the energy in watt-hours, $\mathrm{nCT}$ s is the number of CTs, VAC is the phase to ground voltage (nominally $277 \mathrm{~V}$ ), CTamps is the average of the current passing through the nCTs, pulses is the number of pulses output, and FSHz is the full scale pulse frequency $(4 \mathrm{~Hz})$. The energy per pulse at full scale with three $100 \mathrm{amp}$ CTs is $5.771 \mathrm{Wh} /$ pulse. 
The significant uncertainties are accuracies of the CTs and WHM. Errors associated with counting the pulses are small and are neglected. Errors in sensing the line voltage are assumed to be embedded in the accuracy of the WHM. The WHM uncertainty at full scale per pulse is calculated as the energy per pulse at full scale times the accuracy at full scale.

$$
\mathrm{U}_{\mathrm{WHM}, 95}= \pm \frac{3 \times 277 \times 100 \times 1}{4 \times 3,600} \times 0.50 \%= \pm 0.029 \mathrm{Wh} / \mathrm{pulse}
$$

The CT uncertainty is stated as a percentage of the current, and the sensitivity coefficient is calculated from Equation C.8.

$$
\begin{aligned}
& \mathrm{U}_{\mathrm{CT}, 95}=100 \times 0.01=1 \mathrm{~A} \\
& \theta_{\mathrm{CT}}=\frac{\partial \mathrm{E}}{\partial \mathrm{CTamps}}=\frac{3 \times 277 \times 1}{4 \times 3,600}=0.0577 \mathrm{Wh} / \text { pulse } / \mathrm{A}
\end{aligned}
$$

Both uncertainties are assumed to be systematic with normal distributions at $95 \%$ confidence and large degrees of freedom. Therefore, the standard uncertainty $U_{B}$ is found by dividing the uncertainties by a coverage factor of 2 . The coverage factor to have $90 \%$ confidence in the final result with $v \geq 30$ is 1.7 . The absolute and relative uncertainties are calculated in Table C-5.

Table C-5 Uncertainties for Electrical Energy Measurements

\begin{tabular}{|l|l|l|l|l|l|}
\hline \multicolumn{1}{|c|}{$\begin{array}{c}\text { Uncertainty } \\
\text { Source }\end{array}$} & \multicolumn{1}{|c|}{ Units } & $\begin{array}{c}\text { Standard } \\
\text { Systematic } \\
\text { Uncertainty } \\
\mathbf{U}_{\mathrm{B}}\end{array}$ & $\begin{array}{c}\text { Standard } \\
\text { Random } \\
\text { Uncertainty } \\
\mathbf{U}_{\mathrm{A}}\end{array}$ & $\begin{array}{l}\text { Degrees of } \\
\text { Freedom }\end{array}$ & $\begin{array}{l}\text { Sensitivity } \\
\text { Coefficient }\end{array}$ \\
\hline WHM (full scale 100 A) & Wh/pulse & 0.014 & 0.0 & 30 & 1 \\
\hline CT (full scale 100 A) & $\mathrm{A}$ & 0.5 & 0.0 & 30 & 0.0577 \\
\hline WHM (half scale 50 A) & Wh/pulse & 0.008 & 0.0 & 30 & 1 \\
\hline CT (half scale 50 A) & A & 0.25 & 0.0 & 30 & 0.0577 \\
\hline WHM (25 A) & Wh/pulse & 0.0005 & 0.0 & 30 & 1 \\
\hline CT (25 A) & A & 0.125 & 0.0 & 30 & 0.0577 \\
\hline
\end{tabular}

\begin{tabular}{|l|l|l|l|l|}
\hline \multicolumn{1}{|c|}{ Uncertainty } & \multicolumn{1}{|c|}{ Units } & $\begin{array}{c}\text { Standard } \\
\text { Systematic } \\
\text { Uncertainty } \\
\sqrt{\sum\left(\theta \mathrm{U}_{\mathrm{B}}\right)_{\mathrm{i}}^{2}}\end{array}$ & $\begin{array}{c}\text { Standard } \\
\text { Random } \\
\text { Uncertainty } \\
\sqrt{\sum\left(\theta \mathrm{U}_{\mathrm{A}}\right)_{\mathrm{i}}^{2}}\end{array}$ & \multicolumn{1}{|c|}{$\begin{array}{c}\text { Combined Uncertainty } \\
\mathrm{U}_{90}\end{array}$} \\
\hline \hline Full scale 100 A & $\mathrm{Wh} / \mathrm{pulse}$ & 0.0323 & 0.0 & 0.055 \\
\hline Half scale 50 A & $\mathrm{Wh} /$ pulse & 0.0165 & 0.0 & 0.028 \\
\hline Quarter scale 125 A & Wh/pulse & 0.0086 & 0.0 & 0.015 \\
\hline Full scale 100 A & $\%$ & $0.56 \%$ & 0.0 & $0.95 \%$ \\
\hline Half scale 50 A & $\%$ & $0.57 \%$ & 0.0 & $0.97 \%$ \\
\hline Quarter scale 125 A & $\%$ & $0.60 \%$ & 0.0 & $1.01 \%$ \\
\hline
\end{tabular}

The full-scale uncertainty is $\mathrm{U}_{90}= \pm 1 \%$ with 30 degrees of freedom, and the half-scale uncertainty is $\mathrm{U}_{90}$ $= \pm 1 \%$ with 30 degrees of freedom. The relative uncertainties apply to circuits using different sized CTs assuming the same WHM, number of CTs, and relative sensor accuracies. 
This type of electrical meter would most likely be used to record 15-min or hourly total energy use, which then may also be condensed to daily, monthly, or yearly energy use. The uncertainty for the total energy measurement could be estimated in two ways: first by applying the relative uncertainties calculated above to the total energy, and second by combining the uncertainty per pulse for all the pulses in the total energy. For example, assume the energy total with an average of $50 \%$ power over $1 \mathrm{~h}$ is $24 \mathrm{kWh}$, which is 4,159 pulses. If we assume the uncertainty in the total energy is $1 \%, \mathrm{U}_{90}= \pm 240 \mathrm{Wh}$. By comparison, assuming the uncertainty per pulse is $\mathrm{U}_{90}= \pm 0.034 \mathrm{Wh}$, the uncertainty in the total is $\mathrm{U}_{90}=$ $\pm\left[4,159(0.028)^{2}\right]^{1 / 2}= \pm 1.8 \mathrm{Wh}$. The first method is more conservative and is recommended in this procedure.

\section{C.9.3 - Building energy use intensity uncertainty}

Estimate the uncertainty in the calculation of the annual site Building Energy Use Intensity (BEUI) of a building. The building electricity use is determined from a monitoring system similar to that used in Example C.9.2 and the gas use is from the utility bill. It is a two-story building with the gross interior floor area of $28,800 \mathrm{ft}^{2}$ as determined from the building drawings. The annual electricity use is $745.8 \times 10^{6}$ Btu and the annual gas use is $497.2 \times 10^{6} \mathrm{Btu}$.

We assume that the building dimensions are measured with an accuracy of $\pm 1 \mathrm{ft}$, and that this is a systematic uncertainty with a symmetric and normal probability distribution and $95 \%$ coverage. The uncertainty in the electricity total is assumed to be $\mathrm{U}_{68}= \pm 0.5 \%$ as determined in Example C.9.2 assuming an average of $50 \%$ power. The uncertainty in the gas measurements is based on at least three factors. The gas is billed on an energy content basis, which is determined by measuring the gas volume and multiplying by an energy multiplier. The energy multiplier is calculated monthly and depends on the energy content of the gas and the average outdoor air temperature. The accuracy of the gas meter is specified to be $\pm 2 \%$, which is typical for utility gas metering. This value is assumed to be a systematic uncertainty with a normal probability distribution and 95\% coverage and 30 degrees of freedom. The uncertainty in the energy multiplier is assumed to be $\pm 2 \%$ with $95 \%$ coverage, 30 degrees of freedom, and all systematic uncertainties. Finally, an uncertainty is associated with the difference in the energy multiplier and the actual energy content of the delivered gas. This uncertainty is estimated from the variation in the monthly values of the energy multiplier with temperature compensation term removed over a 3 -yr period $(n=36)$. The uncertainty is estimated from the relative standard deviation of the monthly energy multiplier, which is $\mathrm{s}=0.8 \%$. The total uncertainty for the gas meter is $\mathrm{U}_{\mathrm{B}}=\left((2 / 2)^{2}+\right.$ $\left.(2 / 2)^{2}\right)^{1 / 2}=1.41 \%$ and $U_{A}=0.8 \%$.

\section{Building Area Uncertainty}

The building dimensions for each floor are length $=160 \pm 1 \mathrm{ft}$ and width $=90 \pm 1 \mathrm{ft}$. The area is calculated as $\mathrm{A}=2 \times \mathrm{L} \times \mathrm{W}$ (see Table C-6).

Table C-6 Absolute Uncertainty for Building Area

\begin{tabular}{|l|l|l|l|c|c|}
\hline $\begin{array}{c}\text { Uncertainty } \\
\text { Source }\end{array}$ & Units & $\begin{array}{c}\text { Standard } \\
\text { Systematic } \\
\text { Uncertainty } \\
\mathrm{U}_{\mathrm{B}}\end{array}$ & $\begin{array}{c}\text { Standard } \\
\text { Random } \\
\text { Uncertainty } \\
\mathrm{U}_{\mathrm{A}}\end{array}$ & $\begin{array}{c}\text { Absolute } \\
\text { Sensitivity } \\
\theta_{\mathrm{i}}\end{array}$ & $\begin{array}{c}\text { Combined Uncertainty } \\
\mathrm{U}_{90}\end{array}$ \\
\hline \hline Length & $\mathrm{ft}$ & 0.5 & 0 & $2 \times \mathrm{W}=180$ & $1.7 \sqrt{\sum\left(\theta_{\mathrm{i}} \mathrm{U}_{\mathrm{Bi}}\right)^{2}+\sum\left(\theta_{\mathrm{i}} \mathrm{U}_{\mathrm{Ai}}\right)^{2}}$ \\
\hline Width & $\mathrm{ft}$ & 0.5 & 0 & $2 \times \mathrm{L}=320$ & \\
\hline Total & $\mathrm{ft}^{2}$ & & & & $312 \approx 1 \%$ \\
\hline
\end{tabular}




\section{Building Energy Use Intensity Uncertainty}

The BEUI is calculated from BUEI $=\left(\mathrm{E}_{\text {elec }}+\mathrm{E}_{\text {gas }}\right) / \mathrm{A}$ (see Table C-7).

Table C-7 Absolute Uncertainty for BEUI

\begin{tabular}{|c|c|c|c|c|c|c|}
\hline $\begin{array}{l}\text { Uncertainty } \\
\text { Source }\end{array}$ & Unit & $\begin{array}{l}\text { Nom. } \\
\text { Value }\end{array}$ & $\begin{array}{c}\text { Standard } \\
\text { Systematic } \\
\text { Uncertainty } \\
U_{B}\end{array}$ & \begin{tabular}{|} 
Standard \\
Random \\
Uncertainty \\
$U_{\mathrm{A}}$
\end{tabular} & $\begin{array}{c}\text { Absolute } \\
\text { Sensitivity } \\
\theta_{\mathrm{i}}\end{array}$ & $\begin{array}{c}\text { Combined Uncertainty } \\
\mathrm{U}_{90} \\
1.7 \sqrt{\sum\left(\theta_{\mathrm{i}} \mathrm{U}_{\mathrm{Bi}}\right)^{2}+\sum\left(\theta_{\mathrm{i}} \mathrm{U}_{\mathrm{Ai}}\right)^{2}}\end{array}$ \\
\hline Area & $\mathrm{ft}^{2}$ & 28,800 & 273 & 0 & $\begin{array}{l}-E / A^{2}=- \\
1.499 E-03\end{array}$ & \\
\hline $\begin{array}{l}\text { Electric } \\
\text { Energy }\end{array}$ & kBtu & 745,800 & 3,729 & 0 & $\begin{array}{l}1 / A= \\
3.4722 E-05\end{array}$ & \\
\hline \begin{tabular}{|l|} 
Gas \\
Energy \\
\end{tabular} & kBtu & 497,200 & 7,011 & 3,978 & $\begin{array}{l}1 / A= \\
3.4722 \mathrm{E}-05\end{array}$ & \\
\hline BEUI & $\begin{array}{l}\mathrm{kBtu} / \\
\mathrm{ft}^{2}\end{array}$ & 43 & & & & 0.9 \\
\hline
\end{tabular}

Therefore, the BEUI $=43 \pm 0.9 \mathrm{kBtu} / \mathrm{ft}^{2}$ (90\% coverage). More than half of this uncertainty comes from the area measurement.

\section{C.9.4 - Uncertainty of estimated data}

In an all-electric office building, the major end uses (heating, ventilating, and air-conditioning [HVAC], lights, and plug loads) are submetered every $15 \mathrm{~min}$ for 1 month with the same type of electrical meter system as that used in Example C.9.2. The on-site weather conditions (dry-bulb temperature, RH, and global horizontal solar radiation) are also measured on the same time interval. The electrical monitoring system was down for 9 days in the middle of a month; however, the weather data were recorded for the entire month. The building operating schedule is consistent for weekdays and weekends according to the light and plug load energy use. The HVAC controls did not change during this period. The weekday and weekend control settings for the HVAC systems are very different, so they should be treated separately. The measured dry-bulb temperature and HVAC energy is shown in Table C-10. The missing measured data (shown shaded) are filled with the linear regression formula.

Estimate the weekday HVAC energy consumption for the month by filling in the missing data.

The missing data can be estimated by multiplying the average of the measured daily energy use by the number of missing days, or from a linear regression between the daily HVAC energy use and the daily outdoor dry-bulb temperature. Both methods will be completed here for comparison. There are 23 weekdays during the month and 16 weekdays of good data; therefore, there are 7 days of missing energy data. The total energy for the 16 days of measured data is $6,598 \mathrm{kWh}$.

Method \#1 - Average daily energy use

From the weekday measured energy data, the average daily HVAC energy is $E_{\text {avg }}=412.4 \mathrm{kWh}$ with a standard deviation of $35.0 \mathrm{kWh}$ (Equation C.3). The average value was used to fill in the days of missing data to give a 7 day total of $2,887 \mathrm{kWh}$ and a monthly weekday ( 23 day) total of 9,485 $\mathrm{kWh}$. The random uncertainty for the sum of the 7 days is $\mathrm{U}_{\mathrm{A}-68}=\left[7 \mathrm{x}(35)^{2}\right]^{1 / 2}=92.6 \mathrm{kWh}$. The systematic uncertainty is taken from Example C.9.2 to be $\mathrm{U}_{\mathrm{B}-68}= \pm 0.5 \%$ assuming an average of $50 \%$ power for the whole 23 days. Assuming the degrees of freedom is 30 for the systematic uncertainty and 15 for the random uncertainty, 
the effective degrees of freedom from Equation C. 11 is 23 . The coverage factor for $90 \%$ confidence is 1.71 .

Table C-8 Uncertainty for Filling Data with Averaging

\begin{tabular}{|c|c|c|c|c|c|}
\hline $\begin{array}{l}\text { Uncertainty } \\
\text { Source }\end{array}$ & Units & $\begin{array}{c}\text { Standard } \\
\text { Systematic } \\
\text { Uncertainty } \\
U_{\mathrm{B}}\end{array}$ & $\begin{array}{c}\text { Standard } \\
\text { Random } \\
\text { Uncertainty } \\
\mathrm{U}_{\mathrm{A}} \\
\end{array}$ & $\begin{array}{l}\text { Degrees of } \\
\text { Freedom }\end{array}$ & $\begin{array}{l}\text { Sensitivity } \\
\text { Coefficient }\end{array}$ \\
\hline Regression Analysis & $\mathrm{kWh}$ & 0 & 92.6 & 15 & 1 \\
\hline WHM & $\mathrm{kWh}$ & 46.3 & 0.0 & 30 & 1 \\
\hline \multicolumn{4}{|c|}{ Effective degrees of freedom = } & 23 & \\
\hline
\end{tabular}

\begin{tabular}{|l|l|l|l|l|}
\hline Uncertainty & Units & $\begin{array}{c}\text { Standard } \\
\text { Systematic } \\
\text { Uncertainty } \\
\sqrt{\sum\left(\theta \mathrm{U}_{\mathrm{B}}\right)_{\mathrm{i}}^{2}}\end{array}$ & $\begin{array}{c}\text { Standard } \\
\text { Random } \\
\text { Uncertainty }\end{array}$ & $\begin{array}{c}\text { Combined Uncertainty } \\
\mathrm{U}_{90}\end{array}$ \\
& $\sqrt{\sum\left(\theta \mathrm{U}_{\mathrm{A}}\right)_{\mathrm{i}}^{2}}$ & $1.71 \sqrt{\sum\left(\mathrm{U}_{\mathrm{B}}\right)^{2}+\sum\left(\mathrm{U}_{\mathrm{A}}\right)^{2}}$ \\
\hline \hline Monthly Total & $\mathrm{kWh}$ & 46.3 & 92.6 & 177 \\
\hline
\end{tabular}

The total weekday HVAC energy use for the month is estimated by the averaging method to be

$$
\mathrm{E}=9,485 \pm 177 \mathrm{kWh} \text { at } 90 \% \text { confidence }
$$

Method \#2 - Linear regression of daily HVAC energy and outdoor temperature

The linear regression of the daily HVAC energy use with daily average outdoor temperature produces the function $\mathrm{E}=5.357 \mathrm{~T}_{\mathrm{db}}+27.23$ as shown in Figure $\mathrm{C}-1$, which gives an estimated total for the 7 missing days of $\mathrm{E}=2,790 \mathrm{kWh}$. The residual standard deviation for estimating 1 day of energy use is calculated from Equation C. 5 to be $24.2 \mathrm{kWh}$. The random uncertainty for the sum of the 7 days is $\mathrm{U}_{\mathrm{A}-68}=[7 \mathrm{x}$ $\left.(24.2)^{2}\right]^{1 / 2}=64.1 \mathrm{kWh}$. The systematic uncertainty is taken from Example C.9.2 to be $\mathrm{U}_{\mathrm{B}-68}= \pm 0.5 \%$ assuming an average of 50\% power for all 23 days. There are 14 degrees of freedom (16 days of data minus 2 parameters in the linear regression formula) for the random uncertainty and 30 for the systematic uncertainty. Before applying the linear regression formula, the average daily temperature for the days of missing energy data is verified to be within the range of average daily temperatures for the days with measured energy data. One day is $1.5^{\circ} \mathrm{F}$ cooler than the lowest daily temperature in the measured data set, and one day is $1.2^{\circ} \mathrm{F}$ warmer than the highest daily temperature in the measured data set. These two days are only slightly outside the range of data used in the regression, and the building systems should have the same operating characteristics at these temperatures. Therefore, the error should be within the uncertainty bounds. 
Table C-9 Uncertainty for Filling Data with Regression Analysis

\begin{tabular}{|l|l|l|l|l|l|}
\hline $\begin{array}{c}\text { Uncertainty } \\
\text { Source }\end{array}$ & Units & $\begin{array}{c}\text { Standard } \\
\text { Systematic } \\
\text { Uncertainty } \\
\mathbf{U}_{\mathbf{B}}\end{array}$ & $\begin{array}{c}\text { Standard } \\
\text { Random } \\
\text { Uncertainty } \\
\mathbf{U}_{\mathbf{A}}\end{array}$ & $\begin{array}{c}\text { Degrees of } \\
\text { Freedom }\end{array}$ & $\begin{array}{l}\text { Sensitivity } \\
\text { Coefficient }\end{array}$ \\
\hline Regression Analysis & $\mathrm{kWh}$ & 0 & 64.0 & 14 & 1 \\
\hline WHM & $\mathrm{kWh}$ & 46.9 & 0.0 & 30 & 1 \\
\hline \multicolumn{7}{|c|}{ Effective degrees of freedom $=$} & 29 & \\
\hline
\end{tabular}

\begin{tabular}{|l|l|l|l|l|}
\hline Uncertainty & Units & $\begin{array}{c}\text { Standard } \\
\text { Systematic } \\
\text { Uncertainty } \\
\sqrt{\sum\left(\theta \mathrm{U}_{\mathrm{B}}\right)_{\mathrm{i}}^{2}}\end{array}$ & $\begin{array}{c}\text { Standard } \\
\text { Random } \\
\text { Uncertainty }\end{array}$ & $\begin{array}{c}\text { Combined Uncertainty } \\
\sqrt{\sum\left(\theta \mathrm{U}_{\mathrm{A}}\right)_{\mathrm{i}}^{2}}\end{array}$ \\
\hline Monthly Total & $\mathrm{kWh}$ & 46.9 & 64.0 & 135 \\
\hline
\end{tabular}

$$
\mathrm{E}_{\text {reg }}=9,405 \pm 135 \mathrm{kWh} \text { at } 90 \% \text { confidence }
$$

The uncertainty from the regression method is smaller than from the averaging method, which is expected because the averaging method does not account for weather variations. The difference in total energy between the two methods is $80 \mathrm{kWh}$, which is within the uncertainty bounds of the both methods.

Table C-10 Dry-Bulb Temperature and HVAC Energy (Filled Data Are Shaded)

\begin{tabular}{|l|l|l|l|l|}
\hline \multicolumn{1}{|c|}{$\mathbf{T}\left({ }^{\circ} \mathbf{F}\right)$} & \multicolumn{1}{|c|}{$\mathbf{E}(\mathbf{k W h})$} & & \multicolumn{1}{|c|}{$\mathbf{T}\left({ }^{\circ} \mathbf{F}\right)$} & \multicolumn{1}{|c|}{$\mathbf{( k W h )}$} \\
\hline 75.2 & 462.5 & & 76.1 & 422.5 \\
\hline 75.4 & 430.3 & & 75.2 & 411.0 \\
\hline 77.0 & 438.5 & 73.3 & 451.8 \\
\hline 77.9 & 433.3 & & 69.7 & 416.5 \\
\hline 72.0 & 465.0 & & 71.0 & 373.5 \\
\hline 63.7 & 369.7 & & 75.1 & 401.5 \\
\hline 60.5 & 352.0 & & 70.9 & 397.0 \\
\hline 62.8 & 364.8 & & 67.6 & 403.3 \\
\hline 68.2 & 393.5 & & 69.9 & 388.8 \\
\hline 73.9 & 424.0 & & 62.0 & 356.3 \\
\hline 75.7 & 433.9 & & 62.0 & 346.5 \\
\hline 79.2 & 452.6 & & & \\
\hline
\end{tabular}




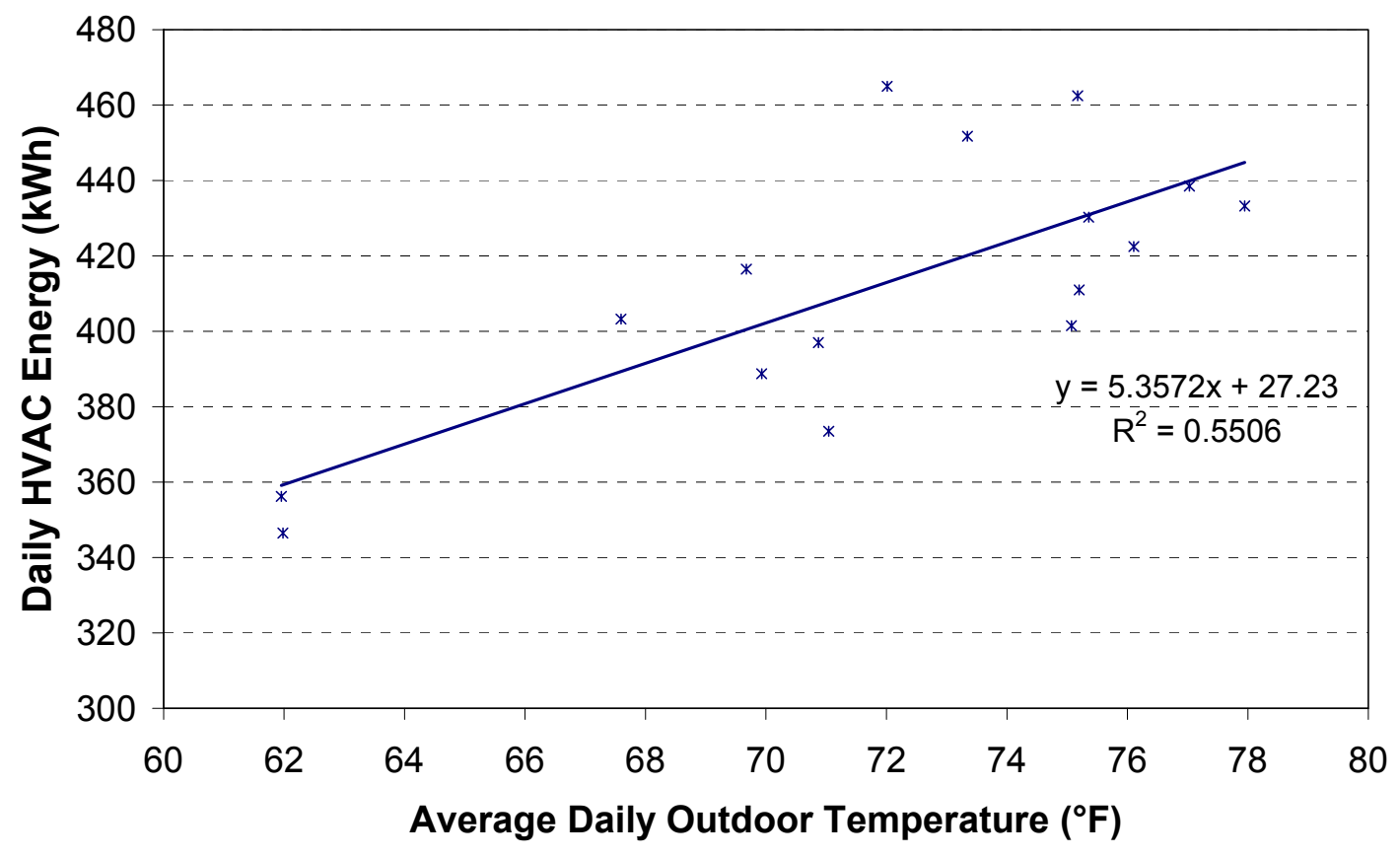

\section{Figure C-1 Linear regression of daily HVAC energy and average daily outdoor temperature}

\section{References}

ASHRAE (2002). Measurement of Energy and Demand Savings. ASHRAE Guideline 14-2002. Atlanta, GA: American Society of Heating, Refrigerating and Air-Conditioning Engineers, Inc.

ASME (1998). Test Uncertainty: Instruments and Apparatus. ASME Standard PTC 19.1-98. New York, NY: American Society of Mechanical Engineers.

Dieck, R.H. (1997). Measurement Uncertainty, Methods and Applications, Second ed. Research Triangle Park, NC: Instrument Society of America.

ISO (1995). Guide to the Expression of Uncertainty in Measurement. ISBN 92-67-10188-9. Geneva, Switzerland: International Organization for Standardization.

IPMVP (2002). Concepts and Options for Determining Energy and Water Savings. Volume I. International Performance Measurement and Verification Protocol, DOE/GO-102002-1554. Washington D.C.: U.S. Department of Energy. www.ipmvp.org. (Accessed April 18, 2003.)

NIST (1994). Guidelines for Evaluating and Expressing the Uncertainty of NIST Measurement Results. NIST Technical Note 1297, 1994 Edition. Gaithersburg, MD: National Institute for Standards and Technology. 


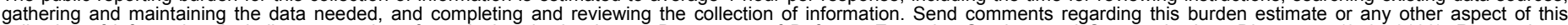

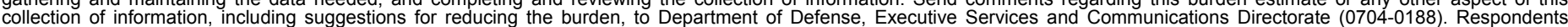

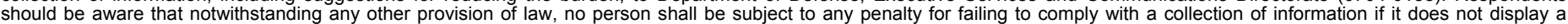

currently alid OMB control number.

PLEASE DO NOT RETURN YOUR FORM TO THE ABOVE ORGANIZATION.

\begin{tabular}{l|l|l}
\hline $\begin{array}{l}\text { 1. REPORT DATE }(D D-M M-Y Y Y Y) \\
\text { October } 2005\end{array}$ & $\begin{array}{l}\text { 2. } \\
\text { REPORT TYPE } \\
\text { Technical report }\end{array}$ & $\begin{array}{l}\text { DATES COVERED (From - To) } \\
2004-2005\end{array}$ \\
\hline
\end{tabular}

4. TITLE AND SUBTITLE

Procedure to Measure Indoor Lighting Energy Performance

5a. CONTRACT NUMBER

DE-AC36-99-GO10337

5b. GRANT NUMBER

5c. PROGRAM ELEMENT NUMBER

6. AUTHOR(S)

M. Deru, N. Blair, and P. Torcellini

5d. PROJECT NUMBER

NREL/TP-550-38602

5e. TASK NUMBER

BEC3.3002

5f. WORK UNIT NUMBER
7. PERFORMING ORGANIZATION NAME(S) AND ADDRESS(ES)

National Renewable Energy Laboratory

1617 Cole Blvd.

Golden, CO 80401-3393

9. SPONSORING/MONITORING AGENCY NAME(S) AND ADDRESS(ES)
8. PERFORMING ORGANIZATION REPORT NUMBER

NREL/TP-550-38602
10. SPONSOR/MONITOR'S ACRONYM(S) NREL

11. SPONSORING/MONITORING AGENCY REPORT NUMBER

12. DISTRIBUTION AVAILABILITY STATEMENT

National Technical Information Service

U.S. Department of Commerce

5285 Port Royal Road

Springfield, VA 22161

13. SUPPLEMENTARY NOTES

14. ABSTRACT (Maximum 200 Words)

This document provides standard definitions of performance metrics and methods to determine them for the energy performance of building interior lighting systems. It can be used for existing buildings and for proposed buildings.

The primary users for whom these documents are intended are building energy analysts and technicians who design, install, and operate data acquisition systems, and who analyze and report building energy performance data. Typical results from the use of this procedure are the monthly and annual energy used for lighting, energy savings from occupancy or daylighting controls, and the percent of the total building energy use that is used by the lighting system. The document is not specifically intended for retrofit applications. However, it does complement Measurement and Verification protocols that do not provide detailed performance metrics or measurement procedures.

15. SUBJECT TERMS

performance metrics; building energy analysis; building energy performance; measurement and characterization; energy consumption; commercial buildings, indoor lighting, lighting energy performance, high-performance buildings

\begin{tabular}{|c|c|c|}
\hline $\begin{array}{l}\text { a. REPORT } \\
\text { Unclassified }\end{array}$ & $\begin{array}{l}\text { b. ABSTRACT } \\
\text { Unclassified }\end{array}$ & $\begin{array}{l}\text { c. THIS PAGE } \\
\text { Unclassified }\end{array}$ \\
\hline
\end{tabular}

\begin{tabular}{|l|l|} 
17. LIMITATION & 18. NUMBER \\
OF ABSTRACT & OF PAGES \\
UL & \\
&
\end{tabular}

19a. NAME OF RESPONSIBLE PERSON

19b. TELEPHONE NUMBER (Include area code) 